GUSTAVO CAREZZATO GONÇALVES

PROTOCOLO DE GERENCIAMENTO BIM NAS FASES

DE CONTRATAÇÃO, PROJETO E OBRA EM

EMPREENDIMENTOS CIVIS BASEADO NA ISO 19650

São Paulo

2018 

GUSTAVO CAREZZATO GONÇALVES

\section{PROTOCOLO DE GERENCIAMENTO BIM NAS FASES DE CONTRATAÇÃO, PROJETO E OBRA EM EMPREENDIMENTOS CIVIS BASEADO NA ISO 19650}

Dissertação apresentada à Escola

Politécnica da Universidade de São Paulo para obtenção do título de Mestre em Ciências.

São Paulo

2018 



\title{
PROTOCOLO DE GERENCIAMENTO BIM NAS FASES DE CONTRATAÇÃO, PROJETO E OBRA EM EMPREENDIMENTOS CIVIS BASEADO NA ISO 19650
}

\author{
Dissertação apresentada à Escola \\ Politécnica da Universidade de São Paulo \\ para obtenção do título de Mestre em \\ Ciências.
}

Área de Concentração: Inovação na Construção Civil.

Orientador: Prof. Dr. Eduardo Toledo Santos

São Paulo 
Autorizo a reprodução e divulgação total ou parcial deste trabalho, por qualquer meio convencional ou eletrônico, para fins de estudo e pesquisa, desde que citada a fonte.

Este exemplar foi revisado e corrigido em relação à versão original, sob responsabilidade única do autor e com a anuência de seu orientador.

São Paulo, de de

Assinatura do autor:

Assinatura do orientador:

Catalogação-na-publicação

\section{CAREZZATO, Gustavo Gonçalves}

Protocolo de gerenciamento BIM nas fases de contratação, projeto e obra em empreendimentos civis baseado na ISO 19650 / G. G. CAREZZATO -versão corr. -- São Paulo, 2018.

$140 \mathrm{p}$.

Dissertação (Mestrado) - Escola Politécnica da Universidade de São Paulo. Departamento de Engenharia de Construção Civil.

1.BIM 2.Normas BIM 3.ISO 19650 I.Universidade de São Paulo. Escola Politécnica. Departamento de Engenharia de Construção Civil II.t. 

CAREZZATO, G.G. Protocolo de gerenciamento BIM nas fases de contratação, projeto e obra em empreendimentos civis baseado na ISO 19650. São Paulo. 2018. 140 p (Mestrado) Escola Politécnica, Universidade de São Paulo, São Paulo, 2018. 


\section{AGRADECIMENTOS}

Ao meu orientador, Prof. Dr. Eduardo Toledo Santos, não somente por ter orientado o desenvolvimento deste trabalho de forma tão dedicada, mas também por me fazer olhar para o futuro quando eu estava preso ao presente. Professor Toledo, meu muito obrigado.

Aos especialistas que se disponibilizaram a me ajudar contribuindo com cada experiência adquirida ao longo de toda uma vida profissional no debate de um assunto tão importante para que eu pudesse finalizar minha pesquisa.

A todos meus amigos que por muitas vezes não puderam contar com minha presença em momentos importantes em suas vidas.

Aos amigos de profissão que sempre estiveram dispostos a me ouvir e a compartilhar suas experiências comigo.

A todos os professores do curso do mestrado profissional Construinova da Escola Politécnica da USP que me encorajaram sempre a dar o meu melhor nas disciplinas que frequentei.

A minha esposa Adriana Rocha Okuma e meu filho Max Okuma Gonçalves que tiveram tanta paciência e compreensão em minha ausência durante todo este período.

E em memória de meus pais, Antonio Gonçalves e Neyde Carezzato Gonçalves, eu vos agradeço por terem me dado toda a estrutura física e moral para que eu pudesse estar hoje passando por mais esta fase grandiosa em minha vida. 



\section{RESUMO}

O BIM está mudando profundamente as práticas tradicionais de desenvolvimento de trabalhos na área da construção civil em todo o mundo. Processos padronizados e protocolos são necessários para definição das novas responsabilidades, bem como boas práticas para que o gerenciamento e utilização dos dados resultantes do trabalho em BIM sejam feitos de forma adequada. Entre os países que desenvolveram normativas BIM, o Reino Unido lidera, junto com os EUA, em número de documentos, servindo de base para normas BIM de outros países. A mais recente norma internacional nesse tema é a ISO19650:2017 que padroniza a criação, gerenciamento e utilização das informações BIM, e serve como base desta pesquisa. A estratégia adotada nesse trabalho é a Pesquisa Construtiva que tem utilização indicada para a solução de problemas práticos nas áreas de arquitetura e engenharia. $O$ objetivo este trabalho é disponibilizar ao mercado da construção civil nacional um documento público que pode ser utilizado como base para o gerenciamento de informações e dados BIM nas fases de contratação, projeto (design) e obra, através na análise da utilização do BIM no mercado nacional e internacional e o comparativo da norma ISO à prática do desenvolvimento do BIM no Brasil. Como resultado, foram identificados fatores que são pertinentes aos procedimentos de contratação e produção e para gerenciamento das informações e dados pertencentes à cadeia da construção de empreendimentos civis no Brasil.

Palavras-chave: BIM, Normas BIM, ISO19650. 


\section{ABSTRACT \\ BIM Management Protocol on the Contracting, Project and Construction Phases in Civil Enterprises Based on ISO 19650}

Worldwide, BIM is profoundly changing the traditional working practices in the construction industry. Therefore, standardized processes and protocols are important to define the new responsibilities, as well as the best practices so that management and data use resulting from BIM work are done properly. Among the countries that have developed BIM standards, UK leads, along with the USA, in number of documents, providing the basis for BIM standards in other countries. One of the most recent BIM standards is ISO19650:2017, which standardizes the development, management and use of BIM information and it is the basis of this research. The strategy used in this work is the Constructive Research which is recommended for solution of practical problems in architecture and engineering. The objective of this work is to make available to the Brazilian construction market a public document that can be used as basis for BIM information management in the contracting, design and construction phases through the analysis of the use of BIM in national and international markets, comparing the ISO standard with the practice of BIM in Brazil. As a result, factors were identified that are pertinent to contracting and production procedures and to the information and data management belonging to the Brazilian construction lifecycle.

Key words: BIM, BIM protocols, ISO19650. 



\section{LISTA DE FIGURAS}

FIgURA 1: GUIAS E NORMAS BIM DISPONIBILIZADOS AO MERCADO ENTRE OS ANOS DE 2007 E 2017 23

FIGURA 2: EVOLUÇÃO DO GRAU DE IMPORTÂNCIA DA GEOMETRIA E DOS DADOS DURANTE AS FASES DO PROJETO. 26

FIGURA 3: ESTRUTURA GERAL DE INSTÂNCIA NO IFC 31

FIGURA 4: CONJUNTO DE PROPRIEDADES PARA TIPOS NO IFC 31

FIgURA 5: CONJUNTO DE PROPRIEDADES PARA QUANTITATIVOS NO IFC 31

FIgURA 6: ATRIBUIÇÕES GERAIS DE GERENCIAMENTO DE PROJETOS BIM NO CICLO DE VIDA DE PROJETOS. 34

FIgURA 7: NÍVEIS DE MATURIDADE BIM 36

FIGURA 8: IMPLANTAÇÃO MACRO DAS ATIVIDADES DO CROSSRAIL .37

FIgURA 9: CRONOGRAMA MACRO DAS ATIVIDADES DO CROSSRAIL. 38

FIgURA 10: RELACIONAMENTO ENTRE AS ATIVIDADES DURANTE AS FASES DO CROSSRAIL 39

FIGURA 11: TIPOS DE CONTRATAÇÃO MAIS COMUNS NA CONSTRUÇÃO. 45

FIGURA 12: REPRESENTAÇÃO DA PESQUISA CONSTRUTIVA COMO ELO ENTRE A TEORIA EXISTENTE E UM PROBLEMA REAL. 48

FIGURA 13: METODOLOGIA APRESENTADA BASEADA NAS CARACTERÍSTICAS DA PESQUISA CONSTRUTIVA. 49

FIgURA 14: RELACIONAMENTO DAS ATIVIDADES BASE PARA PRODUÇÃO DO PNBIM. .50

Figura 15: METOdologia APRESENTAdA BASEAdA NAS CARACTERÍSTICAS DA PESQUISA CONSTRUTIVA. 51

FIGURA 16: ESTRUTURA DA CRIAÇÃO DO CONHECIMENTO NOS GRUPOS FOCAIS.

FIGURA 17: RELACIONAMENTO DE INTERAÇÃO ENTRE AS PARTES INTERESSADAS 



\section{LISTA DE FLUXOGRAMAS}

FLUXOGRAMA 1: FASES APROPRIADAS QUE DEVEM SER PRESENTES EM UM SISTEMA DE GERENCIAMENTO DE INFORMAÇÕES ...................99

FLUXOGRAMA 2: RELACIONAMENTO DAS ATIVIDADES MACRO PARA PRODUÇÃO DE INFORMAÇÕES. 106

FLUXOGRAMA 3: SUBFASES RELACIONADAS AO FLUXO DO DESENVOLVIMENTO DE INFORMAÇÕES E DADOS BIM DO EMPREENDIMENTO.......108

FLUXOGRAMA 4: FLUXOGRAMA DAS ATIVIDADES UTILIZANDO O AMBIENTE COMUM DE DADOS (CDE) 115

FLUXOGRAMA 5: FLUXO COMPLETO DO DESENVOLVIMENTO DE INFORMAÇÕES E DADOS DO EMPREENDIMENTO. 



\section{LISTA DE TABELAS}

TABELA 1: CARACTERÍSTICAS DOS GRUPOS FOCAIS..................................53

TABela 2: Planejamento PARA DESENVOLVIMENTO dAS ATIVIDADES. .........54

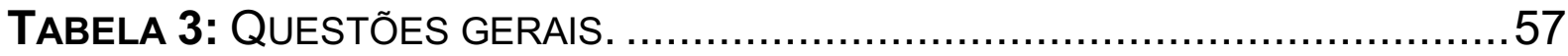

TABELA 4: CoMPARATIVO ENTRE A ISO E A PRÁTICA NO BRASIL REFERENTE AO

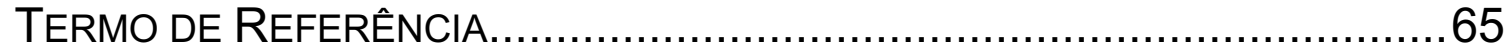

TABELA 5: COMPARATIVO ENTRE A ISO E A PRÁTICA NO BRASIL REFERENTE A LICITAÇÕES E CARTAS CONVITES ...................................................68

TABELA 6: Comparativo ENTRE A ISO E A PRÁtICA NO BRASIL REFERENTE A PROPOSTAS ........................................................................... 70

TABELA 7: COMPARATIVO ENTRE A ISO E A PRÁTICA NO BRASIL REFERENTE A PROPOSTAS ............................................................................. 71

TABELA 8: COMPARATIVO ENTRE A ISO E A PRÁTICA NO BRASIL NA MOBILIZAÇÃO 73

TABELA 9: COMPARATIVO ENTRE A ISO E A PRÁTICA NO BRASIL REFERENTE A PRODUÇÃO COLABORATIVA ............................................................ 74

TABELA 10: COMPARATIVO ENTRE A ISO E A PRÁTICA NO BRASIL REFERENTE A

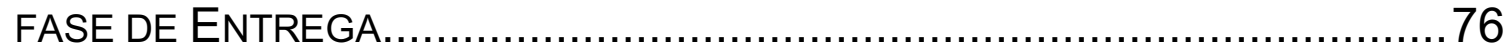

TABELA 11: QUESTÕES ESPECÍFICAS. ............................................... 79

TABELA 12: COMPARATIVO ENTRE TÓPICOS ENTRE O PILOTO PNBIM E APÓS COMENTÁRIOS LEVANTADOS PELO GRUPO FOCAL.................................95 



\section{LISTA DE QUADROS}

QUADRO 1: COMPARATIVO ENTRE OS SISTEMAS DE CLASSIFICAÇÃO DO LOX..33 QUADRO 2: ESTRUTURA DAS ATIVIDADES PERTENCENTES A ABNT NBR 15965

42

QUADRO 3: REQUISITOS SOLICITADOS EM LICITAÇÕES BIM NO BRASIL. .........60 



\section{LISTA DE GRÁFICOS}

GRÁFICO 1: ADOÇÃO DO BIM AO LONGO DO TEMPO …...................................39

GRÁFICO 2: TIPO DE FERRAMENTA UTILIZADA PELO MERCADO BRITÂNICO PARA PRODUÇÃO DE PROJETOS

GRÁFICO 3: NÚMERO DE LICITAÇÕES PÚBLICAS COM USO DE BIM POR ANO ...59

GRÁFICO 4: NÚMERO DE LICITAÇÕES PÚBLICAS COM USO DE BIM POR ÁREA.. 59

GRÁFICO 5: AdERÊNCIA DAS PUBLICAÇÕES NACIONAIS A ISO 19650 ...........76

GRÁFICO 6: FAIXA ETÁRIA DOS PARTICIPANTES .................................... 80

GRÁFICO 7: SETOR DE ATUAÇÃO ....................................................... 81

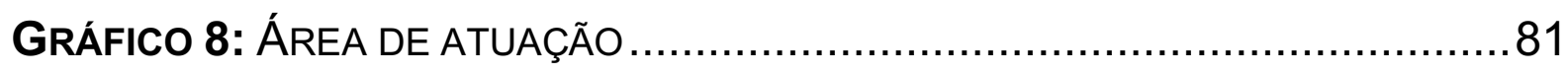

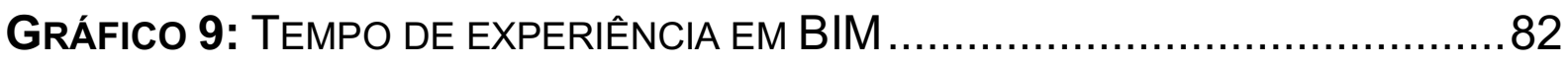

GRÁFICO 10: NÍVEL DE EXPERIÊNCIA NA GESTÃO DE INFORMAÇÕES BIM .......82

GRÁFICO 11: NíVEL DE CONHECIMENTO NA NORMA BRITÂNICA PAS1192-

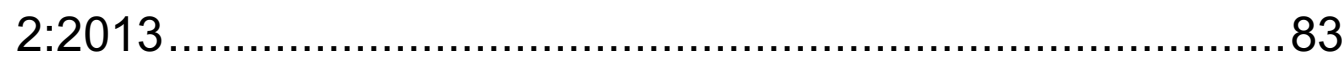

GRÁFICO 12: NÍVEL DE CONHECIMENTO NA NORMA ISO19650 ...................83

GRÁFICO 13: CoNHECIMENTO COM MOdELOS FEDERADOS ..........................84

GRÁFICO 14: IMPORTÂNCIA DE DISPONIBILIZAÇÃO DE MATERIAL BIM PELO

CONTRATANTE .84

GRÁFICO 15: CONHECIMENTO NO PLANO DE EXECUÇÃo BIM ........................85

GRÁfico 16: ENTENDIMENTO SOB O PLANO DE MOBILIZAÇÃO.......................85

GRÁFICO 17: ENTENDIMENTO SOBRE FUNCIONAMENTO DE SISTEMAS DE

GERENCIAMENTO DE INFORMAÇÕES.......................................... 86

GRÁFICO 18: ENTENDIMENTO REFERENTE A LOD.................................. 86

GRÁFICO 19: ENTENDIMENTO REFERENTE A LOI ......................................87

GRÁFICO 20: ENTENDIMENTO REFERENTE AO COBIE...............................87

GRÁFICO 21: TIPOS DE ENTREGÁVEIS................................................... 88

GRÁFICO 22: FATORES QUE PODEM IMPULSIONAR O BIM NO BRASIL .............88 
GRÁFICO 23: MATERIAIS A SEREM DISPONIBILIZADOS PELO CONTRATANTE NA

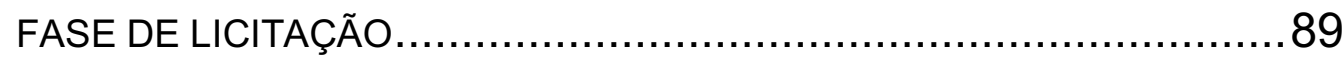

GRÁFICo 24: FUNCIONALIDADES NECESSÁRIAS EM UM SISTEMA DE GERENCIAMENTO DE INFORMAÇÕES...................................90

GRÁFICO 25: ETAPA ONDE O PLANO DE EXECUÇÃo BIM DEVE SER ENTREGUE .91

GRÁFICo 26: ITENS FUNDAMENTAIS QUE DEVEM CONSTAR NO PLANO DE

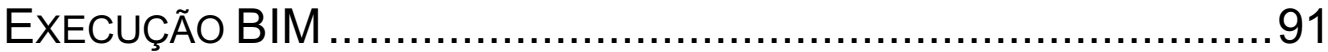

GrÁFICo 27: AVALIAÇÃO dE CAPACIDADE TÉCNICA ...................................99

GRÁFICO 28: PRINCIPAIS FUNÇÕES NA GESTÃO DE INFORMAÇÕES BIM ..........93

GRÁFICO 29: PRINCIPAIS ATIVIDADES NA FASE DE MOBILIZAÇÃO ...................93 



\section{LISTA DE ABREVIATURAS E SIGLAS}

Department for Business, Energy \& Industry Strategy of

BEIS United Kingdom Government - Departamento para Negócios, Energia e Estratégia Industrial do Governo do Reino Unido

BIM Building Information Modelling - Modelagem da Informação da Construção

BSI British Standards Institution

CAPEX Capital Expense

CDE Common Data Environment - Ambiente Comum de Dados

COBie Construction Operations Building Information Exchange

IFC Industry Foundation Classes

LOD Level of Development

LOI Level of Information

MDIC Ministério da Indústria, Comércio Exterior e Serviços da República Federativa do Brasil

MIA Manutenção do Modelo de Informações de Ativos

NBS National British Standard

O\&M Operation and Maintenance - Operação e Manutenção

OPEX Operational Expense

PdC Plano de Comunicação

PIM Project Information Modelling

PPNBIM Piloto Protocolo Nacional BIM 
PNBIM Protocolo Nacional BIM

RIC Requisitos de Informação do Contratante

RICS Royal Institute of Chartered Surveyors

SEIL Secretaria de Infraestrutura e Logística 



\section{SUMÁRIO}

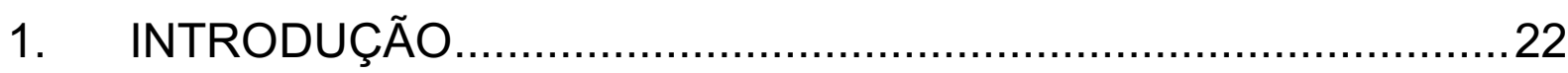

1.1. OBJETIVOS.

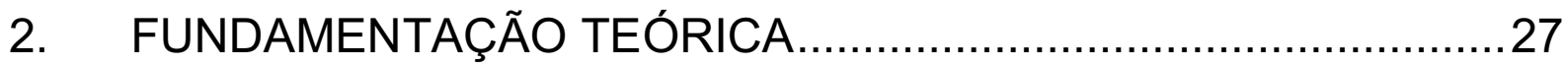

2.1. BIM (Building Information Modelling) …………..........................28

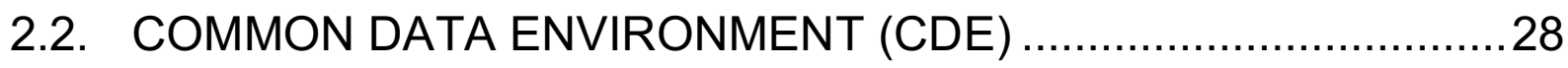

2.3. IFC - INDUSTRY FOUNDATION CLASSES.................................30

2.4. COBie - CONSTRUCTION OPERATIONS BUILDING

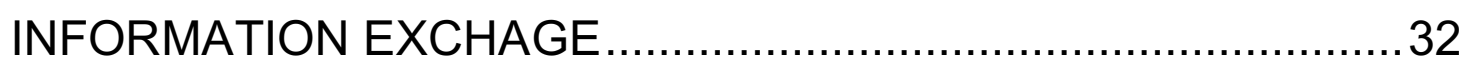

2.5. NÍVEIS DE DESENVOLVIMENTO / DETALHAMENTO ................33

2.7. BIM NO CENÁRIO DA CONSTRUÇÃO CIVIL .............................35

2.8. BIM NO CENÁRIO DA CONSTRUÇÃO CIVIL NACIONAL ...........41

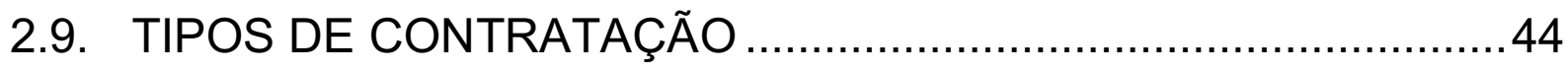

3. MÉTODO DE PESQUISA …………………............................. 47

3.1 FASES DA PESQUISA CONSTRUTIVA ……………….............. 48

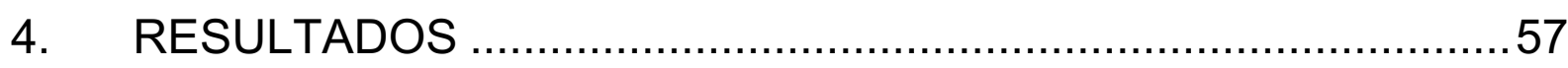

4.1. ANÁLISE DE LICITAÇÕES PÚBLICAS NACIONAIS COM

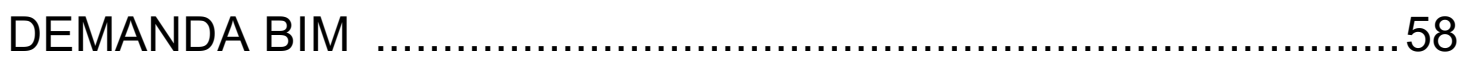

4.2. COMPARATIVO ENTRE A ISO19650 E A PRÁTICA NO

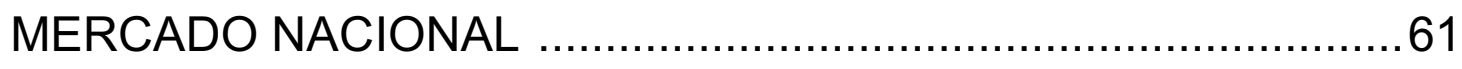

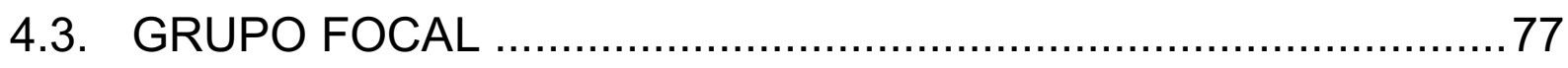

5. CONCLUSÕES E TRABALHOS FUTUROS ………….................96

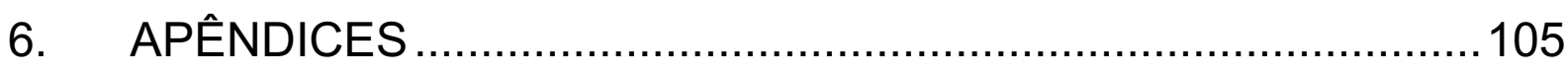





\section{INTRODUÇÃO}

Segmentos da construção civil, nacionais e internacionais, estão migrando cada vez mais para o BIM (Building Information Modelling), inovação que vai muito além de simples modelagem do empreendimento. Em países como EUA e Inglaterra, por exemplo, o nível de amadurecimento na utilização do BIM é alto, isso em razão destes países estarem utilizando esta inovação há mais de uma década (MCGRAWHILL, 2014). Para o NBS National BIM Report (2017) 60\% dos entrevistados veem o BIM como elemento propulsor de maior eficiência com redução de tempo de produção entre a concepção a conclusão do projeto.

Conforme o relatório Diálogos Setoriais para BIM no Brasil e na União Europeia 2015 (KASSEM; AMORIM, 2015) foram identificados fatores que devem ser considerados para aumentar ainda mais a adesão das empresas brasileiras ao BIM. Tais fatores são: 1) a inclusão do BIM como parte de uma estratégia macro do governo federal no setor da construção civil; 2) tornar o BIM gradualmente obrigatório em projetos a serem desenvolvidos para o governo federal; 3) desenvolvimento de manuais para utilização do BIM em projetos; 4) desenvolvimento e disponibilização ao público de bibliotecas digitais; 5) desburocratização dos incentivos fiscais para compra de equipamentos e ferramentas BIM; e 6) maior investimento em educação e treinamento. Sua adoção e maior utilização pode ser impulsionada pela definição, via órgãos governamentais, de normas BIM (SMITH, 2014).

Para que todos os envolvidos na cadeia possam aderir cada vez mais à metodologia BIM, se faz necessária a disponibilização de diretrizes locais claras e objetivas que orientem a todos os envolvidos no processo de desenvolvimento e gerenciamento de informações BIM de como os trabalhos devem ser executados. Existem entidades públicas e privadas no Brasil que estão fornecendo guias, manuais de referência e especificações técnicas que podem ser utilizadas para desenvolvimento de trabalhos BIM. (MAINARDI NETO; SANTOS, 2015) e (FDE, 2017)

No artigo publicado no site da Secretaria de Infraestrutura e Logística do estado do Paraná, em outubro de 2014, os governos de Santa Catarina e Paraná estabeleceram um termo de cooperação técnica entre os dois estados para criação conjunta de diretrizes para o fomento da implantação do BIM na região sul do Brasil. A partir da cooperação inicial entre os dois estados, houve estreitamento das relações no sentido do fomento do BIM também com o estado do Rio Grande do Sul, culminando assim na criação da Rede BIM Gov. Sul envolvendo os 3 estados em janeiro de 2015. (SEIL/PR, 2017) 
Olhando o cenário externo, EUA e Inglaterra lideram em número de normativas disponibilizadas no setor e estas estão servido de base para o desenvolvimento de normas em vários países ao redor do mundo, como em Cingapura por exemplo (CAREZZATO; BARROS; SANTOS, 2016). Na Figura 1 pode ser visto levantamento desenvolvido com base nas normativas publicadas em diversos países.

Figura 1: Guias e Normas BIM disponibilizados ao mercado entre os anos de 2007 e 2017

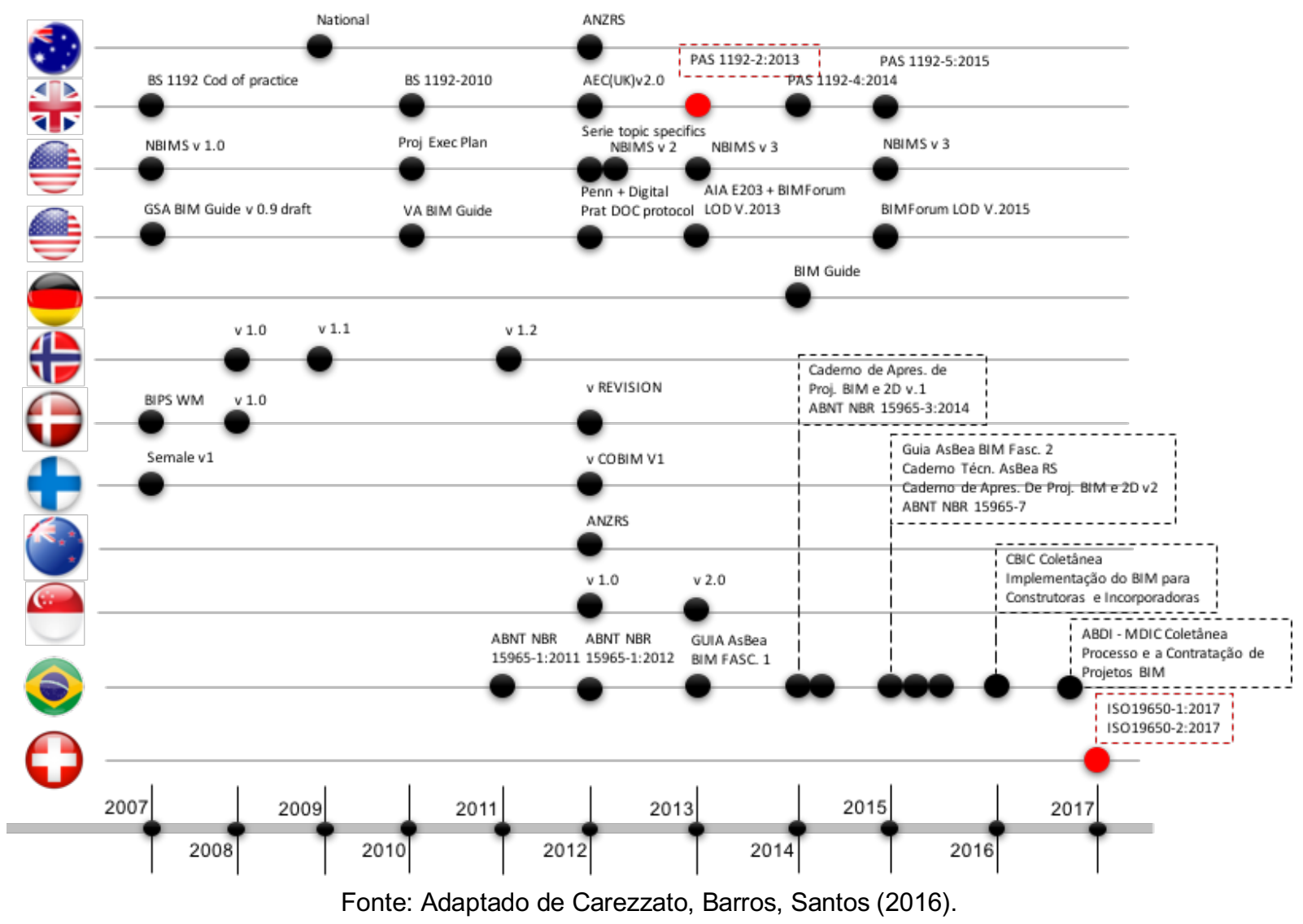

Entre as normas BIM desenvolvidas recentemente, a ISO/DIS 19650-1.2:2017 - Organization of information about construction works / Information management using building information modelling - tendo abrangência internacional, foi eleita para servir de base para o desenvolvimento deste trabalho.

Em geral, a ISO/DIS 19650-1.2:2017, disponível em: https://www.iso.org/standard/68078.html, tem como finalidade fornecer princípios de progresso através do setor do ambiente construído dando suporte ao gerenciamento e produção de informações durante o ciclo de vida dos empreendimentos civis através da utilização do BIM. O uso desta norma é direcionado para: 
- Todos os envolvidos nas fases de contratação, projeto (design), construção e/ou comissionamento; e

- Todos os envolvidos nas atividades de gerenciamento das atividades contidas no ciclo de vida do empreendimento, inclusive O\&M.

A ISO 19650:2017 também indica recomendações para a estrutura de trabalho para o gerenciamento de informações incluindo sua troca, arquivamento, versionamento e organização através de todos os envolvidos no processo. Isso inclui proprietários e seus representantes, gerenciadoras, projetistas, construtora, fornecedores e usuários finais.

Servindo como base da ISO19650, a PAS1192-2:2013 - Specification for information management for the capital delivery phase of construction projects using building information modelling foi desenvolvida para dar suporte a adoção do BIM no Reino Unido e esclarecer como os processos necessários e obrigatórios devem ser seguidos para a gestão da informação na produção e entrega dos projetos realizados com uso do modelo BIM (KASSEM; AMORIM, 2015).

A PAS1192-2 foca a informação que é originada e acumulada a partir das atividades de projeto até a entrega do empreendimento e sua troca e gerenciamento através dos processos BIM. Esta etapa é considerada como PIM (Project Information Modelling). Desta forma, a norma britânica contempla como deve ser desenvolvida a fase de produção da informação desde o briefing até o encerramento da construção do empreendimento.

Além disso, esta norma faz parte de uma estratégia de longo prazo para melhorar a eficiência da construção civil britânica, principalmente no custo efetivo e sustentabilidade nos projetos públicos. A curto prazo, o foco desta estratégia é a obtenção da redução dos custos nas obras públicas em 20 por cento (MATTHEWS, 2016).

As metas do governo britânico com a adoção do BIM nas obras públicas são:

- Reduzir custos com as obras e tempo de entrega dos projetos públicos;

- Reduzir custos de operação das construções, sendo eles edifícios e infraestrutura;

- Ajudar o governo a atingir as metas de redução de emissão de carbono em seus edifícios; e

- Fazer com que a indústria da construção civil britânica se torne mais competitiva no mercado global. 
Produzir informação desnecessária em ambiente não estruturado torna o processo confuso e difícil de coordenar dentro de toda cadeia da construção civil. Manter a integridade da informação e montar estrutura de dados adequada torna o processo mais claro e mais eficiente, possibilitando assim reduzir o tempo e custo de produção. Com isso pode-se focar no que é realmente necessário durante o processo, ao invés de desperdiçar tempo na procura de informações. Ter fácil acesso aos dados e confiabilidade nos mesmos pode influenciar na qualidade do empreendimento na sua fase de operação. (PAS1192-2:2013, 2016)

Durante o desenvolvimento do projeto, o nível de informação e dos dados referentes ao empreendimento aumentam e ficam mais complexos. Ao final, três são os tipos de informação necessária a ser comunicada ao cliente/usuários: 1) Documentação; 2) Dados Estruturados; 3) Modelo Digital. BIM é processo e não apenas modelo $3 \mathrm{D}$, sendo assim é necessário ter clara orientação de como devem funcionar os fluxos de cada fase (ISO, 2017). Os dados na fase de entrega são originados do modelo BIM e são utilizados na fase de operação. Para isso, deve ser criado um ambiente de dados comum para dar suporte a todo o ciclo de vida do empreendimento.

Para May, Taylor e Irwin (2016) o grau de importância nos modelos 3D de sua geometria e de seus dados durante as fases do projeto se alteram conforme a evolução de seu desenvolvimento. Isto é, a importância do desenvolvimento e utilização da geometria dos modelos 3D nas fases iniciais do projeto é grande para que se possa utilizar os benefícios que a construção virtual proporciona a todos os envolvidos no processo. A deteç̧ão de interferências e a compatibilização espacial são alguns dos exemplos. Conforme a evolução do desenvolvimento do projeto, os dados começam a ser inseridos nas entidades que formam os modelos e neste momento é possível notar, como mostrado na Figura 2, que se inicia uma inversão de importância entre a representação geométrica virtual e o nível de informações e dados. 
Figura 2: Evolução do grau de importância da geometria e dos dados durante as fases do projeto.

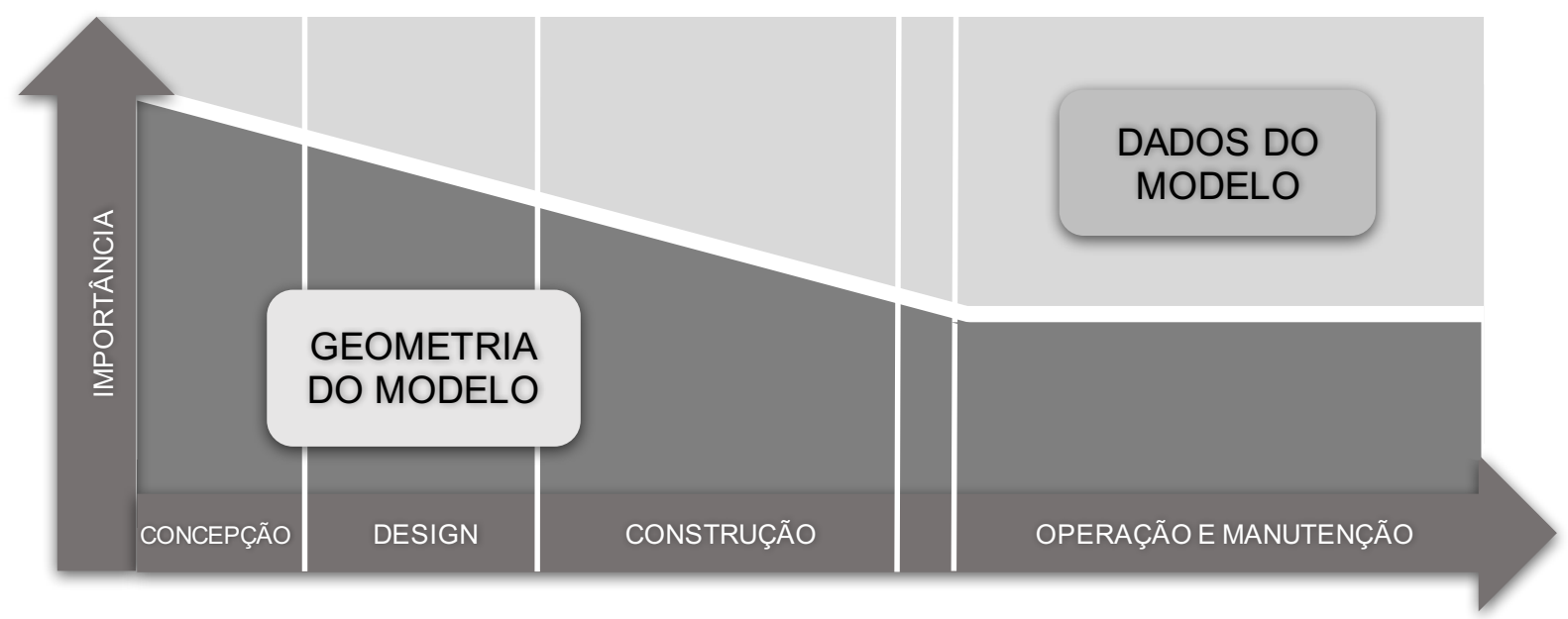

Fonte: Adaptado de May, Taylor e Irwin (2016)

Desta forma este trabalho tem como principal foco disponibilizar ao mercado da construção civil brasileira, à semelhança da ISO19650:2017, uma sugestão de estrutura para o desenvolvimento de um Protocolo Nacional BIM (PNBIM) sendo este um documento público com o objetivo em fornecer orientação específica para a padronização da produção e gestão das informações associadas a execução do trabalho colaborativo BIM. Desta forma, informações também importantes, porém geradas com utilização de outras metodologias, não serão cobertas por este estudo.

Através da disponibilização do PNBIM, os envolvidos em todas as fases do empreendimento (contratação, design, construção, comissionamento, operação e manutenção) que pretendem desenvolver ou que já desenvolvem trabalhos utilizando o BIM terão diretrizes claras e padronizadas de como as informações e os dados gerados devem ser desenvolvidos, gerenciados e entregues para serem utilizados na fase de operação e manutenção de empreendimentos civis. 


\subsection{OBJETIVOS}

Este trabalho analisou os principais aspectos relacionados à normalização do BIM e as boas práticas que estão sendo desenvolvidas tanto no mercado da construção civil nacional quanto a internacional de forma a identificar os pontos relevantes que devem constar em um Protocolo BIM.

\section{Geral:}

A presente dissertação tem como objetivo disponibilizar ao mercado da construção civil nacional um documento público que possa ser utilizado como base para o gerenciamento de informações e dados BIM nas fases de contratação, projeto (design) e obra.

\section{Específicos:}

a) Análise da utilização do BIM do mercado da construção civil;

b) Análise crítica do conteúdo da norma ISO19650-1.2:2017;

c) Avaliação analítica da norma para verificação de sua aderência ao mercado brasileiro, identificando os pontos que devem ser alterados/modificados para o enquadramento no cenário nacional, caso necessário;

d) Propor um Protocolo BIM adaptado ao cenário da construção civil nacional, com foco no desenvolvimento de projetos e gerenciamento de obras;

e) Validar o Protocolo Nacional BIM através de discussão junto a especialistas BIM com experiência comprovada nas diversas áreas da construção civil nacional.

\section{FUNDAMENTAÇÃO TEÓRICA}

Para embasar os principais conceitos relacionados ao tema deste trabalho, neste capítulo são descritos os conceitos relacionados à definição do BIM, ao BIM no cenário da construção civil no mundo, a utilização do BIM no cenário da construção civil nacional e as modalidades de contratação mais comuns no mercado. 


\subsection{BIM (Building Information Modelling)}

Do acrônimo da língua inglesa para Building Information Modelling - BIM, tem sua tradução no Brasil como Modelagem da Informação da Construção conforme indicação da NBR-ISO 12.006:2.

A tecnologia aplicada a forma de se trabalhar, como característica do BIM, e combinada com as dimensões de recursos (pessoas), processos e a estrutura organizacional tem o potencial de impactar significativamente a indústria. (RICS, 2017)

Os modelos 3D, desenvolvidos de forma virtual através de ferramentas de modelagem, são formados por objetos paramétricos que garantem sua confiabilidade. (DELATORRE, 2015) Entre as características que definem os objetos paramétricos (EASTMAN, 2011) estão:

- Conter definições geométricas, com dados e regras associados;

- Possuir geometria não redundante e que não permite inconsistências;

- Possuir regras paramétricas que se modificam e se adaptam automaticamente conforme qualquer alteração; e

- Poder se vincular no recebimento, divulgação ou exportação de conjuntos de atributos para outras aplicações ou modelos.

O BIM está mudando profundamente as práticas tradicionais da construção, em termos de pessoas, processos, trabalho, cultura, comunicação e modelos de negócio (Wilson; Heng 2011). Para a adoção do BIM é necessário que mudanças sejam aplicadas na maneira de trabalho, pois o desenvolvimento de um modelo integrado desenvolvido em ambiente virtual que representa os projetos de construção civil requer alta colaboração e comunicação entre todas as equipes envolvidas no processo. (MAINARDI NETO, 2015)

\subsection{COMMON DATA ENVIRONMENT (CDE)}

Para dar suporte a necessidade deste alto nível de colaboração e comunicação entre os envolvidos nos trabalhos BIM a ISO19650 descreve o Ambiente Comum de Dados ou Common Data Environment (CDE) como uma plataforma necessária para o compartilhamento de informações do processo de entregas dos produtos desenvolvidos através do BIM para empreendimentos civis. 
O CDE também definido como a única fonte de informações para qualquer projeto, usado para coletar, gerenciar e disseminar toda e qualquer informação relevante aprovada para equipes multidisciplinares em um processo gerenciado (Autodesk, 2016). Para o NBS (2016) com a utilização de um sistema único para obtenção de informação, resultado este de um trabalho colaborativo entre as equipes multidisciplinares, existe a diminuição de erros e duplicação de dados.

A ISO 19650-1.2:2017 descreve como um CDE deve acomodar a informação dos projetos BIM e permita também que as equipes de projeto multidisciplinares colaborem num ambiente gerenciado. Para acomodar um processo colaborativo BIM um CDE deve incluir quatro capacidades de gerenciamento de dados fundamentais:

- Espaço de trabalho de projeto compartilhado para membros de diferentes equipes multidisciplinares de projetos, de empresas em diferentes locais;

- Acesso controlado das informações armazenadas no CDE;

- Um processo de aprovação estruturado e configurável para o controle do fluxo de informações do projeto; e

- Um processo de acompanhamento e gerenciamento das atividades relacionadas às informações e controles do CDE.

Como uma única fonte de informação não há discussão sobre qual versão da informação deve ser referenciada. Conforme o NBS (2016) o CDE deve servir como a fonte final e trazer uma série de vantagens para todos os envolvidos tais como:

- Informações compartilhadas devem resultar em dados coordenados que, por sua vez, reduzirão o tempo e o custo em seu projeto.

- Os membros da equipe de projeto podem usar o CDE para gerar os documentos e visualizar diferentes arquivos centrais que precisam ser combinados;

- Fundamental utilização no modelo central para o desenvolvimento da coordenação; e

- As informações sobre a produção disponibilizadas no CDE devem estar corretas, assumindo que os usuários aderem aos processos de compartilhamento de informações para que não haja conflito principalmente nas fases iniciais de design.

Para a função de responsável pelo CDE a BSI (2016) propõe a nomeação do gestor de informação que tem a função distinta do coordenador BIM, não havendo de sua parte qualquer responsabilidade pelo design, detecção de interferências ou coordenação dos modelos. O coordenador de informação é responsável por manter a gama de informações e dados que são gerados, compartilhados e sincronizados. $\mathrm{Na}$ 
prática, um membro da equipe sênior normalmente assumirá esse papel de coordenação.

\subsection{IFC - INDUSTRY FOUNDATION CLASSES}

O IFC (Industry Foundation Classes) tem como fundamento disponibilizar, através de um formato aberto internacional para BIM, a troca e compartilhamento dos dados BIM entre aplicativos desenvolvidos por diferentes fornecedores de softwares. (GSC, 2014) A primeira aplicação desenvolvida com este conceito foi com a utilização do ARCHICAD da empresa húngara GRAPHISOFT, hoje pertencente a alemã NEMETSCHEK.

Hoje diversas são as ferramentas pertencentes ao BIM disponíveis no mercado. Sendo assim é importante que haja interoperabilidade entre estas ferramentas para que as informações circulem sem perda entre todas as etapas do empreendimento. Para isso a base IFC é utilizada para centralizar todas as informações em um único ambiente (arquivo) onde podem ser acessadas pelas diversas equipes envolvidas no ciclo de vida do empreendimento (projeto, construção e operação/manutenção).

Diversos podem ser os serviços desenvolvidos em cada etapa do ciclo do empreendimento tal como em projeto a checagem das regras de projeto, simulações e análise de estimativas como por exemplo. Na fase de construção, tais informações serão usadas para gerenciamento e as mesmas poderão ser usadas posteriormente na operação e manutenção do empreendimento. Neste caso, é necessário ter um escopo claro de modelagem definindo quais serão os serviços a serem desenvolvidos para que não sejam inseridas no modelo informações desnecessárias que não serão utilizadas nas etapas posteriores à modelagem.

Em elementos utilizados na fase de desenvolvimento de projetos (design) a inclusão de informações tais como a de localização geográfica é necessária (latitude, longitude e elevação) e características locais do empreendimento (endereço físico). Tais informações poderão ser usadas, ainda na fase de concepção de projeto, para desenvolvimento de diversas simulações preliminares (insolação, tráfego de pessoas e veículos entre outros). Os resultados destas simulações podem influenciar, ainda bem no início dos trabalhos, na decisão da melhor implantação do empreendimento no terreno ou no melhor posicionamento das escadas rolantes em uma estação de Metrô por exemplo. 
Nas Figuras 3, 4 e 5 abaixo é possível encontrar os esquemas gerais dos diagramas de instância, de conjunto de propriedades para tipos de objeto, de conjunto de propriedades para desempenho e por último o conjunto de propriedades para quantitativos que são utilizados pelo IFC.

Figura 3: Estrutura geral de instância no IFC

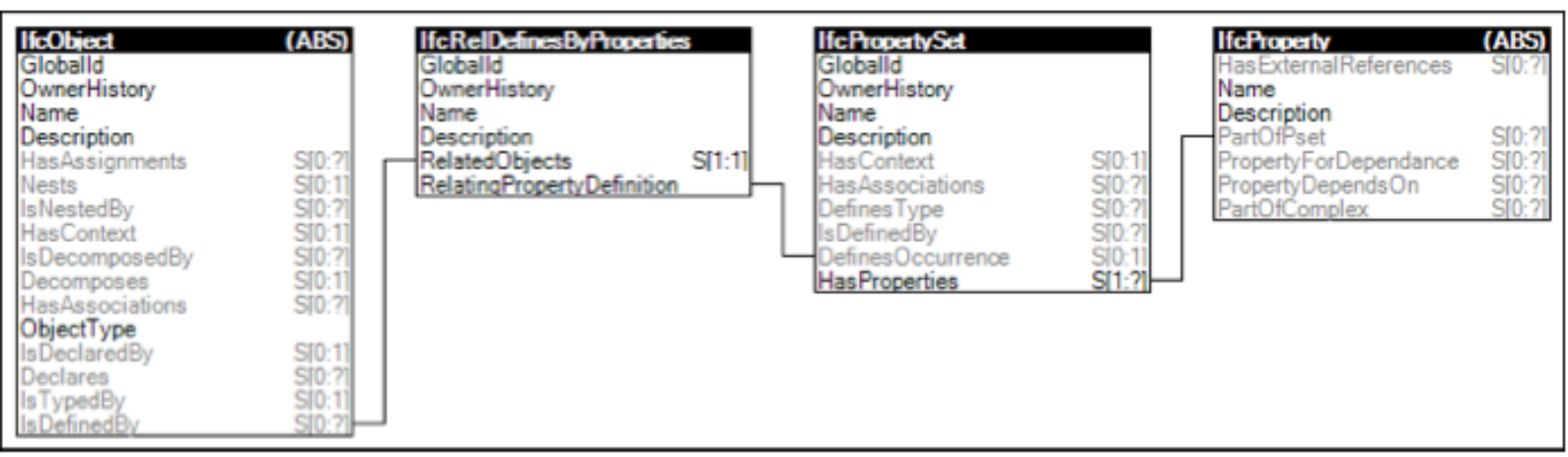

Fonte: buildingSMART.

Figura 4: conjunto de propriedades para tipos no IFC

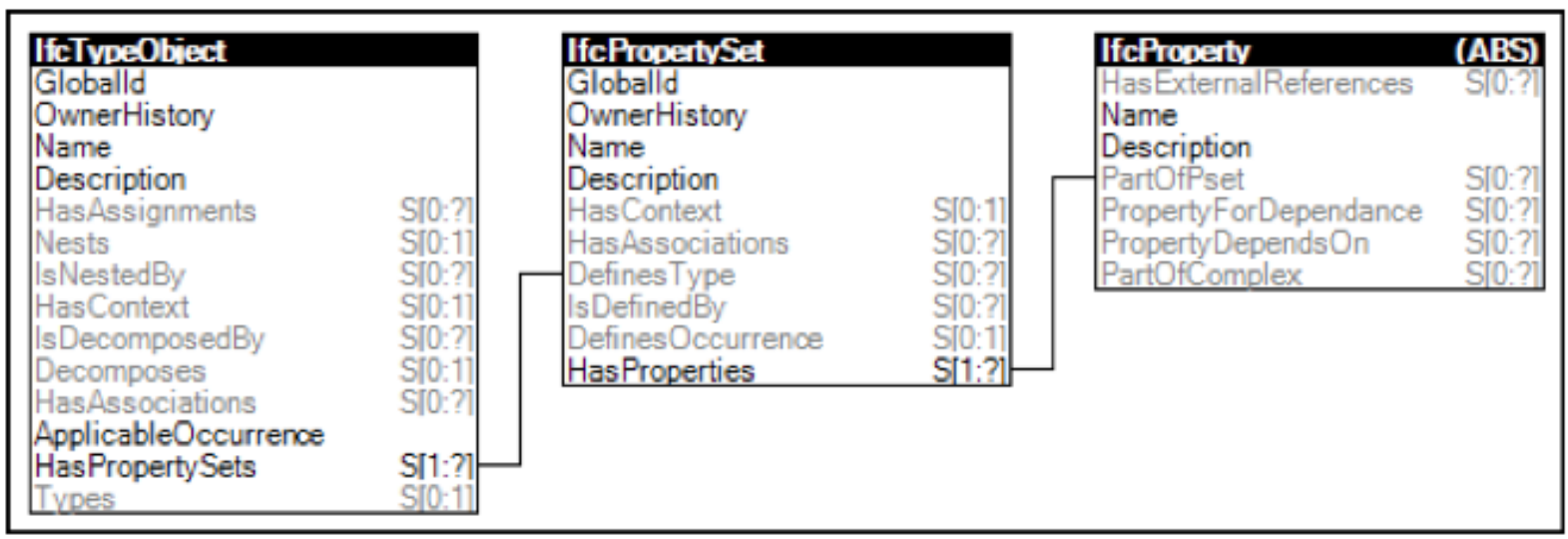

Fonte: buildingSMART.

Figura 5: Conjunto de propriedades para quantitativos no IFC

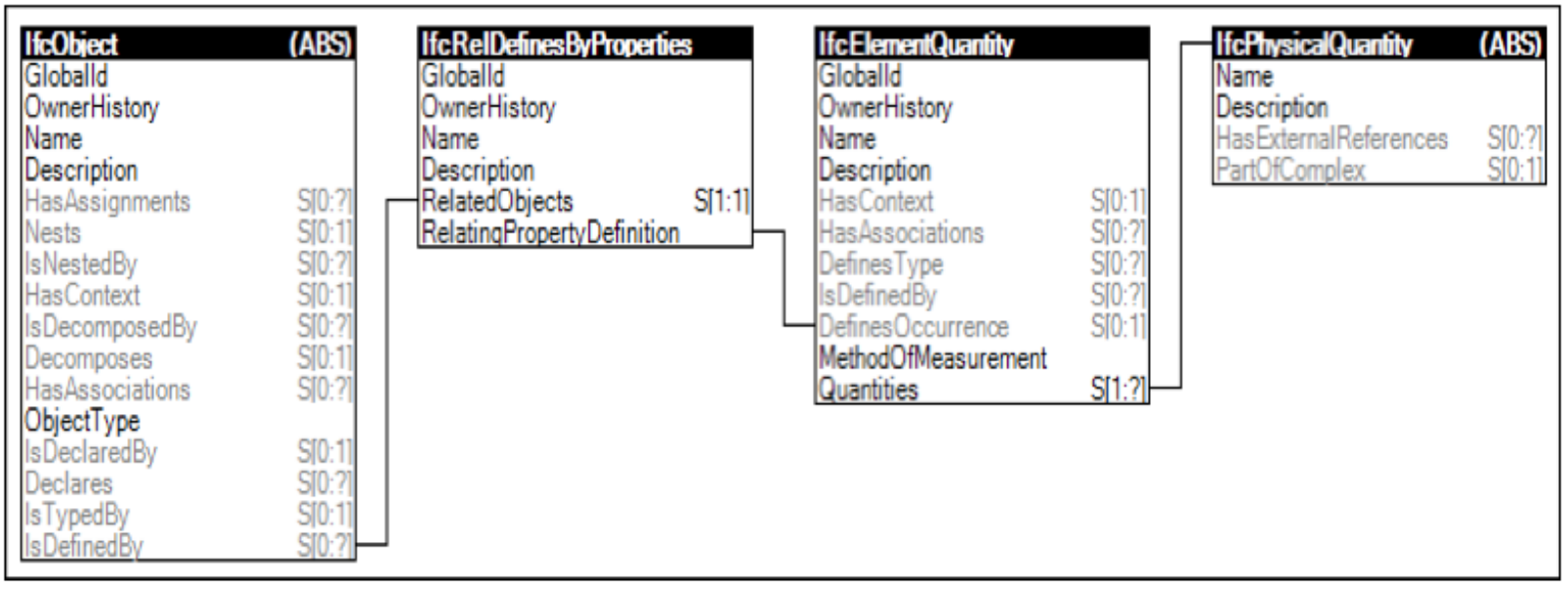

Fonte: buildingSMART. 


\subsection{COBIe - CONSTRUCTION OPERATIONS BUILDING INFORMATION EXCHAGE}

As informações necessárias para os proprietários e operadores de instalações são variadas, sendo estas desde projetos da instalação até números de série e datas de instalação de equipamentos com garantia. Tradicionalmente, as informações são fornecidas na fase de encerramento da obra através de caixas com material físico, sendo estes projetos, manuais de operação e manutenção, entre tantos outros (Autodesk, 2016).

O COBie permite que os responsáveis forneçam informações eletrônicas diretamente sobre a instalação à medida que essas informações são criadas (NBS; 2012), isto é, as informações de instalações, por exemplo, são inseridas ao longo das fases do projeto e a troca destes dados é feita por um formato de dados estruturados, usualmente apresentados em planilhas.

A planilha COBie contém dados de todos os envolvidos no processo, tais como dos projetistas, do empreiteiro e seus subcontratados, dos fornecedores e do cliente. Em um projeto BIM, as planilhas COBie de todos os envolvidos são mescladas onde os campos e guias são preenchidos conforme o amadurecimento do projeto (design) e desenvolvimento da obra, em preparação para a fase de operação e manutenção O\&M. Em geral, os arquivos COBie não são destinados a serem "lidos" pelos usuários finais. Em vez disso, eles são um veículo que pode ser usado para trocar informações de espaço e equipamentos entre sistemas (BRODT; EAST; KIRBY, 2006).

A BS1192-4 fornece orientação e recomendações para o uso do COBie pelo governo do Reino Unido para trocar informações de instalações entre o contratante e a cadeia de suprimentos. O tempo e o número de pontos de troca específicos estão alinhados às fases do projeto e variam dependendo dos requisitos individuais dos clientes para se adequarem aos seus processos internos e aprovações. No mínimo, provavelmente haverá quatro trocas de dados: 1) na fase de conceituação; 2) no final do projeto conceitual; 3) no final do desenvolvimento do design; e 4) na entrega da obra. 


\subsection{NÍVEIS DE DESENVOLVIMENTO / DETALHAMENTO}

Formado por objetos, o modelo 3D além de sua representação volumétrica possui informações que podem ser utilizadas nas diversas fases do ciclo de vida do empreendimento. Para haver maior entendimento no mercado da construção sobre como os objetos devem ser desenvolvidos e quais informações devem ser inseridas foram desenvolvidos pelo mundo sistemas de classificações atendendo as características locais de mercado.

Em 2007, a Dinamarca desenvolveu um sistema de classificação baseado em níveis de informação (0-6) cobrindo dados geométricos e não geométricos desenvolvidos dos elementos virtuais que formam o modelo 3D. (BOLPAGNI, 2016)

Em 2013, o BIMForum publicou o Level of Development Specification baseado no protocolo do AIA (American Institute of Architects). Este documento serviu de referência para o desenvolvimento de diversos guias BIM e documentos de referência em diversos países tais como: 1) Austrália; 2) Canadá; 3) Cingapura; 4) China; 5) Alemanha; e 6) França entre outros. (BOLPAGNI, 2016). Já os EUA usam o US Levels of Development (LOD100-LOD500)

Para melhor ilustrar as diversas referências disponíveis no mercado mundial Bolpagni (2016) desenvolveu um trabalho (Quadro 1) contendo o comparativo entre os diversos sistemas de classificação.

Quadro 1: Comparativo entre os sistemas de classificação do LoX

\begin{tabular}{|c|c|c|c|c|c|c|c|c|c|c|c|c|c|}
\hline País & Fonte & Título & sistema LoX & \multicolumn{10}{|c|}{ Níveis } \\
\hline AUS & CRC 2009 & Object data levels & $\begin{array}{l}\text { Object data levels - Level of } \\
\text { Detail }\end{array}$ & - & - & - & A & B & C & - & D & $\mathrm{E}$ & - \\
\hline AUS & NATSPEC 2011 & $\begin{array}{l}\text { NATSPEC BIM } \\
\text { Object/Element } \\
\text { Matrix (BOEM) }\end{array}$ & Level of Development (LOD) & - & - & & 100 & 200 & 300 & & 400 & 500 & \\
\hline USA & \begin{tabular}{|l} 
PennState \\
University 2012
\end{tabular} & $\begin{array}{l}\text { BIM Information } \\
\text { Exchenge - Level } \\
\text { os Detail Matrix }\end{array}$ & Level of Development (LOD) & - & - & & 100 & 200 & 300 & & 400 & 500 & \\
\hline UK & PAS 1192-2:2013 & - & $\begin{array}{l}\text { Level of model Definition } \\
\text { Level of model Detail (LOD) } \\
\text { Level of model information (LOI) }\end{array}$ & - & - & 1 & 2 & 3 & 4 & - & 5 & 6 & 7 \\
\hline CAN & AEC (CAN) 2014 & \begin{tabular}{|l} 
Information \\
exchance \\
worksheet or \\
modelling matrix
\end{tabular} & Level of Development (LOD) & - & - & & 100 & 200 & 300 & 350 & 400 & 500 & \\
\hline UK & AEC (UK) & - & $\begin{array}{l}\text { Level of model Definition } \\
\text { Level of model Detail (LOD) } \\
\text { Level of model information (LOI) }\end{array}$ & - & - & 1 & 2 & 3 & 4 & - & 5 & 6 & 7 \\
\hline \multirow{2}{*}{ USA } & \multirow{2}{*}{ USIBD } & \multirow{2}{*}{ - } & Level of Development & - & - & & 100 & 200 & 300 & & 400 & 500 & \\
\hline & & & Level of Accuracy & & & \multicolumn{8}{|c|}{$10 ; 20 ; 30 ; 40 ; 50$} \\
\hline
\end{tabular}

Fonte: Adaptado de Bolpagni (2016). 


\subsection{Responsabilidades no gerenciamento das atividades BIM}

Responsabilidades na aplicação e gestão do BIM são necessárias ao longo do ciclo de vida de um projeto (Figura 6). Conforme apresentado pelo RICS (2017) no documento BIM for Project Managers diversas são as responsabilidades atreladas as atividades BIM pertencentes as 3 fases presentes ciclo de vida de um projeto (préconstrução, construção e encerramento).

Desta maneira, processos padronizados e protocolos são necessários para definição de responsabilidades, bem como boas práticas para que o gerenciamento dos dados seja adequado à estrutura da equipe e aos requisitos do projeto ( $\mathrm{Gu}$; London, 2010).

Figura 6: Atribuições gerais de gerenciamento de projetos BIM no ciclo de vida de projetos

\begin{tabular}{|c|c|c|}
\hline Stage & Project Manager's BIM Role & BIM applioations \\
\hline \multirow{7}{*}{$\begin{array}{l}\text { Briefing, Inception and } \\
\text { Pre-construction }\end{array}$} & Feasibility analysis [technical and financial] & $\begin{array}{l}\text { - BIM adoption question } \\
\text { - Challenges to BIM adoption } \\
\text { - Concept-stage BIM }\end{array}$ \\
\hline & Value engineering & $\begin{array}{l}\text { Options selection using BIM, Conceptual Estimating Modelling, } \\
\text { Energy Analysis, Design Analysis }\end{array}$ \\
\hline & Design management & $\begin{array}{l}\text { BIM information exchange, } 5 \mathrm{D} \text { [rapid cost feedback to design } \\
\text { changes], BIM Coordination }\end{array}$ \\
\hline & Risk analysis and safety & Simulation, Virtual Reality [VR] and Augmented Reality [AR] \\
\hline & Scheduling & 4D Modelling \\
\hline & Constructability analysis & 4D Modelling, virtual mock-ups, VR and AR \\
\hline & Procurement [design and construction] & $\begin{array}{l}\text { BIM skills and capability mapping, BIM enabled Supply Chain } \\
\text { Management, Constraint Analysis }\end{array}$ \\
\hline \multirow{4}{*}{ Construction } & Phasing and prototyping & 40 \\
\hline & RFIs and issue resolution & BIM information exchange, BIM coordination \\
\hline & Change management & BIM information exchange \\
\hline & Monitoring and control & $\begin{array}{l}\text { 4D and 5D, Constraint Analysis, Progress Tracking and } \\
\text { Production Planning }\end{array}$ \\
\hline \multirow{3}{*}{ Project closure } & Contract and financial closure & Record model \\
\hline & Project closure & Record model, Asset Information Model \\
\hline & Handover & Record model, BIM for FM, Asset Information Management \\
\hline
\end{tabular}

Fonte: RICS (2017) 


\subsection{BIM NO CENÁRIO DA CONSTRUÇÃO CIVIL}

O amadurecimento da adoção do BIM tende a gerar a consolidação dos documentos, guias, normas e protocolos, em função da necessidade de integração e padronização na produção de dados, com o objetivo de atender a todo o ciclo de vida da construção. Está evidente que os países pioneiros na utilização do BIM têm incrementado as publicações técnicas e orientativas em busca da exploração máxima dos benefícios da utilização do BIM (MCGRAW-HIL, 2014) (SMITH, 2014). Desta forma, os esforços de padronizações tornam-se concentrados, ao invés de ocorrer a fragmentação com eventuais divergências de informações, e fomenta a implementação do BIM no mercado.

A estratégia de construção do governo do Reino Unido, por exemplo, emprega um roteiro de maturidade do BIM para estabelecer metas realistas de conformidade com o BIM para sua cadeia de suprimentos sendo exigido desde abril de 2016 para o desenvolvimento dos projetos públicos (BSI, 2015).

Grande parte da estratégia de construção e do plano de ação do governo do Reino Unido foi baseada na exploração dos benefícios do BIM na construção e operação de empreendimentos públicos e descreve 3 níveis de maturidade do BIM (Figura 7). O Reino Unido nomeia o Nível 2 do BIM como ponto focal para o mandato que vem sendo exigido pelo governo britânico desde abril de 2016.

No Nível 0 todo o processo de desenvolvimento dos projetos (design), sua documentação e obtenção das informações são feitos de maneira convencional, isto é, através de plantas 2D e extração manual das informações e dados.

No Nível 1 de maturidade BIM muitas empresas usam software e processos BIM internamente para, por exemplo, melhorar a qualidade do design ou produzir a documentação de projeto de forma mais eficiente, mas não compartilham seu modelo gráfico com parceiros externos. Os desenhos tradicionais formam a base da colaboração, coordenação e entregas do projeto.

No Nível 2, o uso do BIM deve ser mais sofisticado, contendo trabalho colaborativo e compartilhamento de informações de projeto digital. As equipes do projeto (arquitetos, construtores, fabricantes, etc.) usam suas ferramentas escolhidas para produzir modelos 3D com informações técnicas inseridas aos componentes que compõem os modelos. A colaboração é conseguida através do intercâmbio de 
informações gráficas e não gráficas entre as diferentes partes da equipe do projeto para criar um modelo federado.

Figura 7: Níveis de maturidade BIM

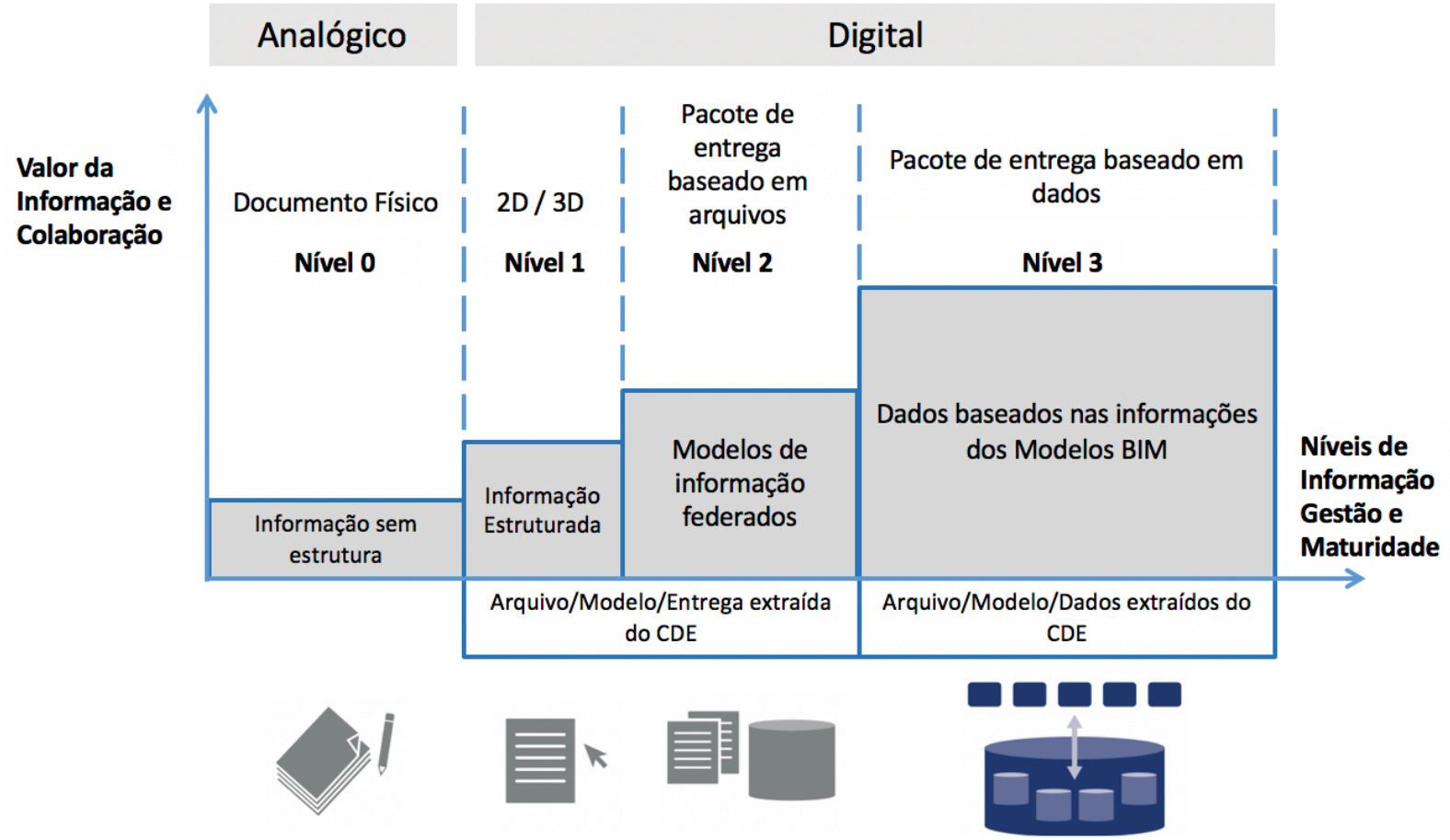

Fonte: Adaptado de ISO19650-1.2 (2017).

No Nível 3, todas as informações e dados a serem utilizados para desenvolvimento do empreendimento devem ser extraídos de um único modelo BIM que deve estar no Common Data Environment (CDE), ou Ambiente Comum de Dados.

Para Taylor (2016), devido à sua importância, a responsabilidade pelo desenvolvimento, disponibilização e manutenção do CDE deve ser do cliente ou contratante e sua utilização deve ser iniciada no início do CAPEX (Capital Expense), fase de abertura e despesas dos gastos para desenvolvimento do ativo construído, passando por todas as fases de projeto, obra e O\&M.

$\mathrm{Na}$ prática alguns projetos públicos na área de infraestrutura tais como o do Crossrail no Reino Unido por exemplo, foram usados como pilotos para verificação da aplicabilidade dos novos métodos propostos e para obtenção de sugestões e comentários dos setores da indústria e do governo local.

Para May, Taylor e Irwin (2016), o projeto do Crossrail é na atualidade um dos maiores projetos de construção da Europa. Totalizando, no final da obra, $142 \mathrm{~km}$ de trilhos, $42 \mathrm{~km}$ de túneis (onde foram utilizadas 8 máquinas perfuratrizes 
simultaneamente), reforma de 40 estações e construção de 10 novas, Figura 8 que atenderão 1,5 milhão de pessoas. Os trabalhos foram iniciados em 2009 e hoje existem 10.000 pessoas trabalhando em 40 canteiros de obras simultaneamente.

Figura 8: Implantação macro das atividades do Crossrail

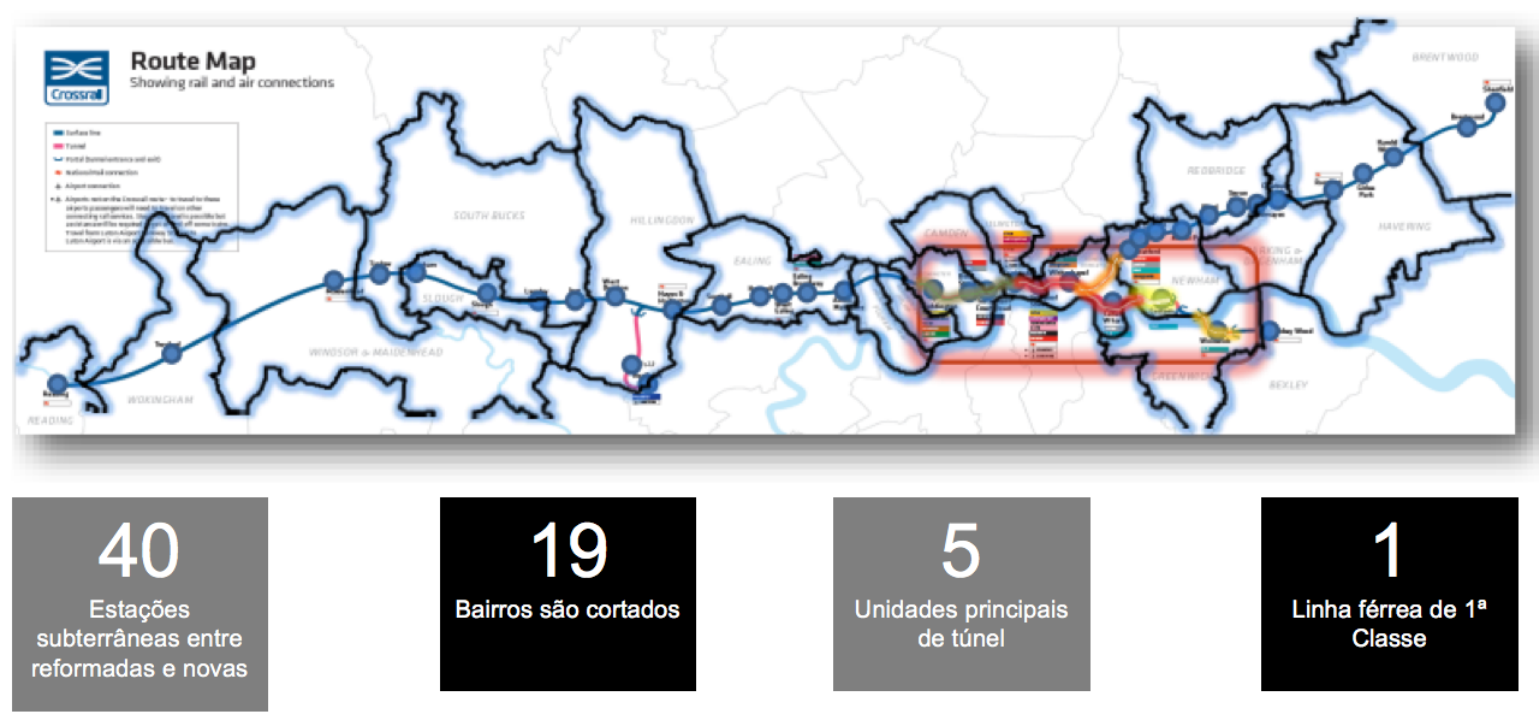

Fonte: Adaptado de May, Taylor, Irwin (2016)

Este esforço aumentará a capacidade de transporte sobre trilhos em Londres em 10 por cento com o valor total disponível para conclusão em $£ 14,8$ bilhões. 0 processo gerou 4,5 milhões de toneladas de material de escavação, sendo mais de 98 por cento exportados e usados para criar 1.500 acres de reservas naturais.

Além da expansão da rede metro-ferroviária de Londres, o Crossrail trará outros benefícios, tais como:

- Estimativa da criação de $£ 5,5$ bilhões em valor agregado;

- Entrega de 57.000 novas residências;

- Disponibilização de 3,25 milhões de metros quadrados de área comercial; e

- Impactando positivo nos investimentos.

Na Figura 9 é possível encontrar o cronograma macro de execução desde o início das prospecções no ano de 2005 até a etapa de operação da rede que tem 2018 como previsão de início.

Outras disciplinas dentro Crossrail que exigem ou geram informações em relação ao projeto são, por exemplo, a propriedade e equipe jurídica, saúde e segurança, helpdesk, gestão de propriedades e muitos mais. É vital para o sucesso 
do projeto que os dados e informações estejam prontamente disponíveis para todas as equipes que atuam no projeto, e que ele é revisto e atualizado onde informações novas ou mais precisas são encontradas.

Figura 9: Cronograma macro das atividades do Crossrail.

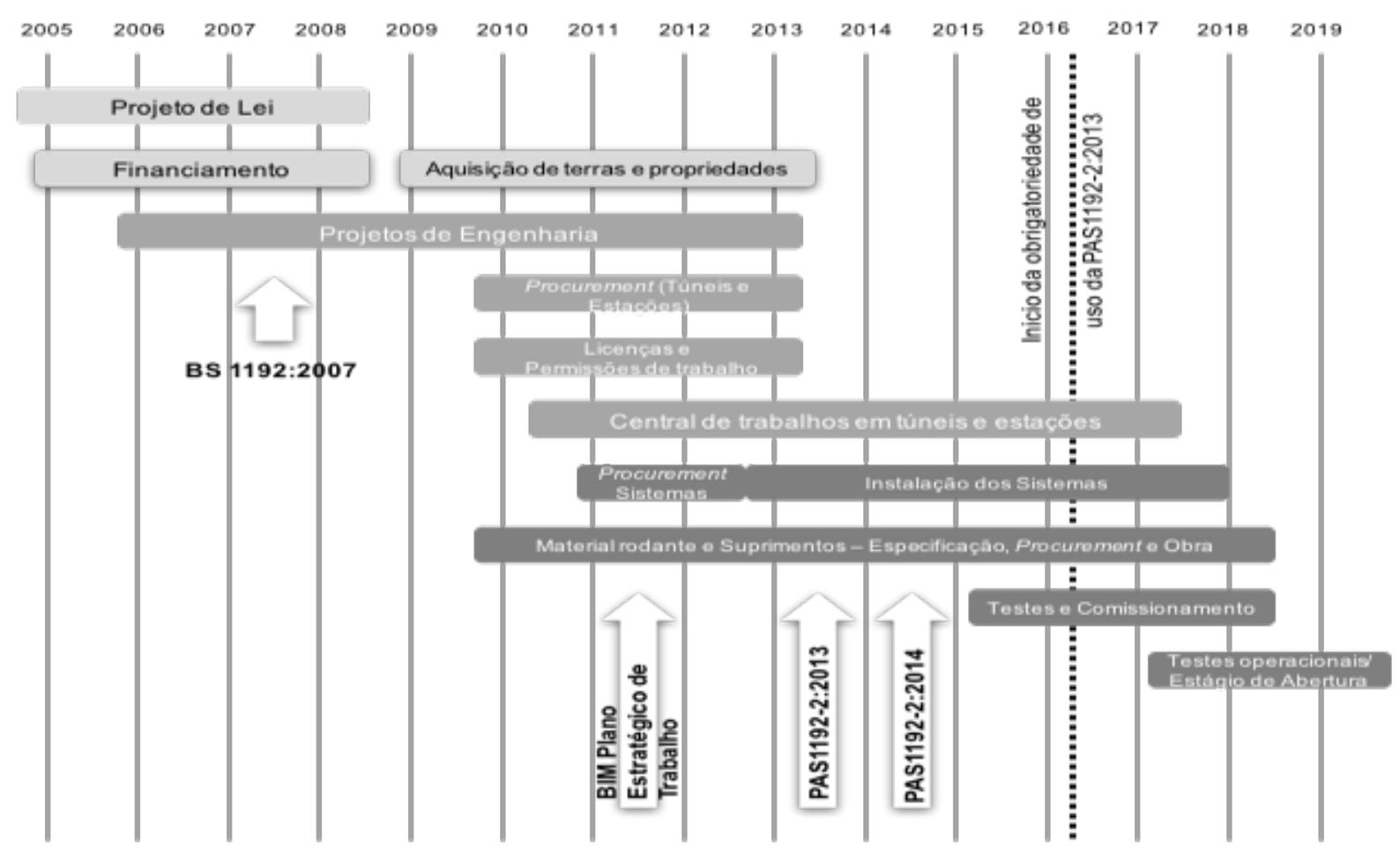

Fonte: Adaptado de May, Taylor, Irwin (2016)

Um dos maiores desafios em grandes projetos de infraestrutura é a integração do ambiente construído e os ativos existentes no processo de design. Esses dados estão frequentemente disponíveis no formato GIS nativo ou em um formato estruturado, ou seja, em relatórios ou planilhas. Todas essas informações devem estar disponíveis para os departamentos de projeto em um formato 3D para ajudar a criar um modelo de recurso 3D dedicado.

Na Figura 10, é demonstrado o relacionamento entre as atividades nas fases de desenvolvimento do projeto Crossrail. Entre as informações necessárias para a construção, são necessárias, além dos dados de design (GIS e CAD) as informações de planejamento, custos, riscos e pleitos. 
Figura 10: Relacionamento entre as atividades durante as fases do Crossrail.

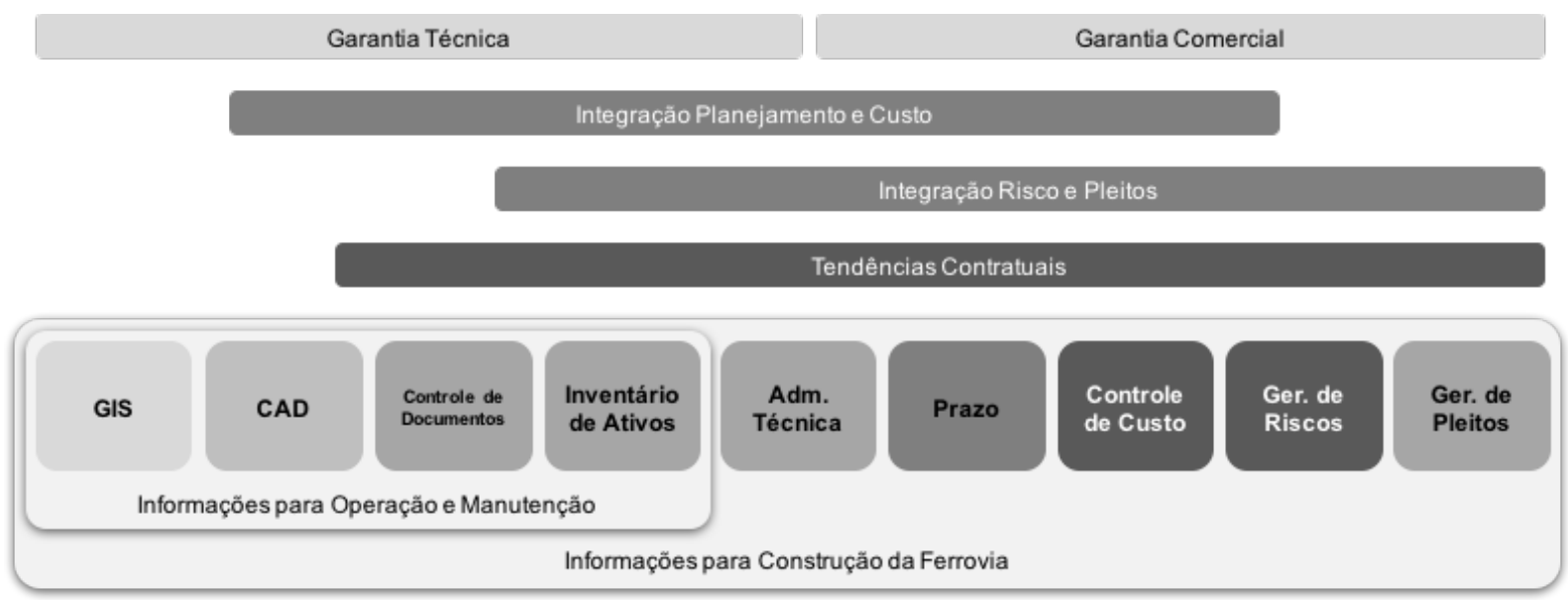

Fonte: Adaptado de Taylor (2016)

Como apresentado no National BIM Report (NBS, 2017) a adoção do BIM pelas empresas do Reino Unido vem aumentado ao passar dos anos. Conforme o Gráfico 1, em 2011 somente 13\% dos entrevistados utilizavam o BIM na época onde aproximadamente 87\% ainda não o utilizavam. Já em 2017 este cenário mudou, 97\% dos participantes sabem o que é BIM e $62 \%$ declararam que o utilizam.

Gráfico 1: Adoção do BIM ao longo do tempo

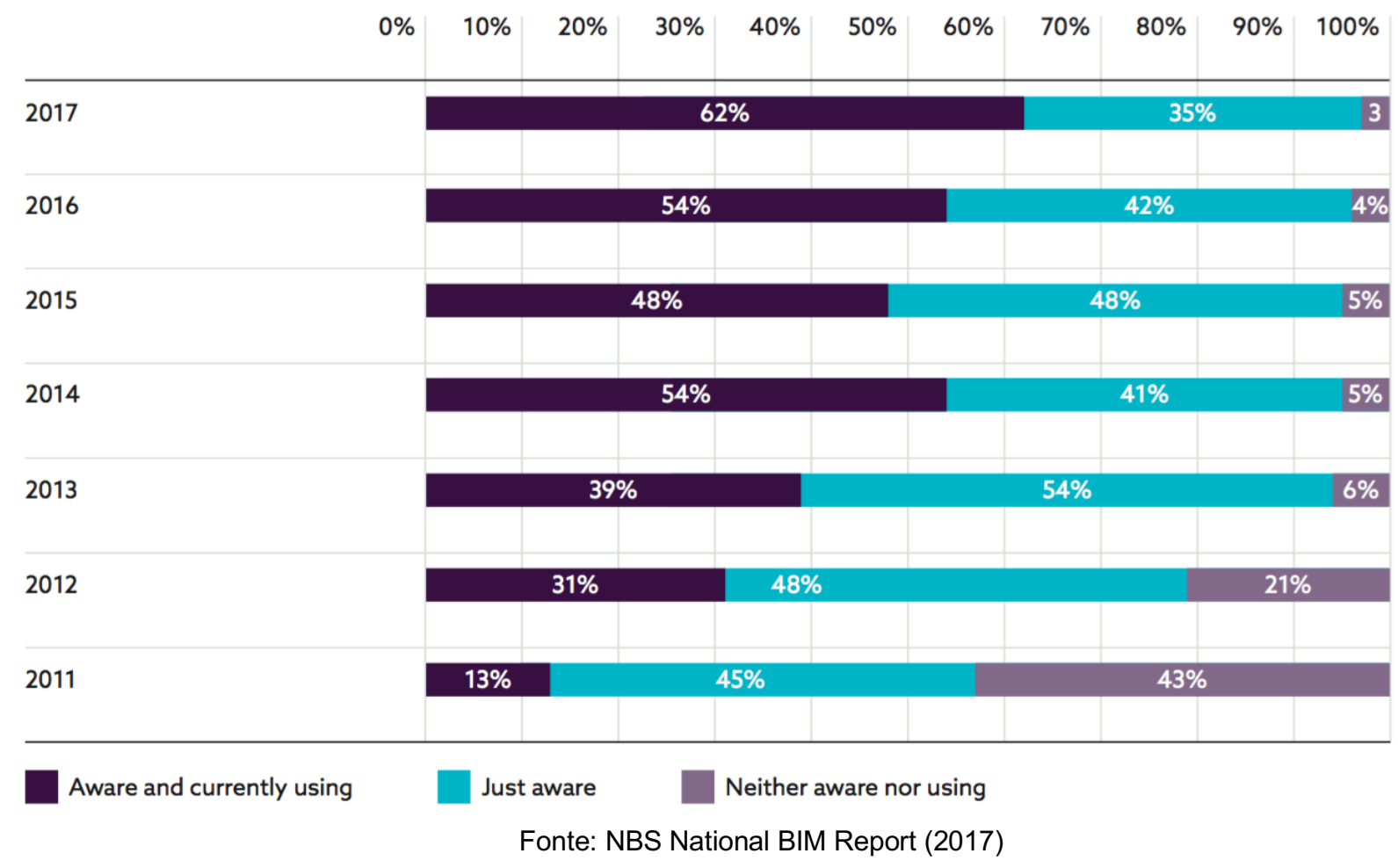


Entretanto, em dados apresentados no mesmo documento, é possível notar que, apesar de todos os esforços do governo britânico no desenvolvimento de normas específicas para o uso do BIM como a PAS1192-2:2013, existem práticas locais que ainda utilizam ferramentas 2D para desenvolvimento dos projetos.

Como pode ser observado na Gráfico 2 aproximadamente $31 \%$ dos participantes mencionaram que ainda utilizam ferramentas 2D e outras ferramentas para produção de projetos (design).

Gráfico 2: Tipo de ferramenta utilizada pelo mercado britânico para produção de projetos

\begin{tabular}{|c|c|c|c|c|c|c|}
\hline & $0 \%$ & $10 \%$ & $20 \%$ & $30 \%$ & $40 \%$ & $50 \%$ \\
\hline Autodesk Revit & $41 \%$ & & & & & \\
\hline Graphisoft ArchiCAD & $15 \%$ & & & & & \\
\hline Autodesk AutoCAD & $14 \%$ & & & & & \\
\hline Autodesk AutoCAD LT & $12 \%$ & & & & & \\
\hline $\begin{array}{l}\text { Nemetscheck } \\
\text { Vectorworks }\end{array}$ & $9 \%$ & & & & & \\
\hline Other & $5 \%$ & & & & & \\
\hline Bentley Microstation & $2 \%$ & & & & & \\
\hline $\begin{array}{l}\text { Trimble Sketchup } \\
\text { (formerly Google Sketchup) }\end{array}$ & $2 \%$ & & & & & \\
\hline $\begin{array}{l}\text { Bentley AECOsim } \\
\text { Building Designer }\end{array}$ & $1 \%$ & & & & & \\
\hline Nemetscheck Allplan & $0 \%$ & & & & & \\
\hline
\end{tabular}

Fonte: NBS National BIM Report (2017)

Importante salientar neste momento que a utilização de ferramentas de modelagem BIM não significa que se esteja desenvolvendo processos BIM. 


\subsection{BIM NO CENÁRIO DA CONSTRUÇÃO CIVIL NACIONAL}

No Brasil, a utilização do BIM tem sido mais encontrada na fase de desenvolvimento de projetos (design) e, recentemente, tem sido também utilizado no gerenciamento e controle na fase de obra.

A AsBEA desenvolveu um Guia com dois volumes (ASBEA, 2013) (ASBEA, 2015a) (ASBEA, 2015b) onde são abordados temas básicos para a implantação e utilização do BIM incluindo novos métodos e posturas envolvidos no processo voltados para empresas projetistas da cadeia da construção civil.

Em 2014, o Governo de Santa Catarina disponibilizou ao mercado o Caderno de Contratação de Projetos que é considerado como o primeiro documento técnico com especificações BIM publicado por um governo estadual (GSC, 2014). O objetivo é dar diretrizes aos prestadores de serviços do Estado em como o desenvolvimento das atividades BIM devem ser desenvolvidas para atender as necessidades no governo local. Desenvolvido pela Secretaria de Planejamento, este documento deve ser integrante em editais para a contratação de serviços pelo Estado.

A Associação Brasileira de Normas Técnicas (ABNT), por meio da Comissão de Estudo Especial de Modelagem de Informação da Construção (CEE-134) está desenvolvendo a primeira norma técnica BIM brasileira, a ABNT NBR 15965 (Sistema de classificação da informação da construção) estabelecendo um padrão de classificação hierárquica aos elementos BIM (MAINARDI NETO; SANTOS, 2015).

Para Catelani e Santos (2016) o foco da ABNT NBR 15965 é disponibilizar ao mercado da construção civil um sistema de classificação das informações possibilitando assim a padronização de nomenclaturas nacional dos elementos utilizados nos processos BIM. A norma é formada por 15 Tabelas (Quadro 2) e seu conteúdo não é resultado de simples traduções de normas já existentes e sim apresentar soluções construtivas e componentes específicos encontrados na realidade da construção civil nacional.

Desta maneira, o mercado nacional terá, ao final do desenvolvimento da NBR 15965, uma norma específica voltada para a classificação na área da Construção.

A Coletânea Implementação do BIM para Construtoras e Incorporadoras (2016) em seis volumes da Câmara Brasileira da Indústria da Construção - CBIC, é estruturada em seis volumes tendo objetivo de tornar o BIM mais acessível de 
orientações de aplicações claras para as empresas do setor da construção de edificações.

Quadro 2: Estrutura das atividades pertencentes a ABNT NBR 15965

\begin{tabular}{|l|l|c|}
\hline \multirow{4}{*}{ Características dos objetos } & \multicolumn{1}{|c|}{ ASSUNTO } & TABELA \\
\hline \multirow{2}{*}{ Processos } & Materiais & OM \\
\cline { 2 - 3 } & Propriedades & OP \\
\hline \multirow{2}{*}{ Recursos } & Fases & $1 \mathrm{~F}$ \\
\cline { 2 - 3 } & Serviços & $1 \mathrm{~S}$ \\
\cline { 2 - 3 } & Disciplinas & $1 \mathrm{D}$ \\
\hline \multirow{2}{*}{ Resultado da construção } & Funções & $2 \mathrm{~N}$ \\
\hline \multirow{2}{*}{ Unidades e espaços da construção } & Equipamentos & $2 \mathrm{Q}$ \\
\hline & Componentes & $2 \mathrm{C}$ \\
\hline & Elementos & $3 \mathrm{E}$ \\
\hline & Construção & $3 \mathrm{R}$ \\
\hline & Unidades pela Função & $4 \mathrm{U}$ \\
\cline { 2 - 3 } & Espaços pela Função & $4 \mathrm{~A}$ \\
\hline & Unidades pela Forma & $4 \mathrm{~V}$ \\
\hline & Espaços pela Forma & $4 \mathrm{~B}$ \\
\hline \multirow{2}{*}{ Informação da construção } & Informação & $5 \mathrm{I}$ \\
\hline
\end{tabular}

Fonte: Adaptado de Catelani e Santos (2016).

Em reconhecimento à importância estratégica do uso de BIM, a exigência de sua utilização começa a ser uma prática comum em editais de grandes contratantes brasileiros. Entre eles pode ser citada a contratação da elaboração e gerenciamento dos projetos (design) de arquitetura e dos projetos complementares do novo empreendimento da FIOCRUZ na cidade de Belo Horizonte - MG (2014).

O novo empreendimento prevê ao seu projeto de implantação o Centro de Desenvolvimento Tecnológico em Saúde que permitirá abrigar plataformas tecnológicas e biotérios para prestação de serviços de alto conteúdo tecnológico e na interface da pesquisa acadêmica.

Em dezembro de 2016, o governo brasileiro, representado pelo MDIC, assinou em Brasília um termo de cooperação junto ao governo britânico, sendo este representado pelo BEIS, para a troca de experiências sobre BIM com o foco de aprimorar o processo de desenvolvimento de uma estratégia nacional brasileira para a disseminação do BIM no país (JETCO, 2016).

Dentro deste acordo entre Brasil e o Reino Unido, cinco são os pontos focais referente ao aprendizado mútuo tais como: 
a) Engajar intercâmbio de conhecimento com apoio de especialistas do Reino Unido para facilitar o desenvolvimento e introdução de uma estratégia brasileira para o BIM;

b) Identificar adaptações necessárias aos padrões britânicos para maximizar a aplicabilidade no Brasil;

c) Desenvolver planos conjuntos para encorajar especialistas britânicos a participar e apoiar as atividades de disseminação do BIM no Brasil;

d) Fomentar as conexões entre os órgãos britânicos e brasileiros responsáveis pela gestão obras públicas e facilitar a troca de conhecimento e melhores práticas relacionadas a cadeia da construção do setor público nacional;

e) Elaborar planos conjuntos de engajamento das partes interessadas com a indústria.

Com base no termo de cooperação, o Governo Federal, através de um decreto presidencial de junho de 2017, criou o Comitê Estratégico de Implementação do Building Information Modelling (BIM) que teve como objetivo propor, no âmbito do Governo Federal, a Estratégia Nacional de Disseminação do BIM no Brasil (MDIC, 2017).

O MDIC (Ministério da Indústria, Comercio Exterior e Serviços) exerceu a presidência destes trabalhos e o comitê é formado por: 1) Casa Civil da Presidência da República; 2) Ministério da Defesa; 3) Ministério do Planejamento, Desenvolvimento e Gestão; 3) Ministério da Ciência, Tecnologia, Inovações e Comunicações; 4) Ministério das Cidades; e 5) pela Secretaria Geral da Presidência da República.

Conforme o MDIC (2017), a criação do Comitê Estratégico de Implementação do Building Information Modelling é um passo importante para promover a competitividade das empresas brasileiras.

Para o desenvolvimento dos trabalhos e apoio técnico ao CE-BIM foram criados seis Grupos de Apoio Técnico - GAT-BIM que foram formados por representantes do governo e por especialistas das diversas áreas da cadeia da construção civil.

Cada um dos grupos teve como foco do trabalho desenvolver diretrizes objetivas ao mercado da construção civil nacional referente a disseminação do BIM no Brasil abrangendo 5 temas como base: 
- Regulamentação / Normalização: tem a estratégia de fortalecer as politicas públicas e as estratégias governamentais destinadas ao estímulo e à gestão do desenvolvimento, inovação e competitividade do setor produtivo no Brasil.

- Plataforma BIM: proposição de ações no âmbito da Biblioteca BIM necessárias para disseminar o BIM no Brasil através da identificação dos atores, envolvidos e do modo de funcionamento, da verificação e da descrição de um plano estratégico para criação de objetos virtuais para a Biblioteca BIM.

- Capacitação: proposição de ações no âmbito de Capacitação necessárias para disseminar o BIM no Brasil através do diagnóstico do cenário atual da capacitação em BIM no país, da identificação da necessidade e possibilidade de inserção do BIM nas grades curriculares de cursos de graduação, de pósgraduação e profissionalizantes, do elenco de iniciativas de qualificação em BIM dos profissionais já atuantes no mercado.

- Infraestrutura Tecnológica: proposição de ações no âmbito de Infraestrutura Tecnológica necessárias para disseminar o BIM no Brasil através da pesquisa sobre requisitos tecnológicos mínimos (hardware, software, redes, tráfego de dados) para utilização do BIM, do diagnóstico da situação atual desses requisitos no Brasil, da pesquisa de linhas de crédito existentes para aquisição de hardware e software e da proposição de ações no âmbito de Infraestrutura Tecnológica.

- Compras Governamentais: levantar e analisar experiências internacionais de países que exigem que projetos de obras custados pelo Governo sejam desenvolvidos em BIM e do levantamento e análise de experiências nacionais em que foi exigido o BIM na licitação.

- Comunicação: tem como finalidade agrupar de forma clara e objetiva todo material desenvolvido pelos demais grupos e fazer a comunicação destes à sociedade e os demais interessados sendo eles do setor público e privado.

\subsection{TIPOS DE CONTRATAÇÃO}

Atualmente seis são os métodos de contratação mais utilizados na cadeia da construção civil nacional. Entretanto não é a maioria que possuem características que criam a oportunidade de maior integração entre todos os envolvidos com a finalidade de obtenção do melhor resultado do Projeto.

Como pode ser observado na Figura 11, seis são os métodos de contratação mais utilizados no mercado nacional na cadeia da construção civil, mas para Eastman et al. (2011) três podem ser considerados os métodos de contratação fundamentais no mercado: Design-Bid-Build (DBB), Design-Build (DB) e Construction Management 
at Risk (CMR) que no Brasil são adotados por Licitação pelo menor preço, Preço fixo e Administração da obra (UECHI et al, 2013) respectivamente.

Observando as características individuais dos três métodos citados por Eastman, dois deles apresentam ambientes propícios para a utilização do BIM. São estes: 1) Design-Build; e 2) Construction Management at Risk.

O primeiro método de contratação citado acima é contratualmente mais adaptado para aumentar a colaboração entre os membros da equipe de projeto e construção já que permite a autonomia entre os principais participantes no estabelecimento das metodologias de trabalho a serem adotadas.

Figura 11: Tipos de contratação mais comuns na construção.

\begin{tabular}{|c|c|}
\hline $\begin{array}{l}\text { DESICN BID BUILD } \\
\text { (DBB) }\end{array}$ & $\begin{array}{l}\text { - A CONTRATANTE assume a criação do projeto, execução da } \\
\text { engenharia e todas as contratações / aquisições incluindo a } \\
\text { gestão do empreendimento e gerenciamento das obras. }\end{array}$ \\
\hline DESICN \& BUILD (D\&B) & $\begin{array}{l}\text { - Empreendimentos de baixa complexidade onde a construção é } \\
\text { predominante em relação à engenharia, suprimentos, } \\
\text { fabricação e montagem }\end{array}$ \\
\hline EPCW & $\begin{array}{l}\text { - O CONTRATADO é responsável por desenvolver os projetos } \\
\text { de engenharia, pelo Suprimentos e Gerenciamento das obras } \\
\text { do empreendimento. }\end{array}$ \\
\hline EPC & $\begin{array}{l}\text { - O CONTRATADO é responsável por desenvolver os projetos } \\
\text { de engenharia, pelo Suprimentos e a execução das obras do } \\
\text { empreendimento, a CONTRATANTE gerencia a obra. }\end{array}$ \\
\hline ALIANGA & $\begin{array}{l}\text { - A CONTRATANTE e a CONTRATADA executam uma gestão } \\
\text { compartilhada do empreendimento definindo funções desde a } \\
\text { engenharia à construção (sociedade virtual). }\end{array}$ \\
\hline TURN KEY & $\begin{array}{l}\text { - O CONTRATADO fica obrigado a entregar a obra em } \\
\text { condições de pleno funcionamento. }\end{array}$ \\
\hline
\end{tabular}

Fonte: Autor

No segundo método, Construction Management at Risk, o proprietário e o gestor da obra assumem juntos os riscos relativos ao cronograma e aos custos finais do empreendimento. Desta forma o cliente dá oportunidade para o construtor em opinar sobre o projeto para que se estabeleça a adoção do melhor método construtivo ainda na fase de projetos.

No que se refere a Produção Integrada do Empreendimento, que compreende diferentes modelos de contrato, destaca-se o Integrated Project Delivery (IPD). O IPD 
caracteriza-se pela participação precoce dos principais agentes, que estabelecem um único contrato multilateral, juntamente com o cliente. $\mathrm{O}$ trabalho colaborativo $\mathrm{e}$ integrado da equipe tem como base instrumentos presentes no contrato, como: compartilhamento de riscos e benefícios; tomadas de decisão compartilhadas; e transparência na troca de informações do projeto.

A contratação no setor privado tem seguido esses modelos e suas variantes. Porém, quanto ao desenvolvimento de projeto, o poder público adotou duas modalidades: a definida pela Lei no 8.666, de 21 de junho de 1993, e o Regime Diferenciado de Contratações Públicas (RDC). A Lei no. 8.666/93 e suas posteriores alterações preveem a licitação com base no "Projeto Básico", o que pode acontecer de quatro formas:

I - Empreitada por preço unitário;

II - Empreitada por preço global;

III - Contratação por tarefa;

IV - Empreitada integral.

Todas as quatro formas devem ser baseadas em planilhas de preço unitário referentes aos serviços, materiais e equipamentos, que devem constar do referido Projeto Básico.

Já o RDC que é utilizado hoje na maioria dos investimentos, regido pela Lei no 12.462, de 4 de agosto de 2011 (que exige um anteprojeto de engenharia no instrumento convocatório), e posteriormente complementada pela Lei no 12.980 , de 28 de maio de 2014, foi criado inicialmente apenas para agilizar a contratação das obras referentes aos eventos esportivos sediados em 2014 e 2016 (Copa do Mundo e Olimpíadas, respectivamente), mas foi gradualmente estendido a outros tipos de obras (ações do PAC e obras do SUS, do sistema de ensino e do sistema prisional). Dentre as inovações trazidas pelo RDC, destaca-se o regime de execução denominado de "contratação integrada", inspirada no Decreto no 2.745/1998, que regulamentava o procedimento licitatório simplificado da Petrobras.

Nesse modelo, cabe ao licitante / proponente desenvolver o projeto básico e o executivo, além de executar a obra, os testes de recebimento, a pré-operação e outros serviços eventualmente necessários para o comissionamento. No que diz respeito á orçamento, o RDC exige, desde o início, a apresentação de "orçamento detalhado do custo global da obra, fundamentado em quantitativos de serviços e fornecimentos propriamente avaliados", mas no caso de projeto integrado, exige apenas "o valor 
estimado da contratação (...) calculado com base nos valores praticados pelo mercado, nos valores pagos pela administração pública em serviços e obras similares ou na avaliação do custo global da obra, aferido mediante orçamento sintético ou metodologia expedita ou paramétrica".

Na prática, o RDC tenta se aproximar do conceito de Design-Build, mas exige o "anteprojeto de engenharia"; enquanto no exterior, a base é feita em especificações de desempenho do objeto a ser construído. Ao se referir a um orçamento detalhado, sem definir o desempenho do produto, ele abre brechas para alterações de escopo e de preços, ainda que a orientação atual do TCU - Tribunal de contas da União - seja que aditivos neste regime de contrato sejam considerados como uma exceção. Em outros países, esse modelo costuma ter o escopo do empreendimento mais nítido e rígido, assim, as variações de preço são mínimas e em geral estão previstas cláusulas de performance que limitam os custos.

Ao contrário do que parece, o RDC tem pouca semelhança com o IPD, pois este é baseado em cláusulas de desempenho, com bonificações e encargos distribuídos por todos os participantes, sejam projetistas e/ou construtores. O Plano de Execução BIM é, portanto, a peça-chave para que órgãos públicos possam exigir e planejar projetos que utilizem o processo BIM. É importante frisar que tanto nas licitações modelo RDC quanto nas em que apenas o projeto básico é licitado, exigências de qualificação dos projetistas deveriam ser incluídas nos editais, de modo a garantir experiência no objeto do contrato e no processo BIM. Hoje, nesse tipo de licitação, existe apenas a exigência de qualificação do construtor.

\section{MÉTODO DE PESQUISA}

O foco deste trabalho é contribuir para solucionar um problema real existente na cadeia da construção civil nacional decorrente da falta de um protocolo BIM para a produção de projetos e gerenciamento de obras. Desta maneira será adotada a Pesquisa Construtiva (Constructive Research ou Design Science Research) como método para realização deste trabalho.

A pesquisa construtiva é utilizada em casos em que deve ser trabalhada a melhora em determinado sistema existente ou há necessidade de correção de problema(s) identificados(s). Para Morais et al. (2016) nas áreas de arquitetura e engenharia pode ser utilizada a pesquisa construtiva para a solução dos problemas práticos. A validação de sua funcionalidade em casos reais deve ser aplicada por 
profissional com extensa experiência técnica pois a sua falta pode influenciar no entendimento do pesquisador no contexto e entendimento do problema (OYEGOKE, 2011). O resultado alcançado deve ser utilizado como legado para realização de estudos futuros (LUKKA, 2014). Desta maneira, o potencial da contribuição da pesquisa construtiva pode servir de ligação entre a teoria existente e um problema real como é mostrado na Figura 12.

Figura 12: Representação da pesquisa construtiva como elo entre a teoria existente e um problema real.

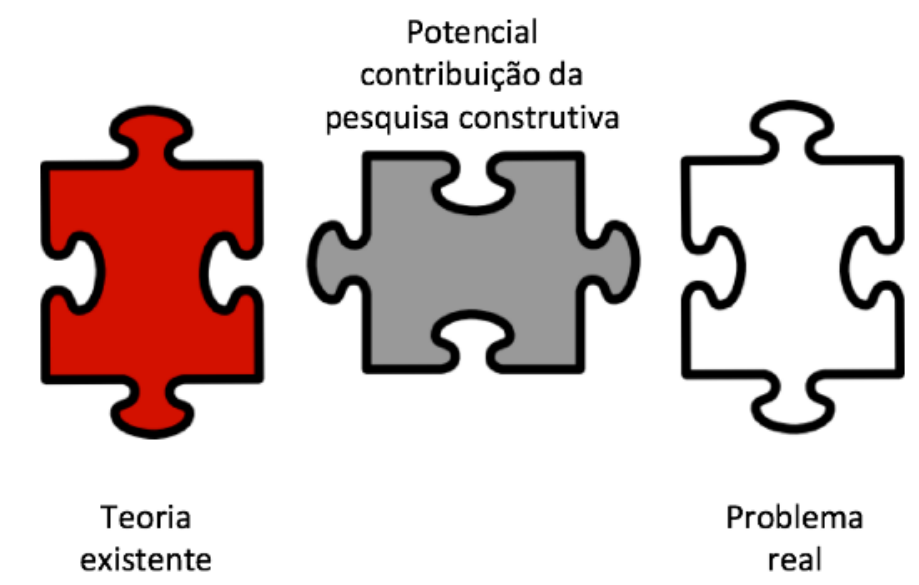

Fonte: Adaptado de Lehtiranta, Junnonen, Kärnä, Pekuri (2015).

\subsection{FASES DA PESQUISA CONSTRUTIVA}

Conforme Lukka (2003), a pesquisa construtiva pode ser dividida nas seguintes fases: 1) encontrar problema prático relevante que tenha potencial de pesquisa; 2) obter compreensão geral e abrangente sobre o tema; 3) projetar uma solução ou produto; 4) demonstrar que a solução ou produto funcionam; 5) demonstrar as conexões teóricas com a contribuição de pesquisa e os conceitos da solução; e 6) examinar o alcance da aplicação da solução.

Conforme indicado por Lukka (2003) sobre a estruturação por etapas da pesquisa e o fluxo desenvolvido por Oyegoke (2011), é mostrado na Figura 13 o relacionamento entre as características do método de pesquisa com o caso específico deste trabalho. 
Figura 13: Método apresentado baseado nas características da pesquisa construtiva.

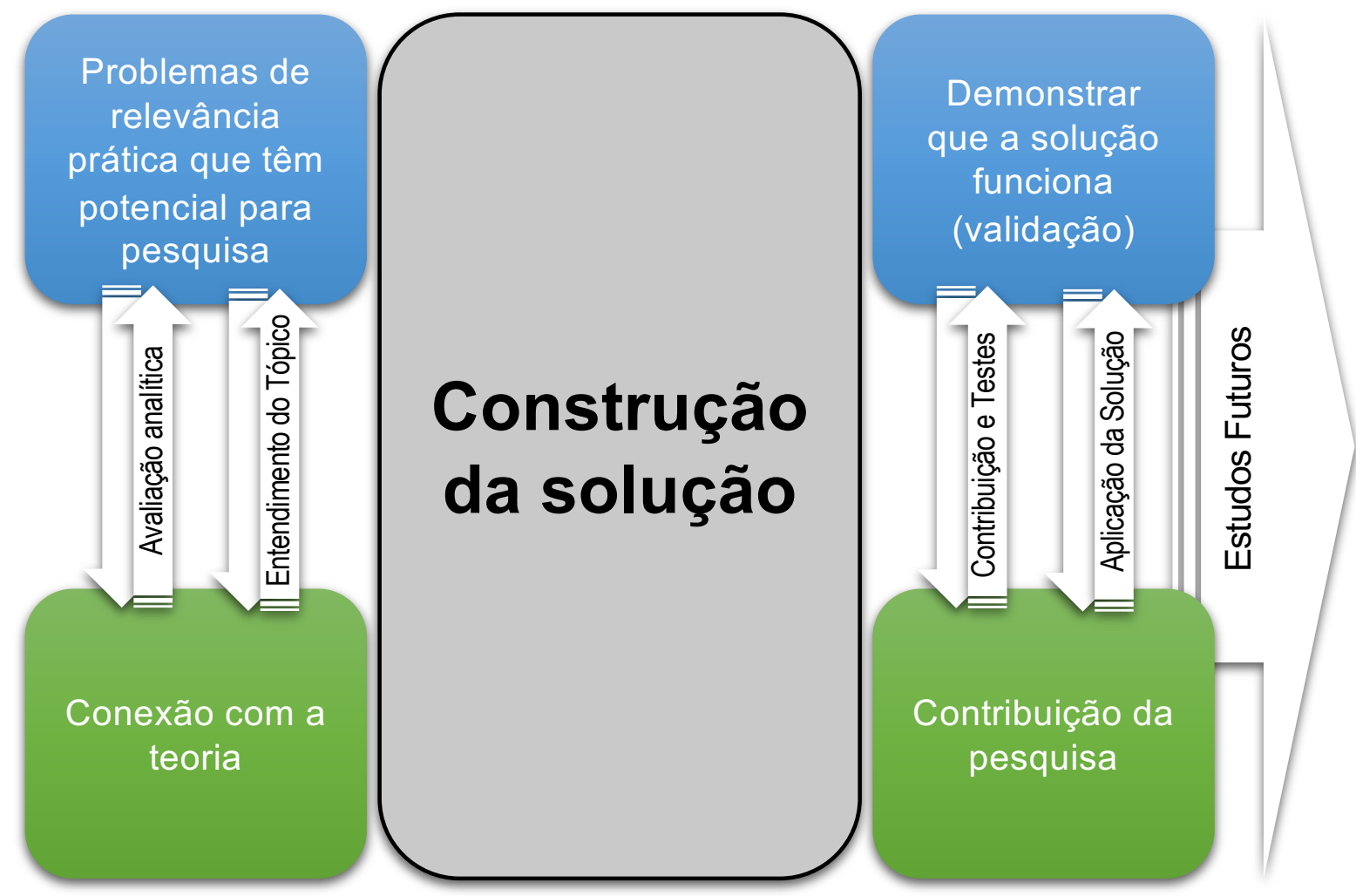

Fonte: Adaptado de Oyegoke (2011).

\subsubsection{Encontrar problema prático relevante que tenha potencial de pesquisa}

Para a definição do problema prático que é utilizado neste trabalho, foi realizada uma revisão bibliográfica inicial com o foco em identificar a situação e os impeditivos para a disseminação do BIM no Brasil. Foram utilizados nesta fase do trabalho a Norma ABNT NBR 15965, Guias BIM nacionais publicados, Caderno de Contratação de Projetos BIM desenvolvido pelo estado de Santa Catarina e licitações públicas que exigem o BIM como base para o desenvolvimento e gerenciamento de projetos civis entre os anos de 2006 a 2011.

\subsubsection{Obtenção do conhecimento geral sobre o tema}

Foram utilizadas para o desenvolvimento desta atividade publicações nacionais e internacionais tais como normas, artigos científicos, livros, sites, dissertações, teses e participação em eventos referentes aos processos de contratação, produção e entrega das informações e dados BIM com a finalidade de ampliar o conhecimento sobre o tema. Com foco na contratação de prestação de serviços utilizando o BIM 
foram levantadas e analisadas as licitações publicadas no mercado nacional de forma a identificar seus requisitos (seção 4.1). Assim, foi possível obter um conhecimento geral sobre o tema escolhido (Figura 14).

Figura 14: Relacionamento das atividades base para produção do PNBIM.

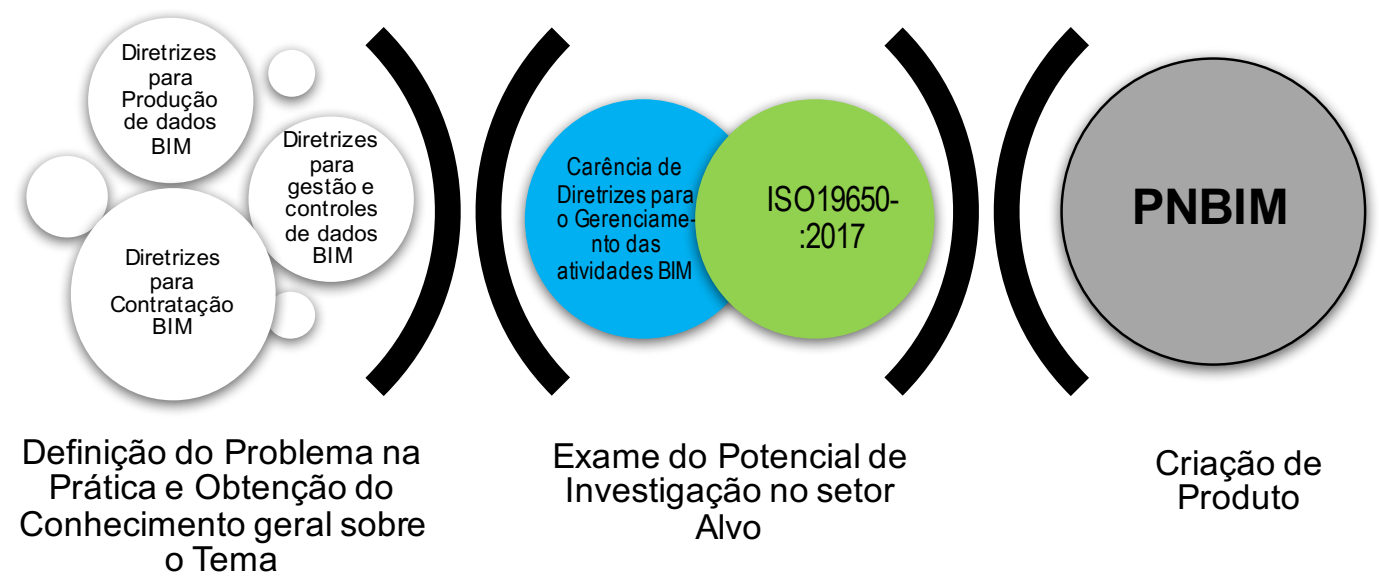

Fonte: Autor.

\subsubsection{Projetar uma solução ou produto}

Após obtenção do conhecimento através do levantamento e análise das informações, foi possível identificar, na cadeia da construção civil nacional, a ausência de um documento orientador referente ao gerenciamento das informações e dados gerados pelo BIM. Desta forma, é sugerido o desenvolvimento de um Protocolo Nacional BIM (PNBIM) que contemple os processos de contratação, produção colaborativa e entrega dos produtos BIM.

\subsubsection{Demonstrar as conexões teóricas com a contribuição de pesquisa e os conceitos da solução}

Conforme dados levantados na fase de obtenção do conhecimento geral sobre o tema e como apresentado na Figura 15, é possível comprovar a viabilidade da utilização da pesquisa construtiva como método principal de desenvolvimento deste trabalho fazendo um comparativo entre as ações sugeridas por Lukka (2003) e Oyegoke (2011) com as ações descritas nas etapas anteriores deste trabalho. 
Figura 15: Método apresentado baseado nas características da pesquisa construtiva.

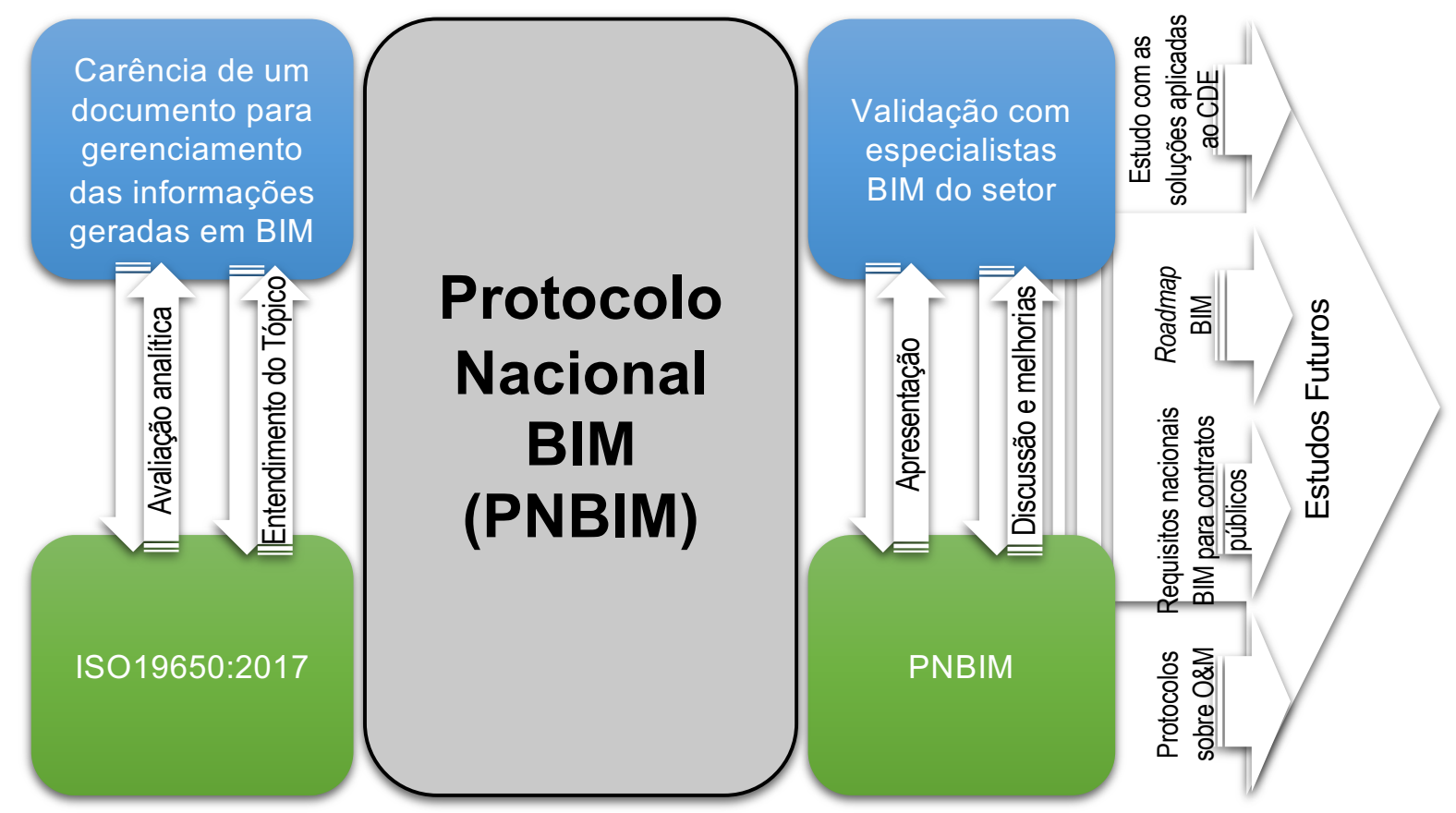

Fonte: Autor

\subsubsection{Examinar o alcance da aplicação da solução}

Como mencionado anteriormente, a elaboração de um PRODUTO que possa ser utilizado para solucionar problemas práticos é a essência da pesquisa construtiva. Conforme a problemática deste trabalho - que está na carência de normativas para a produção e gerenciamento das informações e dados em BIM no Brasil - o produto proposto tem como alcance de aplicação durante as fases do início do CAPEX ao início do OPEX, fase de despesas com a operação e manutenção, pertencentes ao ciclo de vida de empreendimentos civis.

\subsubsection{Demonstrar que a solução ou produto funcionam}

Nesta fase, existe a passagem do conhecimento adquirido nas etapas anteriores para o mundo prático onde isso é a principal diferença desta metodologia para as outras, conforme Lukka (2003) e Oyegoke (2011).

Conforme Van Aken (2014), compreender um problema é apenas metade do caminho para resolvê-lo. O desenvolvimento de testes das soluções práticas é importante para que se possa observar as fontes de resistência quando estas ocorrerem, por exemplo. Desta forma, foi desenvolvida a atividade do Grupo Focal com a presença de profissionais com experiência comprovada no mercado nacional no desenvolvimento de atividades BIM para validar os pontos contidos no PNBIM. 
Na visão de Malhotra (2006), o objetivo principal dos grupos focais, é obter uma visão aprofundada ouvindo um grupo de pessoas com experiência comprovada para falar sobre problemas que interessam ao pesquisador. O valor da técnica está nos resultados inesperados que frequentemente se obtém de um grupo de discussão livre. (OLIVEIRA, 2007)

Quando usada para prover uma janela para o encontro de pesquisa e os dados daí resultantes, a flexibilidade pode ser uma ferramenta valiosa de análise em termos do exame crítico da natureza e do impacto das relações de pesquisa. (BARBOUR, 2009)

Como uma forma de método qualitativo, os grupos focais são basicamente entrevistas em grupo, embora não no sentido de alternância das questões do pesquisador e as respostas dos entrevistados. Em vez disso, o resultado será a confiança na interação dos membros do grupo, baseada nos tópicos fornecidos pelo pesquisador que, na maioria das vezes, é também o moderador. (OLIVEIRA, 2007)

\section{A. Estrutura da criação do conhecimento nos grupos focais}

Conforme presentado na Figura 16, a estrutura dos grupos focais é fundamental para que as atividades possam resultar na validação, através de debate e de discussão, da proposta do PNBIM.

Figura 16: Estrutura da criação do conhecimento nos grupos focais.

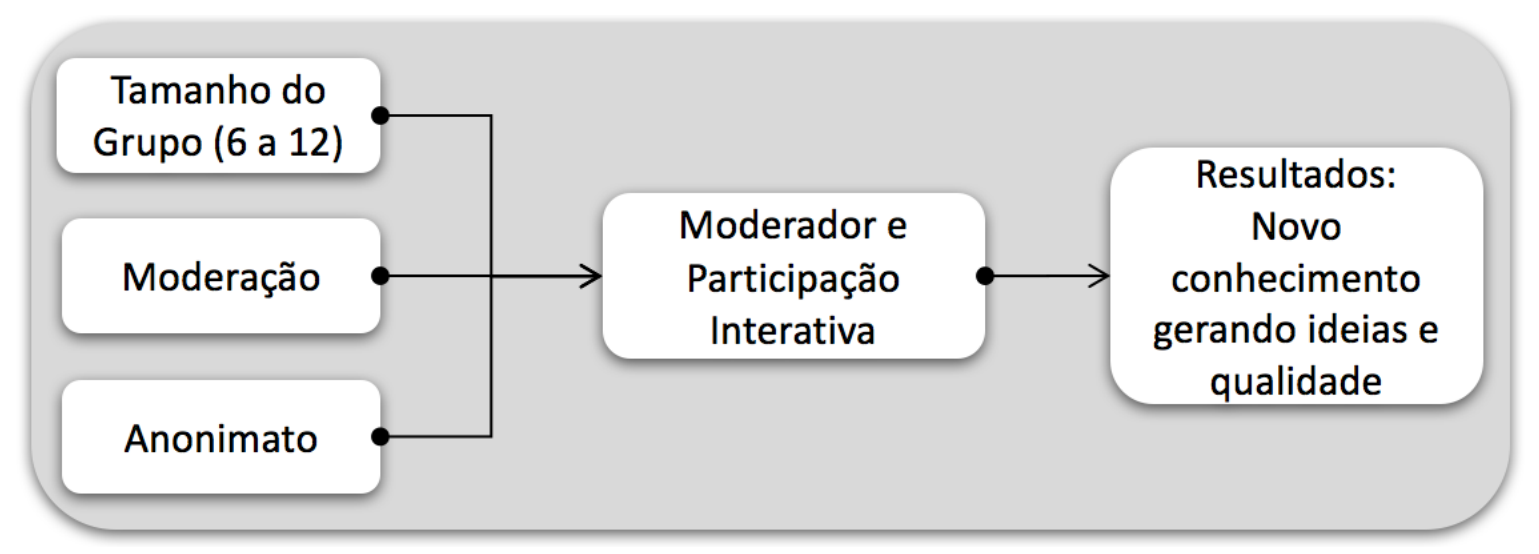

Fonte: Adaptado de Oliveira, 2007 


\section{B. Características dos grupos focais}

Para a possibilidade de coleta de informações com qualidade através das atividades de grupos focais é importante que características, como apresentado na Tabela 1, sejam seguidos pelo responsável do planejamento e execução da atividade.

Tabela 1: Características dos grupos focais

\begin{tabular}{|c|c|c|}
\hline \multicolumn{3}{|c|}{ Características dos Grupos Focais } \\
\hline & Sugerido & Adotado \\
\hline Tamanho do grupo & 8 a 12 pessoas & 8 pessoas \\
\hline Composição do grupo & $\begin{array}{l}\text { Homogênea: entrevistados pré- } \\
\text { selecionados }\end{array}$ & $\begin{array}{l}\text { Homogênea: entrevistados pré- } \\
\text { selecionados }\end{array}$ \\
\hline Contexto físico & Atmosfera informal, descontraída & $\begin{array}{l}\text { A atividade foi desenvolvida em ambiente } \\
\text { onde no mesmo dia havia sido realizado } \\
\text { evento BIM com a presença de diversos } \\
\text { especialistas no tema. }\end{array}$ \\
\hline Duração & 1 a 3 horas & 3 horas \\
\hline Gravação (registro) & Uso de fitas de áudio e vídeo & Vídeo \\
\hline Quantidade de sessões & $\begin{array}{c}\text { Depende de vários fatores, mas se } \\
\text { recomenda a realização de pelo menos } \\
\text { duas sessões. }\end{array}$ & $\begin{array}{l}1 \text { sessão foi realizada por se tratar da } \\
\text { avaliação da proposta deste trabalho }\end{array}$ \\
\hline Moderador & $\begin{array}{c}\text { Habilidades de observação, interpessoais e } \\
\text { de comunicação do moderador. }\end{array}$ & O pesquisador \\
\hline
\end{tabular}

Fonte: Adaptado de Oliveira, 2007

\section{Resumo do planejamento em grupos focais}

O planejamento para elaboração do grupo focal deve contemplar, como mostrado na Tabela 2 , a definição e detalhamento de pontos importantes para que se possa obter a melhor qualidade das informações e dados que se espera com o desenvolvimento da atividade. Entre estes pontos, a definição clara dos objetivos de estudo, identificação do perfil dos possíveis participantes, a infraestrutura (local e material base), as questões a serem feitas e a análise das informações coletadas são itens de extrema importância. 
Tabela 2: Planejamento para desenvolvimento das atividades.

\begin{tabular}{|c|c|}
\hline Etapa & ltens de Verificação \\
\hline \multirow{2}{*}{ Definições iniciais } & Definir claramente os objetivos de estudo \\
\hline & Identificar o público a ser pesquisado \\
\hline \multirow{8}{*}{ Detalhamento do estudo } & Definição do número de sessões \\
\hline & Definição do local, dia e hora. \\
\hline & Infraestrutura necessária \\
\hline & Definição da forma de registro das informações Escolha do moderador e auxiliares \\
\hline & Definição do perfil dos participantes \\
\hline & Definição do número de participantes (por sessão) \\
\hline & Seleção dos participantes \\
\hline & Convite aos participantes \\
\hline \multirow{5}{*}{$\begin{array}{l}\text { Roteiro de questões (por } \\
\text { sessão) }\end{array}$} & Questão Inicial \\
\hline & Questão de Transição \\
\hline & Questões centrais \\
\hline & Questão resumo \\
\hline & Questão final \\
\hline \multirow{3}{*}{ Alternativas de análise } & Listar antecipadamente as possibilidades de análise: \\
\hline & Critérios de classificação das informações, \\
\hline & Comparações que poderão ser feitas, etc. \\
\hline
\end{tabular}

Fonte: Adaptado de Oliveira, 2007

\section{Composição}

Para o desenvolvimento das atividades previstas no decorrer do grupo focal é previsto que, além dos participantes, exista a presença de um moderador, que em muitos casos é o próprio pesquisador, um facilitador e um observador.

\section{E. Integrantes}

- Moderador

Ainda que nem sempre seja possível - ou mesmo desejável - combinar o moderador com o grupo, considerações cuidadosas devem ser feitas sobre o impacto do moderador nos dados gerados, e isso deve ser usado como recurso durante a análise. Algumas equipes de pesquisadores fazem uso estratégico das características pessoais de seus moderadores para gerar dados comparativos (BARBOUR, 2009).

O moderador tem sobre sua responsabilidade a preservação do foco e o correto direcionamento da discussão entre os participantes para que se possa obter a melhor qualidade dos trabalhos propostos. 
Malhotra (2006) acrescenta ainda que, durante a entrevista, o moderador deve: (1) estabelecer relação com o grupo, (2) definir as regras de interação do grupo, (3) fixar objetivos, (4) sondar os entrevistados e provocar intensa discussão nas áreas relevantes e (5) tentar resumir a resposta do grupo para determinar o alcance da concordância (OLIVEIRA, 2007).

- Facilitador

O facilitador é uma pessoa bastante inteirada no foco do assunto que está sendo levado a discussão pelos integrantes do grupo focal tendo sendo familiarizado com as questões que são feitas durante a atividade.

Este pode facilitar a discussão entre os integrantes do grupo baseado em sua experiência no assunto e faz anotações pertinentes.

- Observador

Tem a finalidade de auxiliar o moderador tomando notas que transmitam informações sobre a dinâmica do grupo podendo participar da discussão quando assim for convidado pelo facilitador.

\section{F. Recrutamento}

Os entrevistados devem ser escolhidos da forma que possam fornecer informações uteis a respeito da população de interesse. (OLIVEIRA, 2007)

Uma vez que o grupo será a principal unidade de análise na pesquisa com grupos focais, faz sentido convocá-los para facilitar comparações, ao garantir que os membros do grupo compartilhem pelo menos uma característica importante.

O recrutamento de participantes não é uma ciência exata: pelo contrário, envolve fazer uma série de decisões éticas e pragmáticas. É importante lembrar que os participantes convidados são profissionais ocupados, cujo o tempo de participação na pesquisa faz parte do período de trabalho remunerado de cada um deles e que os mesmos estão se dispondo a participar voluntariamente (BARBOUR, 2009). Desta forma, ser efetivo na organização e no desenvolvimento do trabalho é fundamental. 


\section{G. Ambientes de pesquisa}

É importante, entretanto, considerar o provável impacto que o local escolhido pode causar nos participantes e no foco dos dados que tenderão a ser gerados (BARBOUR, 2009). Para a escolha do ambiente que será realizada a pesquisa pontos importantes devem ser considerados para que se possa obter o máximo de proveito com o desenvolvimento do trabalho. Ambientes silenciosos com pouca interferência externa, que possuam boa iluminação com ventilação adequada e que possibilite aos participantes conforto são algumas características que devem ser consideradas para eleição do local. Caso o ambiente escolhido para a realização da atividade tenha pouca iluminação e que não possua um sistema de ventilação adequado por exemplo, os participantes não se sentirão confortáveis e perderão a concentração com facilidade. Desta forma, a coleta de dados poderá ser prejudicada.

\section{H. Número e tamanho dos grupos}

O tamanho ideal de um grupo é de 08 a 12 pessoas. O número de pessoas que podem prontamente receber igual voz nos procedimentos dependerá não só da habilidade do moderador, mas também no nível de complexidade da discussão desejada (BARBOUR, 2009).

\section{Desenvolvimento de uso de guias e tópicos}

Assim como com todas as ferramentas de pesquisa, é importante considerar a ordem das questões. Qualquer informação de rotina pode ser coletada de uma forma protocolar (BARBOUR, 2009).

\section{J. Questionário}

O questionário geral tem como finalidade obter informações que possam dar subsídios na obtenção de características do grupo referente aos temas centrais antes do início da atividade (Tabela 3 ). 
Tabela 3: Questões gerais.

\begin{tabular}{|c|c|c|}
\hline \multicolumn{3}{|c|}{ Questões Geais } \\
\hline & Questão & Objetivo \\
\hline Questão 1 & Nome completo & \multirow{4}{*}{ Informações gerais } \\
\hline Questão 2 & Organização & \\
\hline Questão 3 & Profissão & \\
\hline Questão 4 & Idade & \\
\hline Questão 5 & Setor & \multirow{2}{*}{ Área de atuação na cadeia da construção } \\
\hline Questão 6 & Área de atuação & \\
\hline Questão 7 & Anos de experiência em BIM & \multirow{2}{*}{ Experiência em BIM } \\
\hline Questão 8 & Nível de conhecimento em gestão de informações BIM & \\
\hline Questão 9 & Você conhece a norma Britânica PAS1192-2:2013? & \multirow{2}{*}{ Conhecimento em normas que são a base da dissertação } \\
\hline Questão 10 & Você conhece a norma ISO19650? & \\
\hline Questão 11 & Qual é seu entendimento por Modelo Federado? & Experiência em BIM \\
\hline Questão 12 & $\begin{array}{l}\text { Na sua opinião o que deve ser feito para impulsionar a } \\
\text { utilização do BIM no Brasil? Selecione as três ações mais } \\
\text { importantes pra você. }\end{array}$ & Necessidades de mercado para disseminação do BIM \\
\hline
\end{tabular}

Fonte: Autor

Os resultados obtidos são disponibilizados mais rapidamente, muitos deles podem ser abstraídos durante a própria discussão entre os membros do grupo.

Desta forma, um grupo de especialistas BIM de diversas áreas da cadeia da construção formarão o grupo focal e serão incentivados pelo moderador da atividade a discutirem sobre pontos relevantes à gestão das informações e dados BIM durante as fases de contratação, produção e entrega de serviços e de produtos. As informações levantadas durante o decorrer da atividade serão coletadas, compiladas e utilizados no desenvolvimento da dissertação.

\section{RESULTADOS}

Este trabalho é focado no estudo e verificação do conteúdo das duas partes da norma ISO 19650 e sua comparação às práticas atuais desenvolvidas pelos prestadores de serviços BIM na cadeia da construção civil brasileira com o intuito de validar o conteúdo proposto no Protocolo Nacional BIM.

A pesquisa foi iniciada com o foco no levantamento das atividades BIM internacionais baseando-se nas experiências de contratação de atividades de construção civil no Reino Unido, no conteúdo das duas partes da norma ISO 19650 e nas práticas atuais no mercado nacional. Este levantamento foi desenvolvido através do estudo de guias e orientativos sobre o tema, dos instrumentos de contratação disponíveis no mercado e da atividade desenvolvida com a contribuição de especialistas BIM com experiência comprovada nas atividades de fornecimento de 
ferramentas BIM, no desenvolvimento de objetos que são utilizados em modelos BIM, no desenvolvimento e gerenciamento de projetos (design) e da obra.

Nas seções seguintes são apresentados os levantamentos e comparativos desenvolvidos para que o desenvolvimento do PNBIM pudesse ser realizado. Este documento poderá ser utilizado por integrantes da cadeia da construção tais como: contratantes, empresas gerenciadoras de projeto e de obra, projetistas, construtoras, gestores de O\&M e fornecedores de ferramentas BIM do mercado

\subsection{RESULTADOS DA ANÁLISE DE LICITAÇÕES PÚBLICAS NACIONAIS COM DEMANDA BIM}

Para o desenvolvimento deste trabalho foram estudadas 20 licitações públicas em diversas áreas entre os anos de 2011 a 2016, Apêndice - B. As licitações foram selecionadas para serem incluídas neste trabalho pois destinaram-se à contratação de prestação de serviços relacionados ao desenvolvimento de projetos (design) na cadeia da construção civil nacional.

Durante o ano de 2017 houve publicações de licitações públicas para contratação de serviços BIM que não abrangeram a produção de projetos (design). Desta forma, estas não foram analisadas e inseridas neste trabalho.

Após a análise das licitações selecionadas, alguns fatos importantes puderam ser observados e são apresentados nos gráficos 3 e 4 . Entre eles pode-se salientar três pontos como mais relevantes: 1) o número crescente de solicitações; 2) área de atuação do contratante; e 3) motivo da contratação.

Outra observação necessária a ser feita é a não homogeneidade do tipo de exigência de critérios para a produção, gerenciamento e entrega dos produtos BIM entre todas as licitações e, principalmente, entre as que têm como objetivo a contratação do mesmo produto fim, uma edificação por exemplo.

No Gráfico 3 pode-se observar que houve aumento significativo no número de solicitações do uso de BIM em licitações públicas entre os anos estudados: em 2011 apenas houve 1 solicitação. Em contraste, 5 foram as licitações com a solicitação de prestação de serviços com a utilização do BIM no ano de 2016. 
Pode-se observar, no Gráfico 4, que diversos segmentos da construção civil fizeram contratações solicitando o BIM: óleo e gás, transportes, segurança nacional, financeiro, pesquisa e saúde e secretarias de estado.

Gráfico 3: Número de licitações públicas com uso de BIM por ano

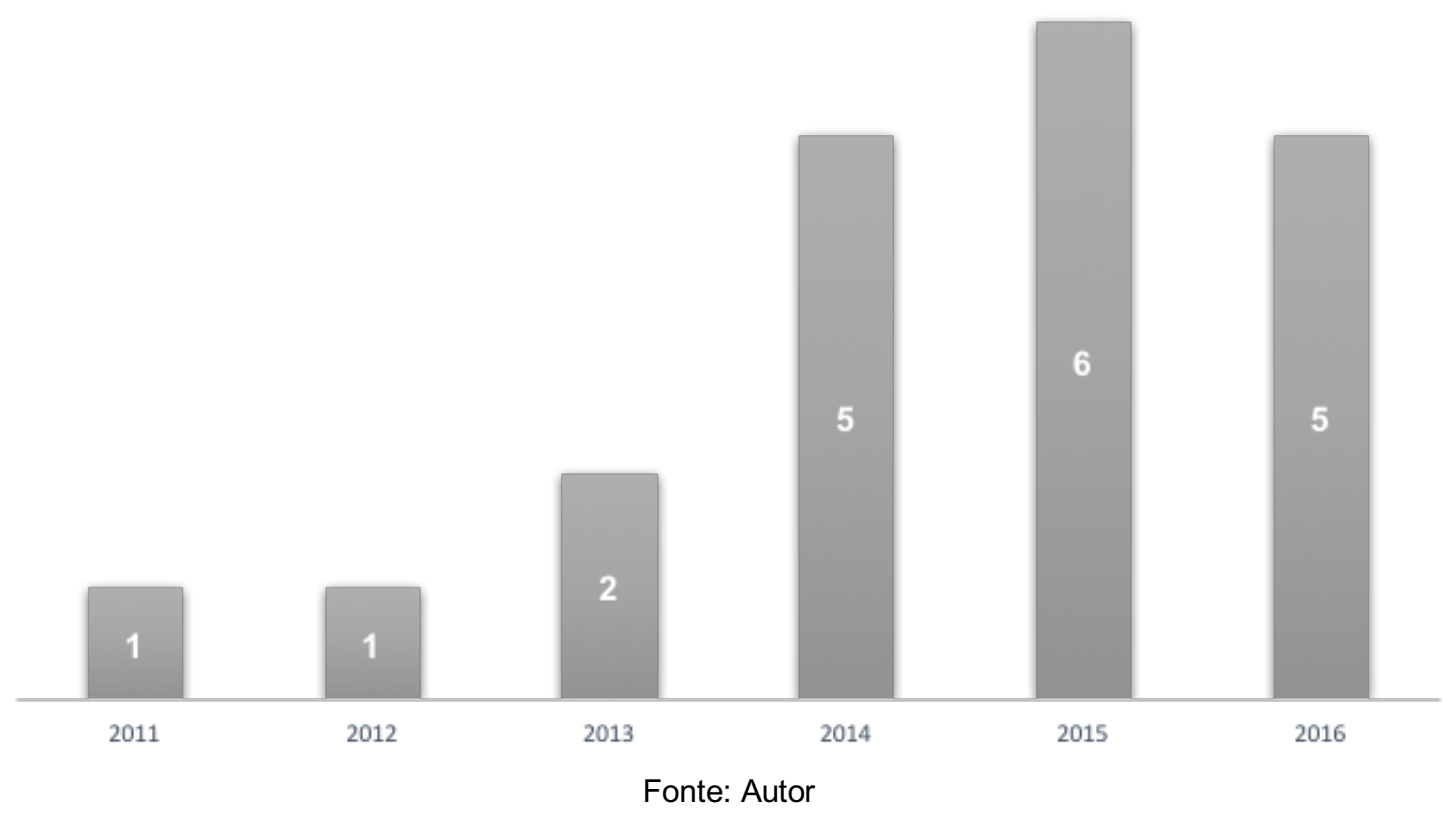

Gráfico 4: Número de licitações públicas com uso de BIM por área.

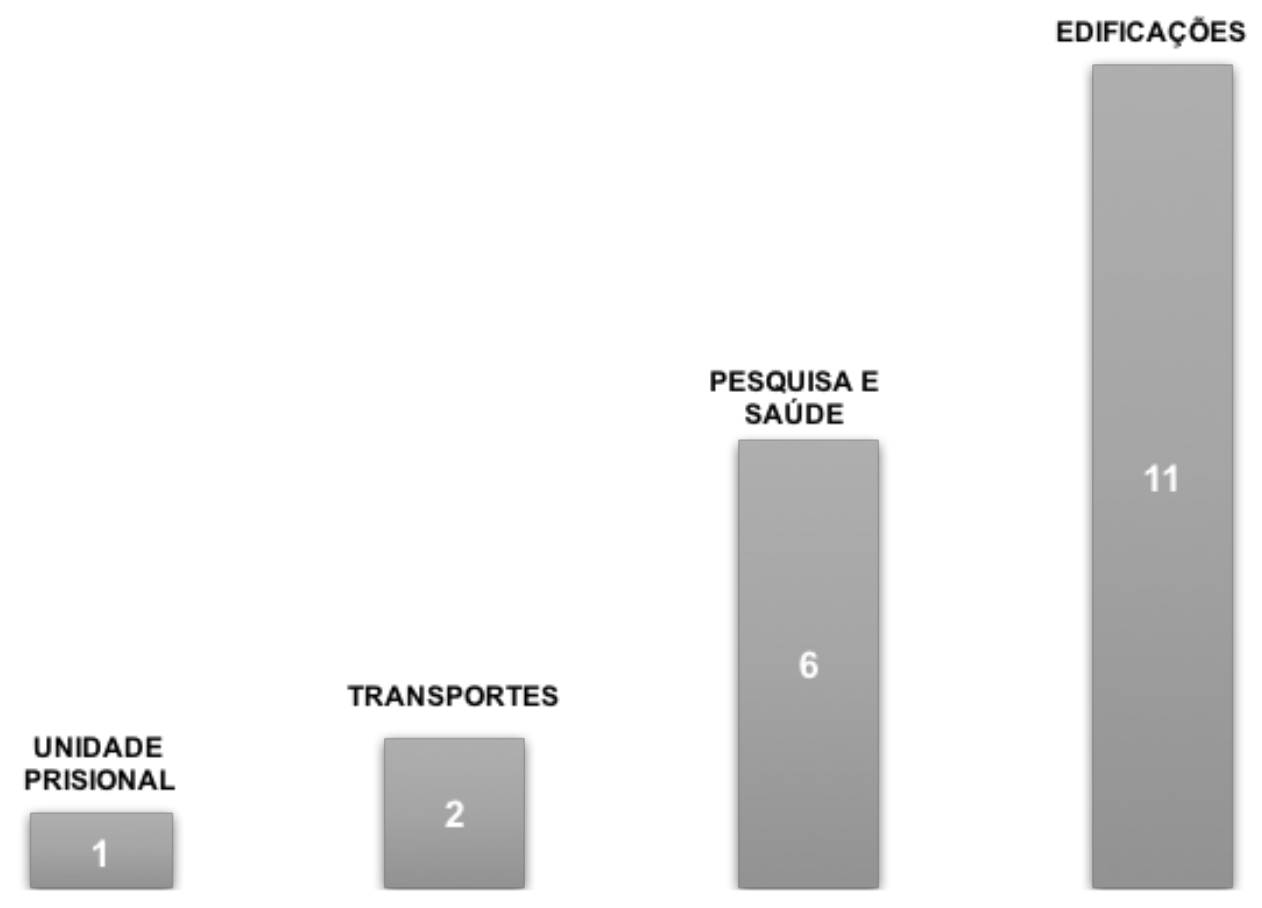

Fonte: Autor

A diversidade do foco dos serviços contratados em BIM pelos contratantes públicos é um fato que deve ser levantado. Pôde ser observado, no estudo feito, que 
a grande maioria, neste caso 11 , foram as solicitações para desenvolvimento de trabalhos BIM referentes a edificações contra 6 na área de pesquisa e saúde, 2 na área de transportes e 1 em unidade prisional.

Desta forma, observa-se que com o aumento da cobrança e contratação do BIM para desenvolvimento das atividades relacionadas à cadeia da contração civil é necessário que exista uma padronização jurídica nos quesitos a serem contratados.

A partir do estudo das licitações levantadas foi possível desenvolver um mapeamento dos requisitos BIM exigidos pelos clientes nas diversas áreas de atividade. Como resultante, foi desenvolvido um comparativo entre os requisitos como pode ser observado no Quadro 3.

Quadro 3: Requisitos solicitados em licitações BIM no Brasil.

\begin{tabular}{|c|c|c|c|c|c|c|c|c|c|c|c|c|c|c|}
\hline REQUISITOS & $\begin{array}{l}\bar{\sigma} \\
\text { ㄱ. } \\
\text { 엉 } \\
\frac{\delta}{4}\end{array}$ & $\begin{array}{l}\text { ণ } \\
\text { N̦ } \\
\text { 옹 } \\
\text { 은 }\end{array}$ & $\begin{array}{l}\text { O } \\
\text { 글 } \\
\text { 은 } \\
\text { 은 }\end{array}$ & $\begin{array}{l}\text { ¿ } \\
\text { N̦ } \\
\text { 몬 } \\
\text { 은 }\end{array}$ & 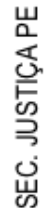 & $\begin{array}{l}\text { ㅇ } \\
\text { के } \\
\text { 폰 } \\
\text { 을 }\end{array}$ & 㟧 & 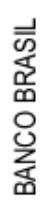 & ஜू & $\frac{u}{\underline{\underline{\alpha}}}$ & 崌 & 店 & $\begin{array}{l}\text { 옹 } \\
\text { 岳 } \\
\text { 䍃 } \\
\text { 妾 }\end{array}$ & 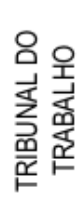 \\
\hline Escopo & $x$ & $x$ & $x$ & $x$ & $x$ & $\mathrm{x}$ & $x$ & $\mathrm{x}$ & $\mathrm{X}$ & $\mathrm{X}$ & $x$ & $x$ & $x$ & $x$ \\
\hline $\begin{array}{l}\text { Caracteristicas das ferramentas } \\
\text { BIM a serem utilizadas e versão } \\
\text { de softwares }\end{array}$ & $x$ & $x$ & $X$ & $x$ & $\mathrm{x}$ & & $X$ & $\mathrm{X}$ & $\mathrm{X}$ & $\mathrm{X}$ & $x$ & $\mathrm{x}$ & $\mathrm{x}$ & \\
\hline $\begin{array}{l}\text { Nível de detalhamento dos } \\
\text { projetos em BIM }\end{array}$ & $x$ & & & & & & $X$ & & & $x$ & $X$ & $x$ & & \\
\hline $\begin{array}{l}\text { GED Gerenciamento Eletrônico } \\
\text { de Documentos }\end{array}$ & & $x$ & $X$ & $x$ & & & & $\mathrm{x}$ & & & & & & \\
\hline Caderno BIM & & $x$ & $x$ & $x$ & & & & & & & & & & \\
\hline Plano de Execução BIM & $\mathrm{X}$ & $x$ & $x$ & $x$ & & & & $x$ & & $\mathrm{X}$ & $x$ & $x$ & & \\
\hline $\begin{array}{l}\text { Critérios de pontuação - } \\
\text { Experiência da empresa e } \\
\text { profissional }\end{array}$ & $x$ & $X$ & $X$ & $X$ & $x$ & $x$ & $X$ & $x$ & $x$ & $x$ & $X$ & $x$ & $x$ & \\
\hline Plano digital de trabalho & & & & & & & & & & & & & & \\
\hline Formatos de trocas & $x$ & $x$ & $x$ & $x$ & & & $x$ & $x$ & $x$ & $x$ & $x$ & $x$ & $x$ & \\
\hline $\begin{array}{l}\text { Sistema de processo e } \\
\text { gerenciamento de dados. } \\
\text { (FUNÇĀO CONTROLE DE } \\
\text { DADOS) }\end{array}$ & $X$ & $X$ & $X$ & $X$ & & & $x$ & & & & & & & \\
\hline Codificação de documentos & & & & & & & & $x$ & & & & & $x$ & \\
\hline
\end{tabular}




\subsection{COMPARATIVO ENTRE A ISO19650 E A PRÁTICA NO MERCADO NACIONAL}

Para o desenvolvimento desta parte do trabalho é apresentado o comparativo entre os itens solicitados na ISO19560 e a prática adotada pelos integrantes da cadeia da construção civil brasileira no que se refere a produção e gerenciamento de trabalhos BIM (Tabelas 6, 7, 8, 9, 10 e 11). Documentos como normas, guias e licitações foram utilizados para o desenvolvimento desta parte do trabalho tais como:

- ABNT NBR 15965 - Sistema de classificação da informação da construção. A norma está dividida em 7 partes e tem como objetivo disponibilizar sistema de classificação baseado no OmniClass mas respeitando as características no mercado da construção brasileira.

- Guia AsBEA - Boas Práticas em BIM, fascículo 1 (2013) onde são abordados temas básicos para a implantação e utilização do BIM em empresas projetistas da cadeia da construção civil. Em seu conteúdo encontra-se sugestão de estruturação interna das empresas, levanta as necessidades de treinamentos específicos, da atualização da infraestrutura, fluxo de trabalho, desenvolvimento de banco de dados e a necessidade de reformulação dos contratos em BIM.

- Caderno de Apresentação de Projetos em BIM do Governo de Santa Catarina (2014) que tem como objetivo dar diretrizes que devem ser utilizadas pelos prestadores de serviços ao Estado com a utilização da metodologia BIM. Este documento também deve ser utilizado como anexo em editais para contratação de serviços pelo Estado e que devem ser desenvolvidos com a metodologia.

- Guia AsBEA - Boas Práticas em BIM, fascículo 2 (2015), onde são demonstrados os novos métodos de trabalho e novas posturas de relacionamento entre todos os envolvidos na produção de projetos são necessários para aqueles que utilizam a metodologia BIM para produção de produtos da cadeia da construção civil, principalmente projetos técnicos. 
- Caderno Técnico AsBEA-RS - Migração BIM, volume 2 (2015), cuja finalidade é de não ser um manual de aplicação passo a passo do BIM, mas de relatar experiências de usuários que, na prática, desenvolveram suas próprias metodologias de trabalho com a nova tecnologia. Em seu conteúdo encontra-se informação sobre a adoção do BIM entre os anos de 2009 a 2012 e intenção de sua utilização no espaço de tempo de cinco anos nas empresas no setor da construção civil nacional.

- Coletânea Implementação do BIM para construtoras e Incorporadoras (2016) que é formada por 5 volumes tendo como objetivo esclarecer, influenciar e facilitar a adesão ao BIM. A coletânea está dividida em 5 volumes: volume 1 - Fundamentos BIM; volume 2 - Implementação BIM; volume 3 - colaboração e Interação BIM; volume 4 - Fluxos de Trabalho BIM; volume 5 - Formas de Contratação.

- Guias BIM ABDI-MDIC (2017) que é formado por 6 volumes e tem como objetivo central consolidar e disponibilizar informações de boas práticas sobre o processo e a contratação de projetos BIM para profissionais dos setores público e privado envolvidos no ciclo de vida de edificações. Os volumes estão divididos da seguinte forma: guia 1 - Processo de projeto BIM; guia 2 - classificação da informação no BIM; guia 3 - BIM na quantificação, orçamentação; guia 4 - contratação e elaboração de projetos BIM na arquitetura e engenharia; guia 5 - avaliação de desempenho energético em projetos BIM; e guia 6 - a implantação de processos BIM. Dois importantes materiais fazem parte deste trabalho desenvolvido em parceria da ABDI e MDIC, o Anexo - Plano de Execução BIM e Fluxograma de processo de projeto BIM.

Por terem sido identificados como os documentos que melhor descrevem as atividades BIM necessárias para o cumprimento do escopo a ser contratado, duas das licitações estudadas foram eleitas para servir de base a esta fase comparativa. Essas licitações tiveram como objetivos:

- Licitação I: contratação para elaboração de estudo preliminar, anteprojeto e projeto executivo de arquitetura e engenharia da nova sede do centro de pesquisa René Rachou no polo tecnológico de Belo Horizonte - FIOCRUZ MINAS; e 
- Licitação II: contratação de gerenciamento de empreendimento (fiscalização dos projetos de arquitetura e engenharias, apoio à licitação, planejamento e fiscalização das obras e acompanhamento da operação assistida para a implantação da nova sede do centro de pesquisa Belo Horizonte - FIOCRUZ MINAS.

Importante ressaltar que a fluxo de contratação para a prestação de serviços seguiu conforme a nomenclatura utilizada neste documento. Isto é, primeiro foram contratados os serviços de desenvolvimento de projetos e, em seguida, ocorreu a contratação dos serviços de gerenciamento das atividades de projeto.

O último documento base utilizado no comparativo é o Guia do Conhecimento em Gerenciamento de Projetos - PMBOK do Project Management Institute - PMI. Este Guia faz parte deste estudo pela solicitação encontrada em licitações que equipes de gerenciamento sejam formadas por profissionais certificados em gerenciamento de projetos PMP - PMI. Este Guia fornece diretrizes para o gerenciamento de projetos descrevendo o ciclo de vida do gerenciamento e seus respectivos processos. Alguns dos itens encontrados nesse Guia são: 1) Definição de um projeto; 2) Definição de gerenciamento de projetos; 3) Relacionamento entre gerenciamento de projetos, gerenciamento de operações e estratégia organizacional; 4) Papel do gerente de projetos; e 5) Conhecimento em gerenciamento de projetos.

Para melhor entendimento os itens comparativos foram separados, obedecendo as fases propostas pela ISO19650: 1) Termo de Referência - Start of delivery phase; 2) Licitação ou carta convite - Invitation to tender; 3) Proposta - Tender response; 4) Mobilização - Mobilization; 5) Produção Colaborativa - Collaborative production of information; e 6) Entrega - Information model delivery. 


\section{TERMO DE REFERÊNCIA - START OF DELIVERY PHASE}

Para a ISO 19650 este documento deve esclarecer as regras, responsabilidades e as atividades essenciais a todos os envolvidos para que exista um efetivo gerenciamento da informação, foco desta norma. As regras presentes neste documento devem conter especificações técnicas, cronograma macro das atividades e obrigações gerais. Tais regras referentes ao gerenciamento das informações e dados não devem focar nas responsabilidades do desenvolvimento de projeto (design) e sim na gestão, dando suporte aos gerentes de projeto e à equipe de projeto (design) e de obra, por exemplo.

No Brasil, conforme descrito pelo Tribunal de Contas do Estado de Minas Gerias (2017), o Termo de Referência (TR) é um instrumento obrigatório para toda contratação pública, sendo desenvolvido a partir de estudos técnicos contendo todos os orientativos que caracterizam o objeto, bem como as condições da contratação.

Na Tabela é possível verificar o comparativo desenvolvido entre os requisitos indicados na ISO 19650 na etapa inicial do CAPEX referentes ao desenvolvimento do Termo de Referência e as informações constantes nos documentos que serviram de base para o estudo. 
Tabela 4: Comparativo entre a ISO e a prática no Brasil referente ao Termo de Referência.

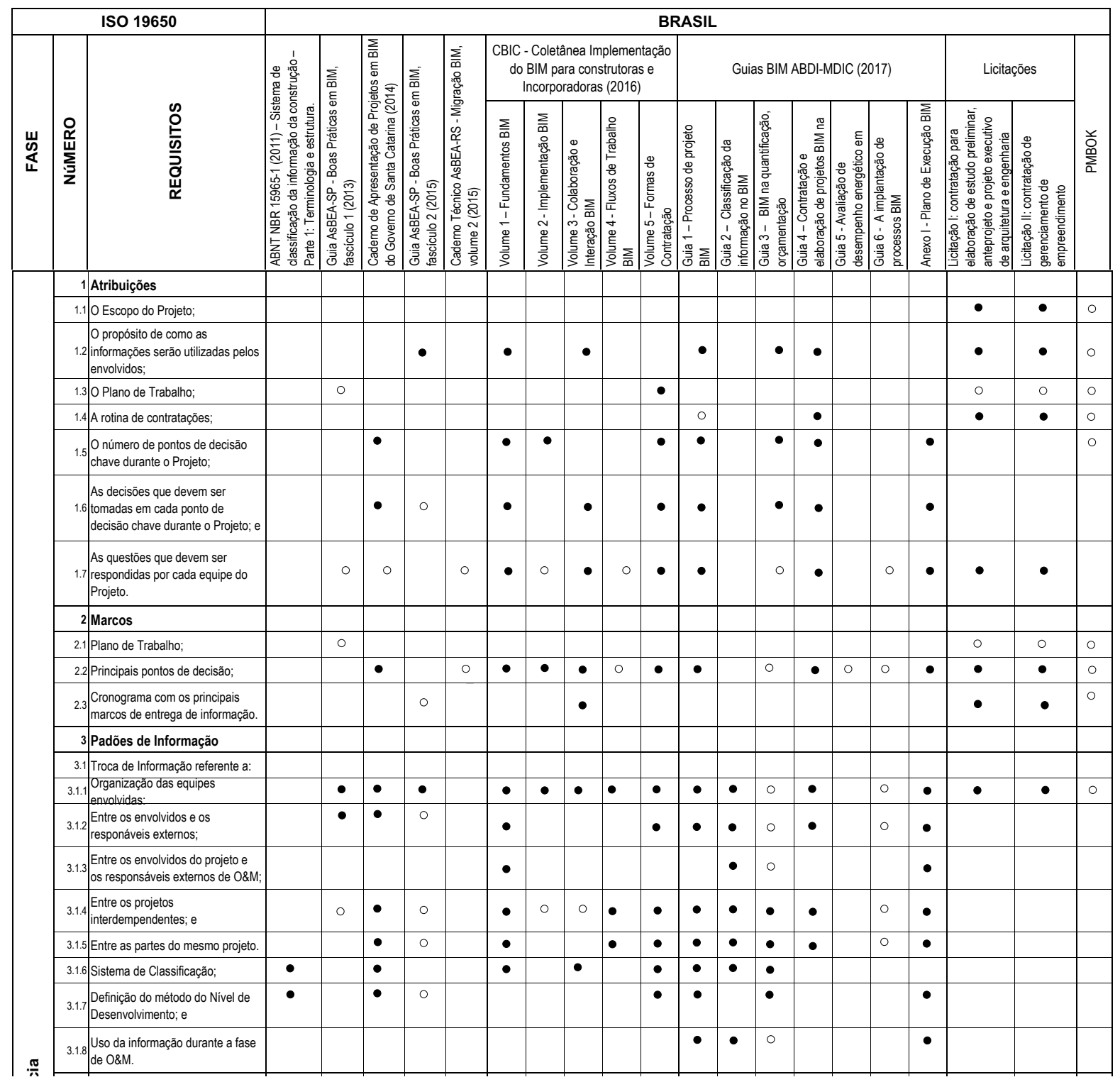


Cont. Tabela 04: Comparativo entre a ISO e a prática no Brasil referente ao Termo de Referência.

\begin{tabular}{|c|c|c|c|c|c|c|c|c|c|c|c|c|c|c|c|c|c|c|c|c|c|c|}
\hline \multicolumn{3}{|c|}{$\begin{array}{r}\text { ISO } 19650 \\
\end{array}$} & \multicolumn{20}{|c|}{ BRASIL } \\
\hline \multirow{28}{*}{ 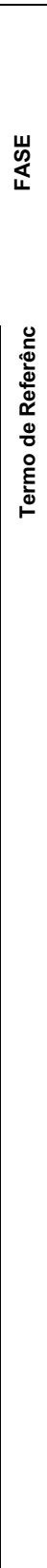 } & \multirow[b]{2}{*}{$\begin{array}{l}\text { O } \\
\stackrel{x}{W} \\
\sum_{3} \\
\mathbf{z}\end{array}$} & \multirow[b]{2}{*}{ 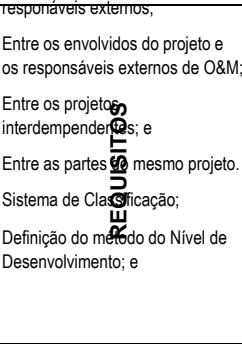 } & \multirow{2}{*}{ 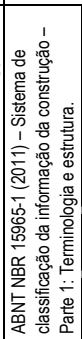 } & \multirow[b]{2}{*}{ 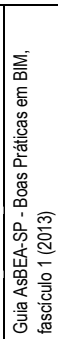 } & \multirow{2}{*}{ 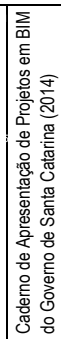 } & \multirow[b]{2}{*}{ 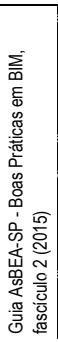 } & \multirow{2}{*}{ 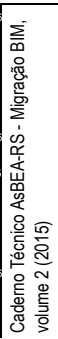 } & \multicolumn{5}{|c|}{$\begin{array}{l}\text { CBIC - Coletânea Implementação } \\
\text { do BIM para construtoras e } \\
\text { Incorporadoras (2016) }\end{array}$} & \multicolumn{7}{|c|}{ Guias BIM ABDI-MDIC (2017) } & \multicolumn{2}{|c|}{ Licitações } & \multirow[b]{2}{*}{ 产 } \\
\hline & & & & & & & & 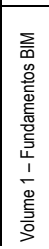 & 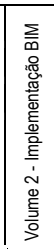 & 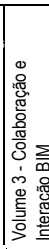 & 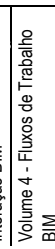 & 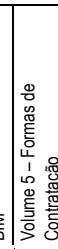 & 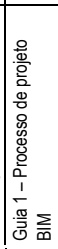 & 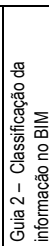 & 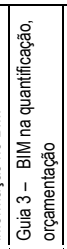 & 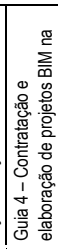 & 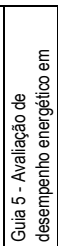 & 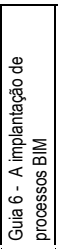 & 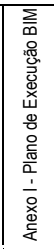 & 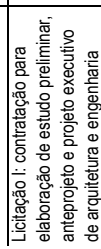 & 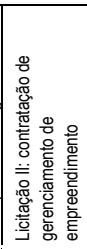 & \\
\hline & & $\begin{array}{l}\text { Método e procedimentos para } \\
\text { produção de informações }\end{array}$ & & & & & & & & & & & & & & & & & & & & \\
\hline & 4.1 & $\begin{array}{l}\text { A caputura de informações de } \\
\text { ativos existentes; }\end{array}$ & & & & & & 0 & & & & & & & & $\bullet$ & $\bullet$ & & 0 & & & \\
\hline & 4.2 & $\begin{array}{l}\text { A elaboração, revisão ou } \\
\text { aprovação de novas informações; }\end{array}$ & & $\circ$ & $\circ$ & & $\circ$ & $\bullet$ & & $\circ$ & $\circ$ & & $\circ$ & $\bullet$ & $\circ$ & $\bullet$ & $\bullet$ & 0 & $\bullet$ & $\circ$ & o & \\
\hline & 4.3 & $\begin{array}{l}\text { A segurança ou distribuição das } \\
\text { informaçoses; }\end{array}$ & & & & & & & & $\bullet$ & & & & o & & & & & 0 & o & $\circ$ & \\
\hline & 4.4 & $\begin{array}{l}\text { A entrega das informações das } \\
\text { referentes equipes. }\end{array}$ & & & & & & $\bullet$ & & & & & & $\bullet$ & & $\bullet$ & $\bullet$ & & $\circ$ & $\circ$ & o & \\
\hline & & \begin{tabular}{|l} 
Informações de referência e \\
recursos compartilhados
\end{tabular} & & & & & & & & & & & & & & & & & & & & \\
\hline & 5.1 & $\begin{array}{l}\text { Informações dos ativos existentes } \\
\text { com base em: }\end{array}$ & & & & & & & & & & & & & & & & & & & & \\
\hline & 5.1 .1 & Entre as equipes internas; & & & & & & $\bullet$ & & & & $\bullet$ & & $\bullet$ & $\bullet$ & $\bullet$ & $\circ$ & & $\bullet$ & & & \\
\hline & 5.1 .2 & Dos demais proprietários de ativos; & & & & & & $\bullet$ & & & & $\bullet$ & & $\bullet$ & $\bullet$ & $\bullet$ & 0 & & $\bullet$ & & & \\
\hline & 5.1 .3 & $\begin{array}{l}\text { Sob licença de provedores } \\
\text { externos; e }\end{array}$ & & & & & & $\bullet$ & & & & $\bullet$ & $\bullet$ & $\bullet$ & & $\bullet$ & & & & & & \\
\hline & 5.1.4 & $\begin{array}{l}\text { Entre bibliotecas públicas e } \\
\text { demais fontes. }\end{array}$ & & & & & & & & & & & $\bullet$ & $\bullet$ & $\bullet$ & & & & & & & \\
\hline & 5.2 & Recursos compartilhados: & & & & & & & & & & & & & & & & & & & & \\
\hline & 5.2 .1 & $\begin{array}{l}\text { Templates do processo ex.: Plano } \\
\text { de Execução BIM e o Plano } \\
\text { Mestre de entrega de informações; }\end{array}$ & & & & & & & & & & & & & & $\bullet$ & & & $\bullet$ & $\circ$ & o & \\
\hline & 5.2 .2 & $\begin{array}{l}\text { Templates de entregáveis tais } \\
\text { como: } 2 D \text {, modelos 3D, relatórios, } \\
\text { etc.; }\end{array}$ & & - & & & & & & & & & - & & 0 & & & & & 0 & $\circ$ & \\
\hline & 5.2 .3 & Estilos gráficos de projeto; & & $\bullet$ & $\bullet$ & & & & & & & & & & & & & & & o & o & \\
\hline & 5.2 .4 & Biblioteca de objetos. & & & & & & $\bullet$ & & & & & $\bullet$ & & & & & & & $\circ$ & & \\
\hline & & $\begin{array}{l}\text { Ambiente Comum de Dados } \\
\text { (CDE) }\end{array}$ & & & & & & & & & & & & & & & & & & & & \\
\hline & 6.1 & $\begin{array}{l}\text { Cada entregável contendo ID } \\
\text { unico baseado em convenção }\end{array}$ & & & $\bullet$ & & & & $\bullet$ & $\bullet$ & & & $\bullet$ & & & & & & & 0 & o & \\
\hline & 6.2 & Padrão de cofdificação & $\bullet$ & $\bullet$ & $\bullet$ & & & & $\bullet$ & $\bullet$ & & & $\bullet$ & $\bullet$ & $\bullet$ & & $\bullet$ & & $\bullet$ & $\bullet$ & $\bullet$ & \\
\hline & 6.3 & Atributos: & & & & & & & & $\bullet$ & & & & & & & & & & & & \\
\hline & 6.4 & Status; & & & & & & & & & & & & & & & & & & & 0 & \\
\hline & 6.5 & Versão e revisão; e & & & & & & & & & & & & & & & & & & & $\circ$ & \\
\hline & 6.6 & Classificação & & & $\bullet$ & & & & & $\bullet$ & & & & $\bullet$ & $\bullet$ & & $\bullet$ & & $\bullet$ & & 0 & \\
\hline & 6.7 & Fluxo de aprovação & & & o & & & & & & & & $\bullet$ & & & & & & $\bullet$ & & 0 & \\
\hline & 6.8 & Histórico de atividades & & & & & & & & $\bullet$ & & & & & & & & & & & 0 & \\
\hline & 6.9 & Permissionamento & & & & & & & & $\bullet$ & & & & & & & & & & & 0 & \\
\hline & & LEGENDA & - & & ISTEN & & & & & & o & MENCI & & & & & & & ISTEN & & & \\
\hline
\end{tabular}

Fonte: Autor

Para esta fase, denominada Termo de Referência, foram analisados os requisitos pertencentes na ISO: 1) Atribuições; 2) Marcos; 3) Padrões de Informação; 4) Métodos e Procedimentos para Produção de Informações; 5) Informações de Referência e Recursos Compartilhados; e 6) Ambiente Comum de Dados. $\mathrm{Na}$ comparação entre o conteúdo destes requisitos e o material utilizado de apoio foi possível identificar similaridades apresentados no conteúdo das licitações públicas levantadas. Estas similaridades são: 
- O propósito de como as informações serão utilizadas pelos envolvidos;

- O número de pontos de decisão chave durante o Projeto;

- As decisões que devem ser tomadas em cada ponto de decisão chave durante o Projeto;

- As questões que devem ser respondidas por cada equipe do Projeto;

- Principais pontos de decisão;

- Nos padrões de informação tais como: 1) Organização das equipes envolvidas; 2) Entre os projetos interdependentes; 3) Entre as partes do mesmo projeto e 4) Sistema de Classificação.

- Padrão de codificação; e

- Classificação.

Entretanto, existem requisitos importantes na ISO 19650 que são pouco ou nada mencionados nos documentos estudados. Tais requisitos são:

- Plano de trabalho;

- Rotina de contratações;

- Captura dos ativos existentes;

- A segurança ou distribuição das informações;

- Recursos compartilhados tais como: 1) Templates dos entregáveis como 2D e 3D; 2) Estilos gráficos do projeto; e 3) Bibliotecas.

\section{LICITAÇÃO OU CARTA CONVITE - INVITATION TO TENDER}

A ISO 19650 indica que este documento orientativo tem como finalidade indicar ao mercado público e privado os requisitos mínimos referentes ao fluxo das atividades de gerenciamento das informações que fazem parte do processo esperado para que o escopo, motivo da contratação, seja atingido.

Conforme Mascena (2017) a licitação ou carta convite são instrumentos orientativos do setor público e privado, respectivamente, pertencentes a um processo administrativo anterior às contratações, indicando como o escopo, motivo da contratação em questão, deve ser atingido. 
Na Tabela é possível verificar o comparativo desenvolvido entre os requisitos indicados na ISO 19650 referentes ao desenvolvimento da Licitação ou Carta Convite e as informações constantes nos documentos que serviram de base para o estudo.

Tabela 5: Comparativo entre a ISO e a prática no Brasil referente a Licitações e Cartas Convites

\begin{tabular}{|c|c|c|c|c|c|c|c|c|c|c|c|c|c|c|c|c|c|c|c|c|c|c|}
\hline \multirow[b]{3}{*}{ 岁 } & \multirow{3}{*}{\multicolumn{2}{|c|}{ 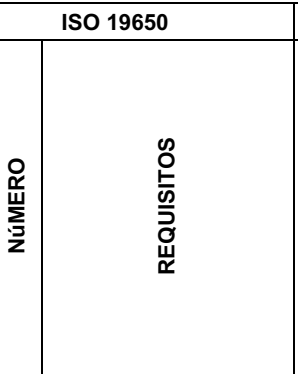 }} & \multicolumn{20}{|c|}{ BRASIL } \\
\hline & & & \multirow[b]{2}{*}{ 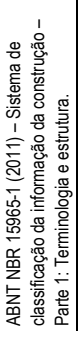 } & \multirow[b]{2}{*}{ 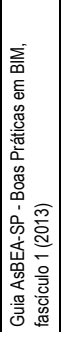 } & \multirow{2}{*}{ 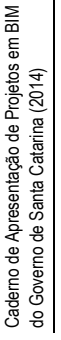 } & \multirow[b]{2}{*}{ 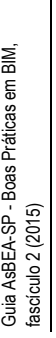 } & \multirow{2}{*}{ 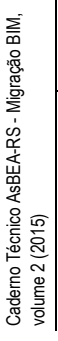 } & \multicolumn{5}{|c|}{$\begin{array}{l}\text { CBIC - Coletânea Implementação } \\
\text { do BIM para construtoras e } \\
\text { Incorporadoras (2016) }\end{array}$} & \multicolumn{7}{|c|}{ Guias BIM ABDI-MDIC (2017) } & \multicolumn{2}{|c|}{ Licitações } & \multirow[b]{2}{*}{\begin{tabular}{|l} 
yo \\
商 \\
d
\end{tabular}} \\
\hline & & & & & & & & 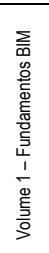 & 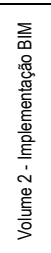 & 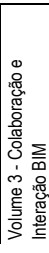 & 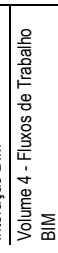 & 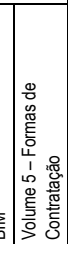 & 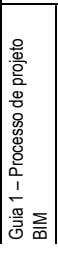 & 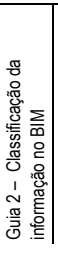 & 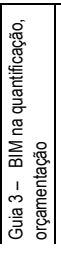 & 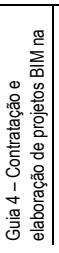 & 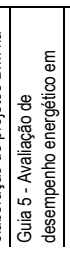 & 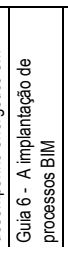 & 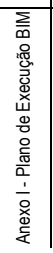 & 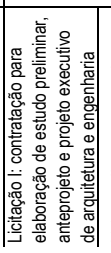 & 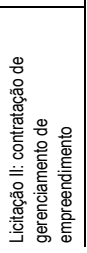 & \\
\hline \multirow{31}{*}{ 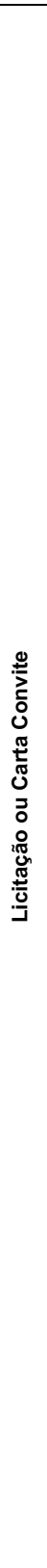 } & 7 & $\begin{array}{l}\text { Requisitos de troca de } \\
\text { informações }\end{array}$ & & & & & & & & & & & & & & & & & & & & \\
\hline & 7.1 & $\begin{array}{l}\text { Definir requisitos de cada } \\
\text { informação: }\end{array}$ & & & $\circ$ & 0 & & $\bullet$ & & 0 & & & 0 & 0 & 0 & & & & $\circ$ & & & \\
\hline & 7.1 .1 & Organizacional; & & & $\circ$ & & & & & $\bullet$ & & $\bullet$ & $\bullet$ & & & $\bullet$ & & & 0 & & & o \\
\hline & 7.1 .2 & Informaçōes de ativos; e & & & & & & $\bullet$ & & & & & $\bullet$ & $\bullet$ & $\bullet$ & $\bullet$ & & & & & & \\
\hline & 7.1 .3 & Informação do projeto. & & & $\bullet$ & - & & $\bullet$ & $\bullet$ & & & $\bullet$ & $\bullet$ & $\bullet$ & $\bullet$ & $\bullet$ & & & & & & $\circ$ \\
\hline & 7.2 & $\begin{array}{l}\text { Estabelecer o Nível de } \\
\text { Desenvolvimento adequado às } \\
\text { necessidades: }\end{array}$ & & & & & & & & & & & & & & & & & & & & \\
\hline & 7.2 .1 & LOD & & & $\bullet$ & $\bullet$ & & $\circ$ & & $\bullet$ & & & $\bullet$ & & $\bullet$ & $\bullet$ & & & $\bullet$ & & & \\
\hline & 7.22 & LOI & & & $\circ$ & $\circ$ & & & & & & & & & & & & & $\bullet$ & & & \\
\hline & 7.3 & $\begin{array}{l}\text { Estabelecer o criterio de } \\
\text { bontuacäo: }\end{array}$ & & & & & & & & & & & & & & & & & & & & \\
\hline & 7.3 .1 & Padrão de informações do projeto; & & & $\bullet$ & $\circ$ & & & & & & $\bullet$ & & & & & & & $\bullet$ & & & \\
\hline & 7.3 .2 & $\begin{array}{l}\text { Procedimentos e métodos de } \\
\text { pontuação; e }\end{array}$ & & & & & & & & & & & & & & & & & & $\bullet$ & $\bullet$ & \\
\hline & 7.3 .3 & $\begin{array}{l}\text { O uso das informações de } \\
\text { referência ou recursos } \\
\text { compartilhados. }\end{array}$ & & & & & & & & & & & & & & & & & $\bullet$ & & & \\
\hline & 7.4 & $\begin{array}{l}\text { Estabelecer cronograma com as } \\
\text { datas marco de entrega das } \\
\text { informações: }\end{array}$ & & & & & & & & & & & & & & & & & & & & \\
\hline & 7.4 .1 & Tempo de revisão e aprovação; e & & & & & & & & & & & & & & & & & & $\bullet$ & $\bullet$ & \\
\hline & 7.4.2 & Processos internos do contratante. & & & & & & & & & & & & & & & & & & & & \\
\hline & 7.5 & $\begin{array}{l}\text { Fornecer material de apoio } \\
\text { necessário aos interessados: }\end{array}$ & & & & & & & & & & & & & & & & & & & & \\
\hline & 7.5 .1 & Informação dos ativos existentes; & & & & & & & & & & & & & & & & & & & & \\
\hline & 7.5 .2 & Recursos compartilhados; & & & & & & & & $\bullet$ & & $\bullet$ & $\bullet$ & & $\bullet$ & & & & & & & \\
\hline & 7.5 .3 & Guias e material de apoio; & & & - & & & & & & - & & - & - & & & & & & - & - & \\
\hline & 7.5 .4 & $\begin{array}{l}\text { Normas e/ou padrões nacionais ou } \\
\text { da indústria; e }\end{array}$ & & - & $\bullet$ & & & & & & $\bullet$ & & - & - & & & & & & $\bullet$ & $\bullet$ & \\
\hline & 7.5 .5 & Exemplos de entregáveis. & & & o & & & & & & & & $\bullet$ & & $\bullet$ & & & & & & & \\
\hline & 8 & $\begin{array}{l}\text { Informações de referência e } \\
\text { recursos compartilhados }\end{array}$ & & & & & & & & & & & & & & & & & & & & \\
\hline & 8.1 & $\begin{array}{l}\text { Informações de referência ou } \\
\text { recursos campartilhados durante o } \\
\text { início do contrato. }\end{array}$ & & & & & & & & & & & & - & & - & & & & - & - & \\
\hline & 8.2 & $\begin{array}{l}\text { Intormaçoes desenvolvidas } \\
\text { durante as fases anteriores a } \\
\text { contratacãn }\end{array}$ & & & & & & & & & & & & - & & - & & & & & & \\
\hline & 8.3 & $\begin{array}{l}\text { Adequação de quais informaçōes } \\
\text { poderão ser utilizadas pelas partes. }\end{array}$ & & & & & & & & & & & & - & $\bullet$ & - & & & & & & \\
\hline & 9 & $\begin{array}{l}\text { Critérios de Avaliação e } \\
\text { atendimento e } \\
\text { esclarecimentos }\end{array}$ & & & & & & & & & & & & & & & & & & & & \\
\hline & 9.1 & $\begin{array}{l}\text { Do conteúdo do Plano de } \\
\text { Execussão BIM. }\end{array}$ & & & & & & & & & & & 0 & & & - & & & & & 0 & \\
\hline & 9.2 & $\begin{array}{l}\text { Competência mínima individual da } \\
\text { equipe técnica de gerenciamento } \\
\text { das informações. }\end{array}$ & & $\circ$ & 0 & & & & 0 & - & $\circ$ & & $\circ$ & & & & & & & - & - & \\
\hline & 9.3 & $\begin{array}{l}\text { Da avaliação da capacidade } \\
\text { técnica da equipe. }\end{array}$ & & & & & & & & & & & & & & & & & & - & - & \\
\hline & 9.4 & Plano de mobilização & & & & & & - & & & & & & & & & & & & 0 & $\circ$ & 0 \\
\hline & 9.5 & Plano de risco & & & & & & - & & & & & & & & & & & & & 0 & $\circ$ \\
\hline & & LEGENDA & $\bullet$ & & STENTE & & & & & & O & MENCIO & & & & & & & TENT & & & \\
\hline
\end{tabular}

Fonte: Autor 
Nesta fase denominada Licitação ou Carta Convite foram analisados os requisitos pertencentes a ISO: 1) Requisitos de troca de Informações; 2) Informações de Referência e Recursos Compartilhados; e 3) Critérios de Avaliação, Atendimento e Esclarecimentos. Na comparação entre o conteúdo destes requisitos e o material utilizado de apoio foi possível identificar:

- O uso das informações de referência ou recursos compartilhados;

- Estabelecer cronograma com as datas macro de entrega das informações;

- Processos internos do contratante;

- Fornecer material de apoio necessário aos interessados;

- Informação de ativos existentes.

\section{PROPOSTA - TENDER RESPONSE}

Para a ISO 19650, a proposta é um documento de resposta desenvolvido pelas partes interessadas que devem responder aos requisitos solicitados pela parte contratante constantes na licitação. Deve fazer parte integrante deste documento, além dos documentos comprobatórios da capacidade técnica individual e da empresa referentes à execução de serviços similares ao que se está contratando, o Plano de Execução BIM. Neste plano devem constar informações referentes aos métodos e procedimentos de produção e gerenciamento das informações e dados, além das características dos equipamentos, softwares e infraestrutura de TI que serão utilizados ao longo da duração do contrato.

Na Tabela é possível verificar o comparativo desenvolvido entre os requisitos indicados na ISO 19650 referentes ao desenvolvimento da Proposta e as informações constantes nos documentos que serviram de base para o estudo. 
Tabela 6: Comparativo entre a ISO e a prática no Brasil referente a Propostas

\begin{tabular}{|c|c|c|c|c|c|c|c|c|c|c|c|c|c|c|c|c|c|c|c|c|c|c|}
\hline \multicolumn{3}{|c|}{ ISO 19650} & \multicolumn{20}{|c|}{ BRASIL } \\
\hline \multirow[b]{2}{*}{$\underset{⿱ 山}{4}$} & \multirow{3}{*}{ 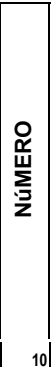 } & \multirow{3}{*}{ 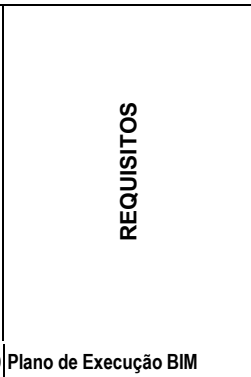 } & \multirow{2}{*}{ 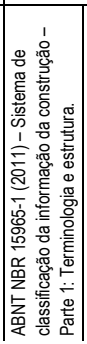 } & \multirow[b]{2}{*}{ 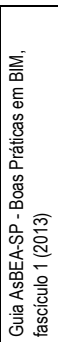 } & \multirow{2}{*}{ 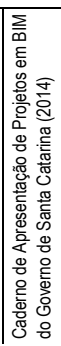 } & \multirow[b]{2}{*}{ 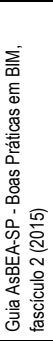 } & \multirow{2}{*}{ 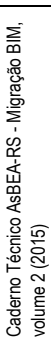 } & \multicolumn{5}{|c|}{$\begin{array}{l}\text { CBIC - Coletânea Implementação } \\
\text { do BIM para construtoras e } \\
\text { Incorporadoras (2016) }\end{array}$} & \multicolumn{7}{|c|}{ Guias BIM ABDI-MDIC (2017) } & \multicolumn{2}{|c|}{ Licitações } & \multirow[b]{2}{*}{$\begin{array}{l}\text { ò } \\
\sum_{0}\end{array}$} \\
\hline & & & & & & & & 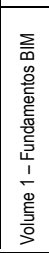 & 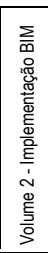 & 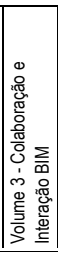 & 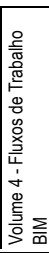 & 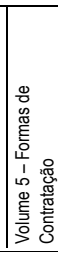 & 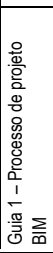 & 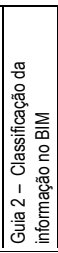 & 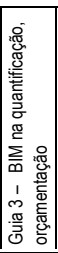 & 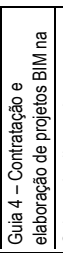 & 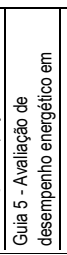 & 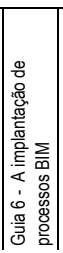 & 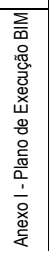 & 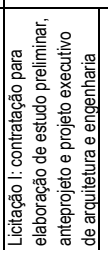 & 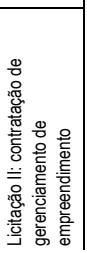 & \\
\hline \multirow{25}{*}{ 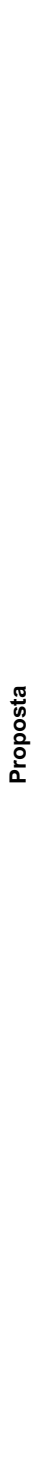 } & & & & & & & & & & & & & & & & & & & & & & \\
\hline & 10.1 & $\begin{array}{l}\text { Nomes e CVs dos colaboradores } \\
\text { que farão parte das equipes de } \\
\text { trabalho }\end{array}$ & & & & & & & & & & & & & & & & & & 0 & 0 & \\
\hline & 10.2 & Troca de informaçōes solicitadas; & & & o & $\circ$ & & 0 & & o & o & & $\bullet$ & $\bullet$ & $\bullet$ & $\bullet$ & & & $\bullet$ & & o & \\
\hline & 10.3 & $\begin{array}{l}\text { Objetivos e metas de colaboração } \\
\text { com o BIM; }\end{array}$ & & & $\circ$ & 0 & & & & & & & $\bullet$ & - & & $\bullet$ & & & $\bullet$ & & $\circ$ & \\
\hline & 10.4 & $\begin{array}{l}\text { Estrutura organizacional e de } \\
\text { relacionamento comercial; }\end{array}$ & & $\bullet$ & & & & & - & & - & & & & & - & & & $\bullet$ & $\circ$ & $\circ$ & \\
\hline & 10.5 & 5 Organograma. & & $\bullet$ & & & & & & & & & & & & o & & & $\bullet$ & o & o & \\
\hline & 10.6 & $\begin{array}{l}\text { Estratégia para o desenvolvimento } \\
\text { dos modelos BIM }\end{array}$ & & $\bullet$ & $\bullet$ & $\bullet$ & & & & & & - & $\bullet$ & - & - & $\bullet$ & & & $\bullet$ & $\circ$ & & \\
\hline & 10.7 & Matriz de responsabilidades; & & $\bullet$ & & & & & & & $\bullet$ & $\circ$ & $\bullet$ & & & $\bullet$ & & & $\bullet$ & $\circ$ & $\circ$ & \\
\hline & 10.8 & Métodos e procedimentos; & & & $\bullet$ & $\bullet$ & $\bullet$ & & $\bullet$ & $\bullet$ & $\bullet$ & & $\bullet$ & $\bullet$ & - & $\bullet$ & - & $\bullet$ & $\bullet$ & $\circ$ & $\circ$ & \\
\hline & 10.9 & $\begin{array}{l}\text { Informações adicionais importantes } \\
\text { ao projetos }\end{array}$ & & & $\bullet$ & & & & & & & & & & & $\bullet$ & & & $\bullet$ & o & o & \\
\hline & 10.10 & $\begin{array}{l}\text { Informações gerais das licenças } \\
\text { incluindo versionamento, hardware } \\
\text { e infraestrutura de TI }\end{array}$ & & - & - & - & - & & & - & & & & & & - & & & - & $\circ$ & $\circ$ & \\
\hline & 11 & Capacidade Técnica & & & & & & & & & & & & & & & & & & & & \\
\hline & 11.1 & Capacidade técnica baseada em: & & & & & & & & & & & & & & & & & & & & \\
\hline & 11.1 .2 & $\begin{array}{l}\text { Gerenciamento de informações } \\
\text { comprovando as experiências } \\
\text { relevantes individuais no } \\
\text { gerenciamento de informações de } \\
\text { acordo com a estratégia de } \\
\text { entregas; }\end{array}$ & & & & & & & - & & & & & & & & & & & 0 & - & \\
\hline & 11.1 .3 & $\begin{array}{l}\text { Experiências individuais com a } \\
\text { responsabilidade em contrato } \\
\text { similares; }\end{array}$ & & & & & & & & - & & & & & & & & & & - & - & \\
\hline & 11.14 & 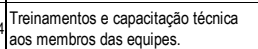 & & - & & $\bullet$ & & & & & & & & & & & & & & - & - & \\
\hline & 11.2 & $\begin{array}{l}\text { Produção de informações baseada } \\
\text { em: }\end{array}$ & & & & & & & & & & & & & & & & & & & & \\
\hline & 11.2 .1 & $\begin{array}{l}\text { Experiência dos colaboradores na } \\
\text { produção de informaçōes de } \\
\text { acordo com os métodos e } \\
\text { procedimentos propostos; }\end{array}$ & & & & & & & & & & & & & & & & & & $\circ$ & - & \\
\hline & 11.2 .2 & $\begin{array}{l}\text { Emperiências individuais com } \\
\text { responsabilidade em contratos } \\
\text { similares; e }\end{array}$ & & & & & & & & - & & & & & & & & & & - & - & \\
\hline & 11.2 .3 & $\begin{array}{l}\text { Treinamentos e capacitação } \\
\text { técnica (experiência) }\end{array}$ & & $\bullet$ & & & & & & & & & & & & & & & & $\bullet$ & - & \\
\hline & 11.3 & TI - Disponibilidade com base em: & & & & & & & & & & & & & & & & & & & & \\
\hline & 11.3.1 & Cronograma proposto; & & & & & & & & $\bullet$ & & & & & & & & & & & & \\
\hline & 11.3 .2 & $\begin{array}{l}\text { Especificações e quantidades } \\
\text { adequados; }\end{array}$ & & - & & & & & & & & & - & & & & & & & & & \\
\hline & 11.3 .3 & $\begin{array}{l}\text { Máxima capacidade de utilização } \\
\text { da equipe de infraestrutura de Tl; e }\end{array}$ & & • & & - & & & & & & & & & & & & & & & & \\
\hline & \begin{tabular}{|l|}
11.3 .4 \\
\end{tabular} & Suporte técnico e legal. & & - & & & & & & & & & & & & & & & & & & \\
\hline
\end{tabular}

\begin{tabular}{|l|l|l|l|l|l|l|}
\hline LEGENDA & $\bullet$ & EXISTENTE & 0 & MENCIONA & & INEXISTENTE \\
\hline
\end{tabular}


Cont. Tabela 7: Comparativo entre a ISO e a prática no Brasil referente a Propostas

\begin{tabular}{|c|c|c|c|c|c|c|c|c|c|c|c|c|c|c|c|c|c|c|c|c|c|c|}
\hline \multirow[b]{3}{*}{ 㟧 } & \multicolumn{2}{|r|}{ ISO 19650} & \multicolumn{20}{|c|}{ BRASIL } \\
\hline & \multirow[b]{2}{*}{ 总 } & \multirow[b]{2}{*}{ 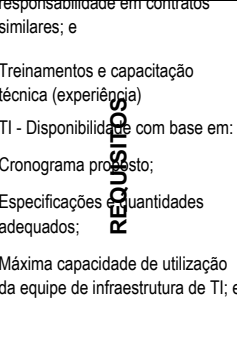 } & \multirow[b]{2}{*}{ 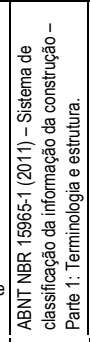 } & \multirow[b]{2}{*}{ 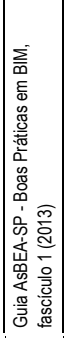 } & \multirow{2}{*}{ 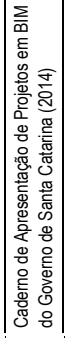 } & \multirow[b]{2}{*}{ 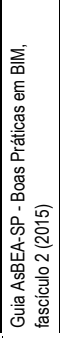 } & \multirow{2}{*}{ 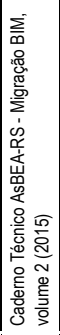 } & \multicolumn{5}{|c|}{\begin{tabular}{|c|} 
CBIC - Coletênea Implementação \\
do BIM para construtoras e \\
Incorporadoras (2016) \\
\end{tabular}} & \multicolumn{7}{|c|}{ Guias BIM ABDI-MDIC (2017) } & \multicolumn{2}{|c|}{ Licitaçôes } & \multirow[b]{2}{*}{$\begin{array}{l}\text { ò } \\
\sum_{a}^{\circ}\end{array}$} \\
\hline & & & & & & & & 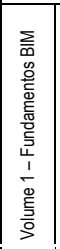 & 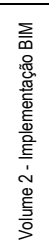 & 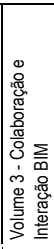 & 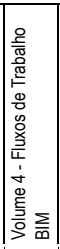 & 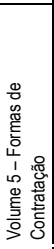 & 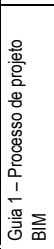 & 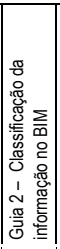 & 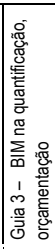 & 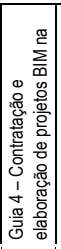 & 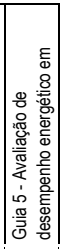 & 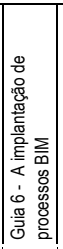 & 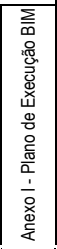 & 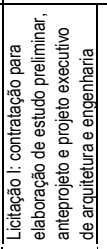 & 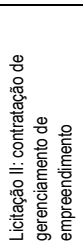 & \\
\hline & 12 & Plano de Mobilização & & & & & & & & & & & & & & & & & & & & \\
\hline & $\left.12.1\right|_{p} ^{n}$ & $\begin{array}{l}\text { Métodos e procedimentos para a } \\
\text { produçāo das informaços }\end{array}$ & & & $\bullet$ & & & & & $\bullet$ & - & - & $\bullet$ & $\bullet$ & $\bullet$ & $\bullet$ & - & $\bullet$ & $\bullet$ & & & \\
\hline & 12.27 & $\begin{array}{l}\text { Testes e troca de informaçōes } \\
\text { entre as equipes }\end{array}$ & & & & & & & & & & & & & & & & & & & & \\
\hline & 12.37 & $\begin{array}{l}\text { Testes de entrega das } \\
\text { informaçōes aos responsáveis }\end{array}$ & & & & & & & & & & & & & & & & & & & & \\
\hline & 12.4 & $\begin{array}{l}\text { Ambiente Comum de Dados } \\
\text { (DDE) - Configuraçăa e testes }\end{array}$ & & & & & & & & & & & & & & & & & & & & \\
\hline & 12.5 , & $\begin{array}{l}\text { Aquisişão e implementação de TI } \\
\text { (software e hardware) }\end{array}$ & & • & & - & - & & - & $\bullet$ & & & & & & & & & & & & \\
\hline & 12.67 & $\begin{array}{l}\text { Todas as demais referências } \\
\text { compartihadas }\end{array}$ & & & & & & & & & & & & & & & & & & & & \\
\hline & $12.7]_{0}^{2}$ & $\begin{array}{l}\text { Plano de capacitaçãa técnica aos } \\
\text { colaboradores envolvidos }\end{array}$ & & $\bullet$ & & - & & & - & & & & & & & & & & & & & $\circ$ \\
\hline & $12.8 \mathrm{C}$ & Contrataçöes & & & & & & & & & & - & & & & & & & & & & $\circ$ \\
\hline & $12.9]_{t}^{4}$ & $\begin{array}{l}\text { Plano de ação para dar suporte a } \\
\text { todos os envolvidos }\end{array}$ & & & & & & & & & & & & & & & & & & & & $\circ$ \\
\hline & $13 \mathrm{~F}$ & Plano de Risco & & & & & & & & & & & & & & & & & & & & \\
\hline & $\left.13.1\right|_{2} ^{2}$ & $\begin{array}{l}\text { Premissas das equipes reterentes } \\
\text { aos requisitos sobre a troca de } \\
\text { informacōes }\end{array}$ & & & & & & & 0 & & & 0 & $\cdot$ & & & & & & & & & \\
\hline & 13.2[ & Datas marco de entregas & & & & & & & o & & & & & & & & & & & & & \\
\hline & 13.3! & $\begin{array}{l}\text { Informaçöes existentes no } \\
\text { protocolo de informaçōes de } \\
\text { nroieto }\end{array}$ & & & & & & & 0 & & & & & & & & & & & & & \\
\hline & $13.4]_{0}^{2}$ & $\begin{array}{l}\text { Estratégia proposta para entrega } \\
\text { das informaçōes }\end{array}$ & & & & & & & 0 & & & & - & & - & & & & & & & \\
\hline & 13.5 & 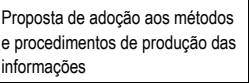 & & & & & & & 0 & & & 0 & - & & & & & & - & & & \\
\hline & 13.6 & $\begin{array}{l}\text { Inclusão, caso necessário, de } \\
\text { emendas as normas do projeto }\end{array}$ & & & & & & & 0 & & & & - & & & & & & & & & \\
\hline & 13.7. $\mathrm{N}$ & Mobilização & & & & & & & 0 & & & & & & & & & & & & & $\circ$ \\
\hline
\end{tabular}

\begin{tabular}{|l|l|l|l|l|l|l|}
\hline LEGENDA & $\bullet$ & EXISTENTE & $\circ$ & MENCIONA & & INEXISTENTE \\
\hline
\end{tabular}

Fonte: Autor

Nesta fase denominada Proposta foram analisados os requisitos pertencentes à ISO: 1) Plano de Execução BIM; 2) Capacidade Técnica; 3) Plano de Mobilização; e 4) Plano de Risco. Na comparação entre o conteúdo destes requisitos e o material utilizado de apoio foi possível identificar que o foco do material disponível no Brasil está na produção e no processo de desenvolvimento dos modelos BIM e possuem pouca ou nenhuma menção na capacidade técnica profissional e corporativa no gerenciamento da produção e entrega das informações geradas no CAPEX.

Os itens menos cobertos pelas publicações estudadas são:

- Gerenciamento de informações comprovando as experiências relevantes individuais no gerenciamento de informações de acordo com a estratégia de entregas; 
- Experiências individuais com a responsabilidade em contrato similares;

- Experiência dos colaboradores na produção de informações de acordo com os métodos e procedimentos propostos;

- Treinamentos e capacitação técnica (experiência);

- Máxima capacidade de utilização da equipe de infraestrutura de TI; e

- Suporte técnico e legal.

Referente à entrega do documento Plano de Execução BIM, é possível observar, através da análise das licitações públicas nacionais, que a solicitação pelos contratantes no mercado da construção civil no Brasil é feita atualmente para que este documento seja desenvolvido pelo contratado na fase posterior a assinatura do contrato.

\section{MOBILIZAÇÃO - MOBILIZATION}

Para a ISO 19650, a fase de mobilização, além da aquisição e instalação dos equipamentos necessários que serão utilizados durante a fase de produção e gerenciamento das informações e dados (seja na fase de design ou da obra), é destinada à realização de testes dos procedimentos pré-estabelecidos, à verificação inicial dos produtos gerados e, principalmente, para a realização de treinamentos para que haja o nivelamento de conhecimento entre todas das partes envolvidas no processo, sejam eles contratantes, contratados e prestadores de serviços.

Outro ponto importante constante nesta fase para a ISO 19650 é a disponibilização, parametrização e realização de testes do Ambiente Comum de Dados (CDE). Para a ISO, o CDE deve ser a única fonte de coleta, gerenciamento e disseminação de cada informação e dado existente nos modelos de informações e dados utilizados no processo de gerenciamento do projeto.

No Brasil, o GED (Gerenciador Eletrônico de Documentos) é o sistema solicitado pelos contratantes aos seus contratados, e tem como função principal ser um repositório de informações e dados desenvolvidos externamente ao longo do contrato e inseridas no sistema ao longo do projeto. 
Na Tabela é possível verificar o comparativo desenvolvido entre os requisitos indicados na ISO 19650 referentes ao desenvolvimento da fase de Mobilização e as informações constantes nos documentos que serviram de base para o estudo.

Tabela 8: Comparativo entre a ISO e a prática no Brasil na Mobilização

\begin{tabular}{|c|c|c|c|c|c|c|c|c|c|c|c|c|c|c|c|c|c|c|c|c|c|c|}
\hline \multirow[b]{3}{*}{ 岁 } & \multicolumn{2}{|r|}{ ISO 19650} & \multicolumn{20}{|c|}{ BRASIL } \\
\hline & \multirow[b]{2}{*}{ 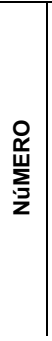 } & \multirow[b]{2}{*}{ 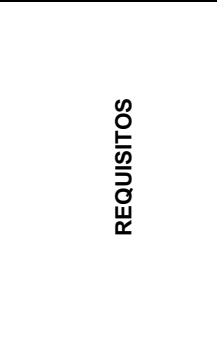 } & \multirow[b]{2}{*}{ 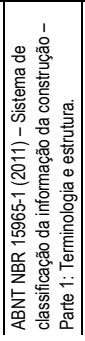 } & \multirow[b]{2}{*}{ 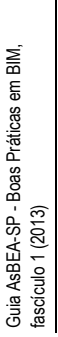 } & \multirow{2}{*}{ 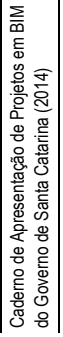 } & \multirow[b]{2}{*}{ 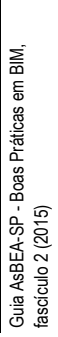 } & \multirow{2}{*}{ 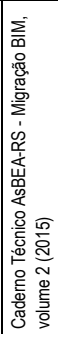 } & \multicolumn{5}{|c|}{$\begin{array}{l}\text { CBIC - Coletânea Implementação } \\
\text { do BIM para construtoras e } \\
\text { Incorporadoras (2016) }\end{array}$} & \multicolumn{7}{|c|}{ Guias BIM ABDI-MDIC (2017) } & \multicolumn{2}{|c|}{ Licitações } & \multirow[b]{2}{*}{$\begin{array}{l}\text { ò } \\
\text { 贾 }\end{array}$} \\
\hline & & & & & & & & 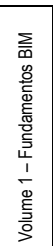 & 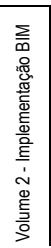 & 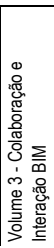 & 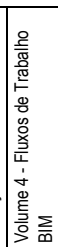 & 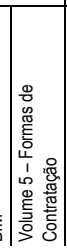 & 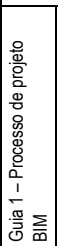 & 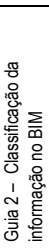 & 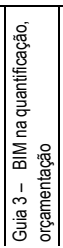 & 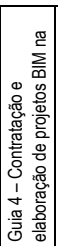 & 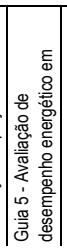 & 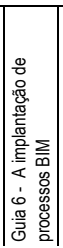 & 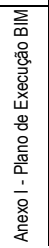 & 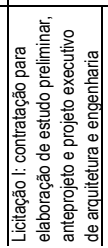 & 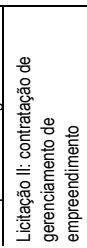 & \\
\hline \multirow{15}{*}{ 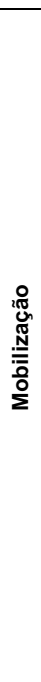 } & \multicolumn{2}{|c|}{\begin{tabular}{l|l}
14 & Recursos \\
\end{tabular}} & & & & & & & & & & & & & & & & & & & & \\
\hline & & & & & & & & $\bullet$ & $\bullet$ & $\bullet$ & & & $\bullet$ & & & & & $\bullet$ & & & & 0 \\
\hline & \multirow{2}{*}{\multicolumn{2}{|c|}{\begin{tabular}{l|l}
15 & Tecnologia da Informação \\
\end{tabular}}} & & & & & & & & & & & & & & & & & & & & \\
\hline & & & & & & & $\bullet$ & & & & & & & & & & & & & & & 0 \\
\hline & \multicolumn{2}{|r|}{\begin{tabular}{l|l}
16 & $\begin{array}{l}\text { Métodos e procedimentos } \\
\text { testados e aprovados }\end{array}$ \\
\end{tabular}} & & & & & & & & & & & & & & & & & & & & \\
\hline & & & & & & & & & & & & & & & & & & & & & & \\
\hline & \multicolumn{2}{|r|}{$\begin{array}{l}\text { Produção colaborativa da } \\
\text { informação }\end{array}$} & & & & & & & & & & & & & & & & & & & & \\
\hline & \multicolumn{2}{|c|}{$17.1 \begin{array}{l}\text { Checar disponibilidade de } \\
\text { referências e recursos } \\
\text { compartilhados }\end{array}$} & & & & & & & & & & & & & & & & & & & & \\
\hline & 17.2 & Gerar informação & & 0 & 0 & 0 & & - & & 0 & 0 & 0 & - & - & - & 0 & 0 & & & & & \\
\hline & 17.3 & Qualidade & & o & 0 & 0 & & 0 & & $\bullet$ & $\bullet$ & 0 & • & 0 & - & - & 0 & & & & & 0 \\
\hline & \multicolumn{2}{|r|}{$17.4 \begin{array}{l}\text { Revisão das informações do } \\
\text { modelo: }\end{array}$} & & & & & & & & & & & & & & & & & & & & \\
\hline & 17.4 .1 & LOD; e & & & $\bullet$ & $\bullet$ & & & & $\bullet$ & & $\bullet$ & $\bullet$ & & $\bullet$ & & & & & & & \\
\hline & \begin{tabular}{|l|}
17.4 .2 \\
\end{tabular} & LOI & & & 0 & 0 & & & & & & & & & & & & & & & & \\
\hline & 17.5 & .5 Pacote de revisão & & & & & & & & & & & & & & & & & & & & \\
\hline & 17.6 & Processo de entrega & & & $\bullet$ & & & $\bullet$ & & $\bullet$ & $\bullet$ & & $\bullet$ & $\bullet$ & $\bullet$ & & $\bullet$ & & & & & $\circ$ \\
\hline & & LEGENDA & $\bullet$ & $\overline{E X I}$ & STENT & & & & & $c$ & o & MENCIO & & & & & & INEXIS & STENT & & & \\
\hline
\end{tabular}

Nesta fase, denominada Mobilização, foram analisados os seguintes requisitos da ISO: 1) Recursos; 2) Tecnologia da Informação; 3) Métodos e Procedimentos Testados e Aprovados; e 4) Produção Colaborativa da Informação. Na comparação entre o conteúdo destes requisitos e o material de apoio utilizado foi possível identificar a existência de orientações similares no que se refere à Produção Colaborativa da Informação. Entretanto, estas orientações são referentes à fase de produção de informações e não referentes diretamente a fase de Mobilização.

Um item identificado com nível orientativo quase nulo entre os documentos utilizados como base no comparativo é referente aos testes da Produção Colaborativa da Informação no que se refere ao LOI (Level of Information). Este item é mencionado superficialmente em dois dos documentos disponíveis no Brasil: 1) Caderno de Apresentação de Projetos em BIM do Governo de Santa Catarina de 2014; e 2) Guia AsBEA-SP - Boas Práticas em BIM, fascículo 2 de 2015. 


\section{PRODUÇÃO COLABORATIVA - COLLABORATIVE PRODUCTION OF INFORMATION}

A ISO 19650 possui como seu fundamento a produção colaborativa de trabalho, em todas as fases envolvidas, para que os objetivos da contratação sejam alcançados. Para tal é necessário que exista intensa interação entre todos os envolvidos no processo de contratação e produção de informações de dados nas fases de projeto (design) e de obra.

Na Tabela é possível verificar o comparativo desenvolvido entre os requisitos indicados na ISO 19650 referentes ao desenvolvimento da fase de Produção Colaborativa das atividades pertencentes às fases de projeto (design) e obra com as informações constantes nos documentos que serviram de base para o estudo.

Tabela 9: Comparativo entre a ISO e a prática no Brasil referente a Produção Colaborativa

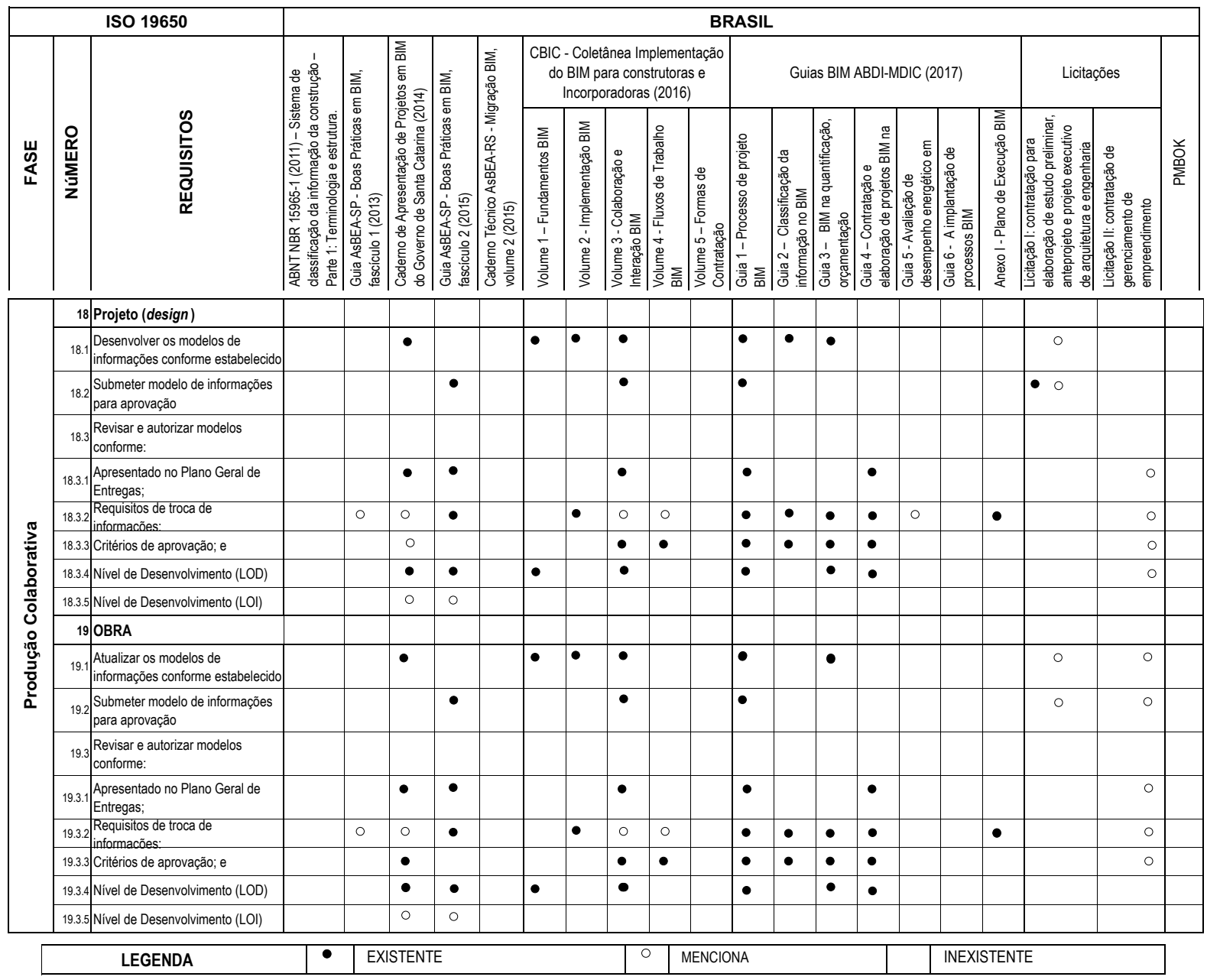

Fonte: Autor 
Nesta fase, denominada Produção Colaborativa, foram analisados os requisitos da ISO nas etapas de: 1) Projeto; e 2) Obra. Na comparação entre o conteúdo destes requisitos e o material de apoio utilizado foi possível identificar que existem, em 3 documentos, referências à atividade de submissão do modelo de informações e somente menção em 2 delas referentes ao LOI (Level of Information).

\section{ENTREGA - INFORMATION MODEL DELIVERY}

Como requisitos apresentados na ISO 19650, a fase de Entrega é reservada para a consolidação e disponibilização ao contratante de três tipos de entregáveis, tais como:

- Documentos: todos documentos físicos pertencentes às fases de contratação;

- Modelos de Informação BIM: todos os modelos BIM federados e nativos que serviram de base para a extração das informações e dados dentro do processo contratado; e

- Informações e dados: utilização do COBie para organização dos dados e informações que serão utilizados na fase de Operação e Manutenção.

Também é estabelecido pela ISO 19650 que, após a conclusão do projeto, a parte contratada deve arquivar todos os pacotes de entrega no CDE de acordo com os métodos e procedimentos de produção das informações e dados acordados. Se o CDE do projeto estiver hospedado externamente, o sistema interno deve ser entregue ao órgão/entidade ou responsável nomeado pelo contratante após a conclusão do projeto.

Na Tabela é possível verificar o comparativo desenvolvido entre os requisitos indicados na ISO 19650 referentes ao desenvolvimento da fase de Entrega e as informações constantes nos documentos que serviram de base para o estudo. 
Tabela 10: Comparativo entre a ISO e a prática no Brasil referente a fase de Entrega

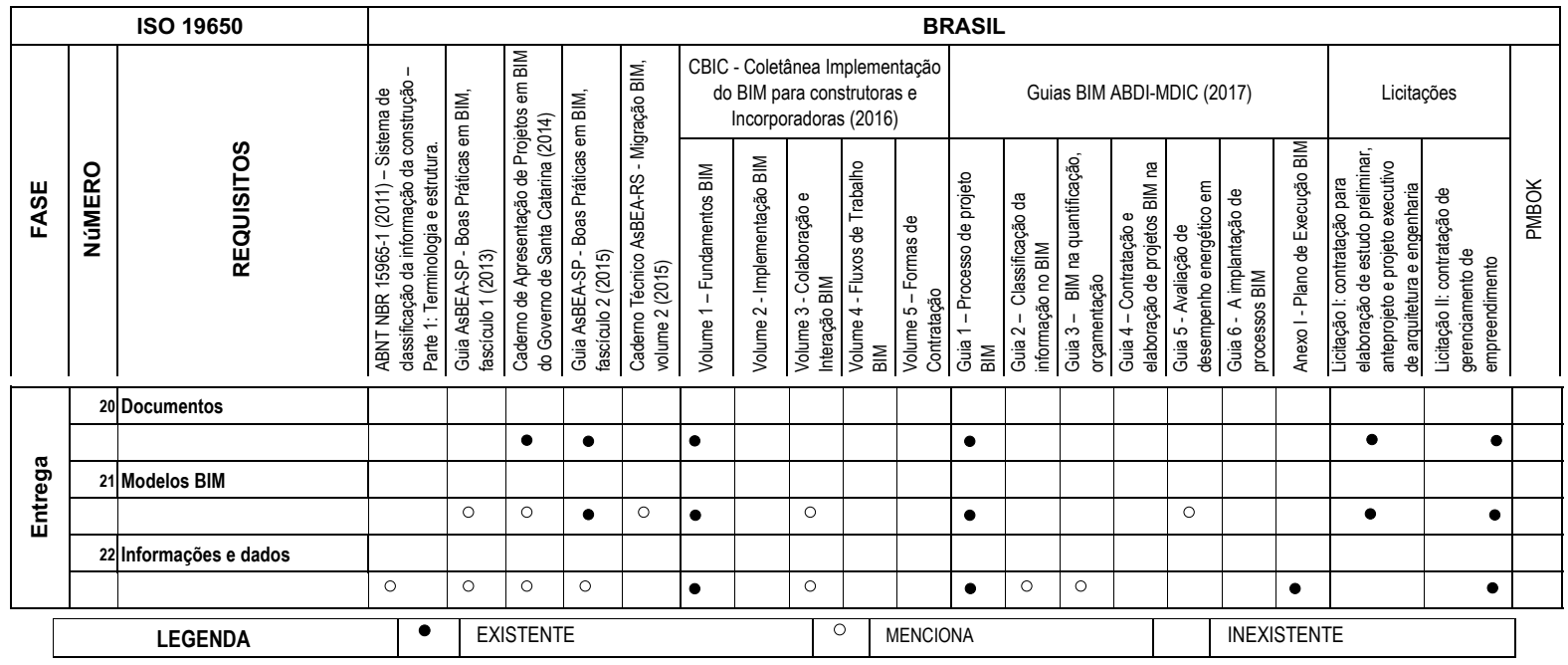

Fonte: Autor

Nesta fase, denominada Entrega, foram analisados os requisitos da ISO pertencentes aos entregáveis: 1) Documentos; 2) Modelos BIM; e 3) Informações e Dados. Na comparação entre o conteúdo destes requisitos e o material de apoio utilizado foi possível identificar que não existe a solicitação, pelo marcado brasileiro, de uma conformidade de padronização na entrega dos dados que serão utilizados na fase de O\&M.

Gráfico 5: Aderência das publicações nacionais à ISO 19650.

\section{PMBOK \\ Licitação \| \\ Licitação I}

Guias BIM ABDI-MDIC (2017)

CBIC - Coletânea BIM (2016)

AsBEA-RS - Migração BIM, volume 2 (2015)

Guia AsBEA-SP fascículo 2 (2015)

Caderno BIM do Governo de Santa Catarina (2014)

Guia AsBEA-SP - fascículo 1 (2013)

ABNT NBR 15965-1 (2011)
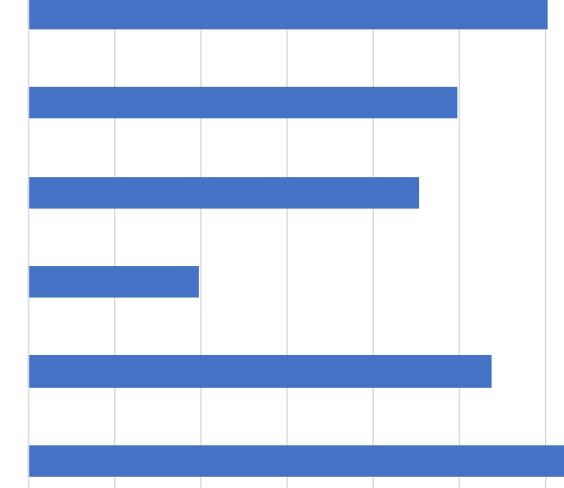
Através do desenvolvimento do estudo comparativo entre os requisitos presentes na norma ISO 19650 e os documentos BIM disponíveis no mercado brasileiro, foi possível identificar, conforme apresentado no Gráfico 5, a porcentagem de aderência de cada publicação. O calculo foi baseado entre os requisitos existentes na ISO 19650 e os itens existentes (peso 1), inexistentes (peso zero) e os mencionados (peso 0,5) contidos nos documentos estudados.

Como resultado do estudo comparativo, podem ser observados pontos importantes:

- Não existe uniformidade no número mínimo de requisitos exigidos pelos contratantes;

- Não existe uniformidade referente ao conteúdo dos requisitos;

- Requisitos tidos como principais na ISO 19650, tais como apresentação do Plano de Execução BIM e a utilização do Ambiente Comum de Dados (CDE) como única fonte de centralização e extração de informações e dados durante a fase do CAPEX não são exigidos pelos contratantes;

- O LOD (Level of Development) para desenvolvimento dos componentes dos modelos BIM é pouco exigido;

- O LOI (Level of Information) para desenvolvimento e amadurecimento no nível de informações constante nos objetos que formam os modelos BIM possui exigência nula dentre os contratantes;

- O COBie ou padrão similar para organização das informações e dados constantes nos modelos BIM não é solicitado.

\subsection{GRUPO FOCAL}

A reunião foi realizada com a presença de 8 especialistas BIM com experiência comprovada em diversas áreas da construção civil nacional após um evento BIM realizado na Escola Politécnica da USP no dia 22 de novembro de 2017.

Este evento teve como objetivo apresentar ao público de especialistas e pesquisadores BIM os requisitos do Protocolo de Desenvolvimento de Bibliotecas BIM, além do anúncio pelo MDIC e ABDI do lançamento da BNBIM (Biblioteca Nacional BIM). Foram realizadas palestras referentes à estrutura do IFC, à estratégia de criação do Chapter Brasil da buildingSMART e do conteúdo ISO 19650. 
Desta forma, o grupo de 8 especialistas BIM das diversas áreas da construção foi incentivado pelo moderador da atividade a discutir sobre os pontos relevantes à gestão das informações e dados BIM durante as fases de contratação, produção e entrega de serviços e de produtos, todos estes pertencentes ao documento inicial denominado PNBIM. As informações levantadas durante o decorrer da atividade foram coletadas através de vídeo e áudio, compiladas, e utilizadas no desenvolvimento da pesquisa.

\subsubsection{Objetivos do grupo focal}

O desenvolvimento deste grupo focal teve como finalidade validar o PNBIM, Apêndice $A$, através da apresentação de seu conteúdo aos participantes da atividade e coletar, através dos comentários levantados, sugestões de alteração de seu conteúdo. A execução da atividade teve como objetivos:

Geral: A partir da apresentação do conteúdo do PNBIM, levantar dados através de discussão entre grupo de profissionais com experiência comprovada em trabalhos BIM de diversas áreas da cadeia da construção civil.

Específicos: Levantar dados específicos ao fluxo e processo no gerenciamento das atividades na produção de informações e dados BIM e fazer as devidas alterações no PNBIM pertencentes as fases:

- Contratação

- Requisitos de necessidades;

- Licitação ou carta convite;

- Proposta;

- Contratação; e

○ Mobilização.

- Produção Colaborativa

- Gestão de informação e dados BIM;

- Sistema de gerenciamento de informações

- Desenvolvimento de informações e dados; e

- Preparo de informações e dados para O\&M.

- Entrega

- Documentos;

- Modelos BIM; e 
○ Informações e dados.

Já o questionário específico (Tabela ) tem como finalidade aprofundar a discussão entre os integrantes da atividade em pontos relevantes ao desenvolvimento do trabalho.

Tabela 11: Questões específicas.

\begin{tabular}{|c|c|c|c|}
\hline \multicolumn{4}{|c|}{ Questões Especificas } \\
\hline \multicolumn{3}{|r|}{ Questão } & Objetivo \\
\hline \multirow{8}{*}{ Contrataçäo } & Questão 1 & $\begin{array}{l}\text { Quais materiais base você considera que sejam } \\
\text { disponibilizados pelo contratante na fase de licitação? }\end{array}$ & $\begin{array}{l}\text { Expressar conhecimento nos requisitos de contratação de } \\
\text { serviços BIM. }\end{array}$ \\
\hline & Questão 2 & $\begin{array}{l}\text { Na sua opinição quais são as funcionalidades necessárias } \\
\text { que devem fazer parte de um sistema de gerenciamento } \\
\text { de informações? }\end{array}$ & $\begin{array}{l}\text { Expressar conhecimento e familiaridade em sistemas de } \\
\text { fgerenciamento de informações BIM }\end{array}$ \\
\hline & Questão 3 & $\begin{array}{l}\text { Na sua opiniāo em que etapa o Plano de Execução BIM } \\
\text { deve ser entregue? }\end{array}$ & $\begin{array}{l}\text { Expressar conhecimento no fluxo de entrega de } \\
\text { documentação para contratação de trabalhos BIM }\end{array}$ \\
\hline & Questão 4 & $\begin{array}{l}\text { Na sua opinião quais os itens fundamentais que devem } \\
\text { fazer parte do Plano de Execução BIM e em que momento } \\
\text { este documento deve ser entregue? }\end{array}$ & $\begin{array}{l}\text { Expressa conhecimento e familiaridade nos itens } \\
\text { necessários para elaboração do Plano de Execução BIM e } \\
\text { no fluxo de documentação }\end{array}$ \\
\hline & Questão 5 & $\begin{array}{l}\text { Na sua opinião o que deve ser considerado para avaliação } \\
\text { da capacidade técnica individual e de empresas } \\
\text { prestadoras de serviços BIM? }\end{array}$ & $\begin{array}{l}\text { Expressa conhecimento das habilidades técnicas } \\
\text { profissionais e comerciais necessárias }\end{array}$ \\
\hline & Questão 6 & $\begin{array}{l}\text { Com quais profissionais deve ser composta a equipe de } \\
\text { gestão da produção de informaçöes BIM? }\end{array}$ & $\begin{array}{l}\text { Expressa conhecimento na estrutura organizacional } \\
\text { necessária }\end{array}$ \\
\hline & Questão 7 & $\begin{array}{l}\text { Quais as informações necessárias que devem fazer parte } \\
\text { das propostas referentes ao desenvolvimento de trabalhos } \\
\text { BIM? }\end{array}$ & $\begin{array}{l}\text { Expressa conhecimento no processo de contrataçăo de } \\
\text { trabalhos BIM }\end{array}$ \\
\hline & Questão 8 & $\begin{array}{l}\text { Pra você quais são as atividades que devem ser } \\
\text { desenvolvidas na fase de Mobilização do contrato? }\end{array}$ & Expressa conhecimento em gestäo de projetos \\
\hline \multirow{2}{*}{$\begin{array}{l}\text { Produção } \\
\text { Colaborativa }\end{array}$} & Questăo 9 & $\begin{array}{l}\text { Na sua opinião como seria o melhor fluxo para utiização } \\
\text { de um sistema de gerenciamento das informações e dos } \\
\text { dados desenvolvidos em BIM? }\end{array}$ & $\begin{array}{l}\text { Expressa conhecimento em sistemas de gerenciamento de } \\
\text { informações BIM como o CDE }\end{array}$ \\
\hline & Questäo 10 & $\begin{array}{l}\text { Para você qual a relevância da verificação gráfica e das } \\
\text { informaçöes nos elementos pertencentes nos modelos } \\
\text { BIM? }\end{array}$ & $\begin{array}{l}\text { Expressa conhecimento em: } \\
\text { Desenvolvimento de modelos para documentação; e } \\
\text { Desenvolvimento de modelos para extração de dados. }\end{array}$ \\
\hline \multirow{4}{*}{ Encerramento } & Questão 11 & $\begin{array}{l}\text { No encerramento dos trabalhos você recebe / entrega } \\
\text { modelos nativos e/ou federados? }\end{array}$ & $\begin{array}{l}\text { Expressa conhecimento no desenvolvimento de modelos } \\
\text { de propriedade e gestão }\end{array}$ \\
\hline & Questão 12 & $\begin{array}{l}\text { No encerramento dos trabalhos você recebe / entrega } \\
\text { informaçöes e dados de forma estruturada para a fase de } \\
\text { O\&M? }\end{array}$ & $\begin{array}{l}\text { Expressa conhecimento no preparo de informações e } \\
\text { dados para fase de O\&M }\end{array}$ \\
\hline & Questão 13 & $\begin{array}{l}\text { No encerramento dos trabalhos você recebe / entrega qual } \\
\text { tipo de documentação? }\end{array}$ & $\begin{array}{l}\text { Expressa conhecimento referente a documentaçăo de } \\
\text { entrega }\end{array}$ \\
\hline & Questão 14 & $\begin{array}{l}\text { No encerramento dos trabalhos você recebe / entrega } \\
\text { histórico de lições aprendidas? }\end{array}$ & Expressa conhecimento em gestäo de projetos \\
\hline
\end{tabular}

Fonte: Autor 


\subsubsection{Produção de dados}

A amostragem é de fundamental importância, pois detém a chave para o potencial comparativo da base de dados existente (BARBOUR, 2009). Dentre os pontos principais para a coleta de dados, é de extrema importância:

- Coletar dos dados por meio de questionário curto;

- Estimular a debate ente os participantes sobre os temas apresentados; e

- Ter atenção ao vocabulário utilizado para facilitar a coleta e organização dos dados coletados.

Pode reformular ou elaborar questões, de modo a fazer os interesses da pesquisa mais claros.

\subsubsection{Indicadores}

Foi disponibilizado, através do sistema Google Forms, um formulário de inscrição aos convidados a participar do grupo focal. Através das respostas a perguntas gerais neste formulário foi possível identificar as características dos participantes mostradas no Gráfico 6. É importante salientar que apenas 6 dos 8 participantes responderam à pesquisa on-line.

Gráfico 6: Faixa etária dos participantes

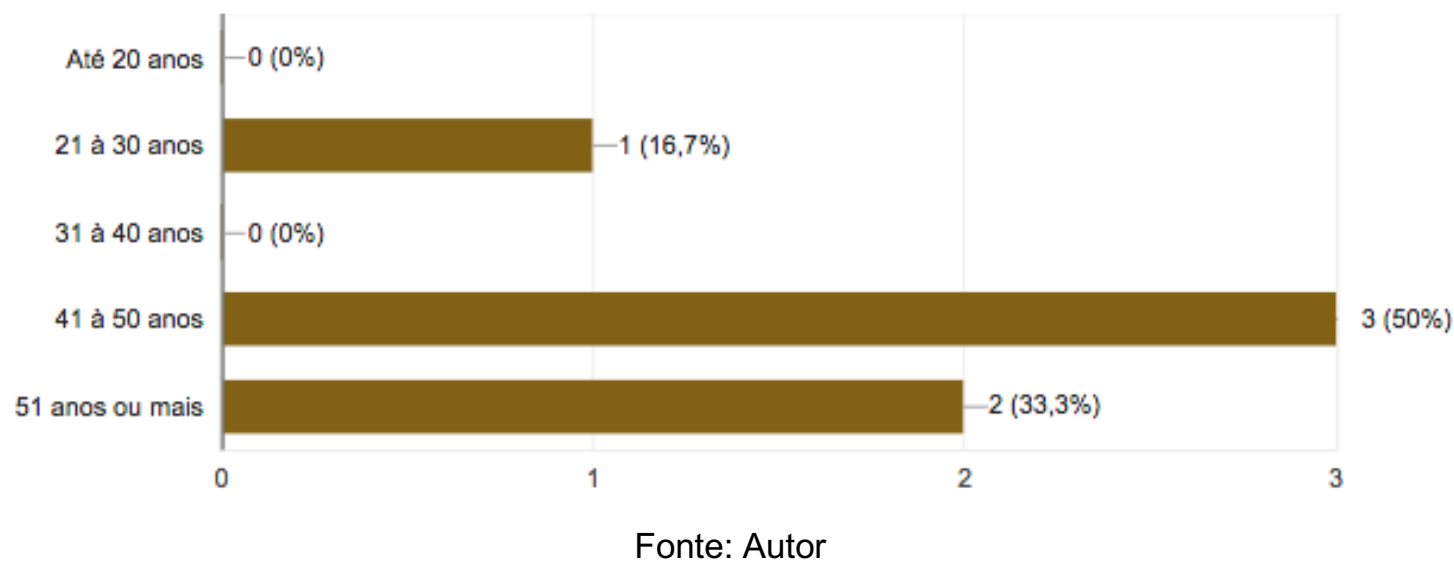


Os três especialistas presentes que se denominaram na categoria "Outros" no setor de atuação (Gráfico 7) foram identificados como pertencentes ao setor de prestadores de serviços da cadeia da construção civil.

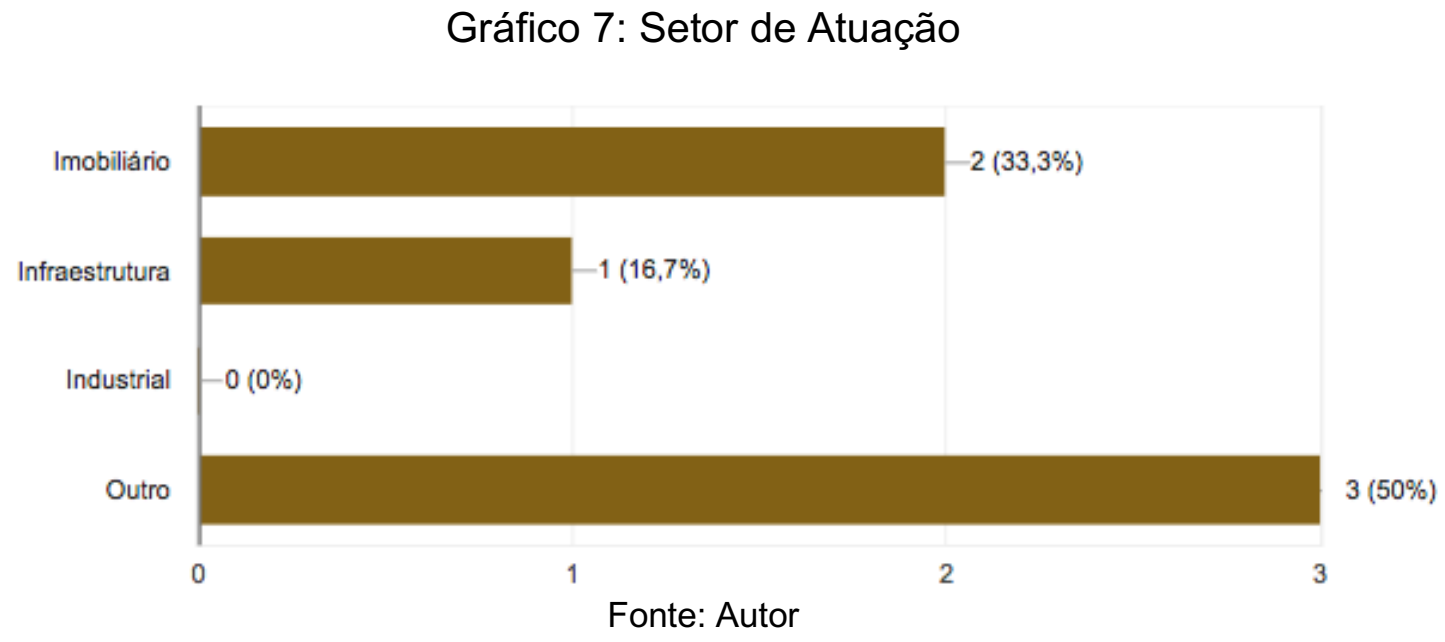

Como observado no Gráfico 8, é possível identificar boa distribuição entre os participantes no que se refere a área de atuação, estando presentes contratantes, prestadores de serviços e fornecedores BIM, dentre outros.

Gráfico 8: Área de atuação

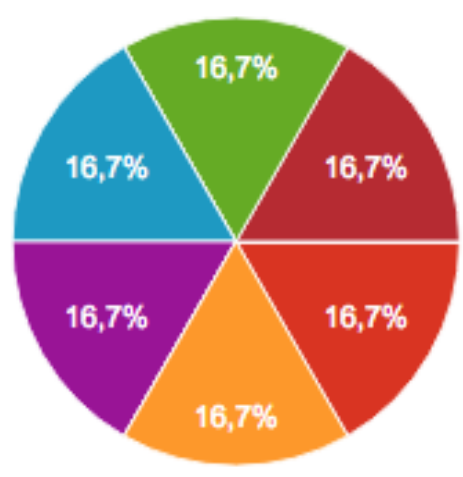

Contratante

Projetista

Construtor

Gerenciador

Desenvolvedor de ferramentas e si...

Academia

Instituiçōes

Desenvolvedor de objetos BIM

$1 / 2 \nabla$

Fonte: Autor 
O Gráfico 9 mostra o tempo de experiência em BIM dos participantes.

Gráfico 9: Tempo de experiência em BIM

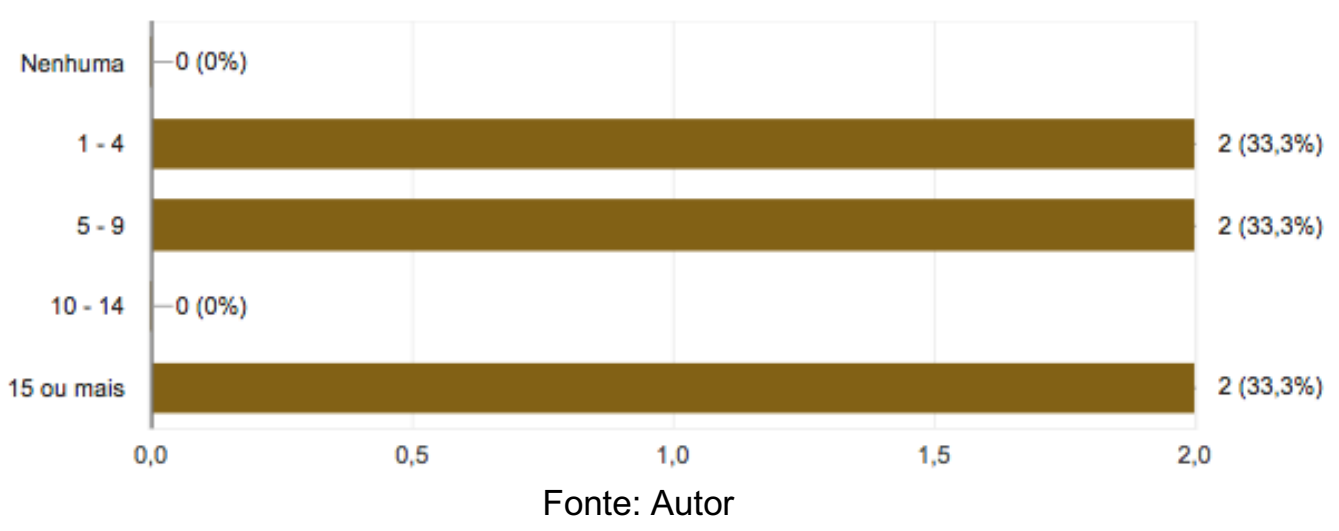

Já no quesito experiência na gestão de informações BIM (Gráfico 10), aproximadamente $33 \%$ se identificaram com nível avançado e mais de $66 \%$ apontaram o entendimento no assunto como intermediário.

Gráfico 10: Nível de experiência na gestão de informações BIM

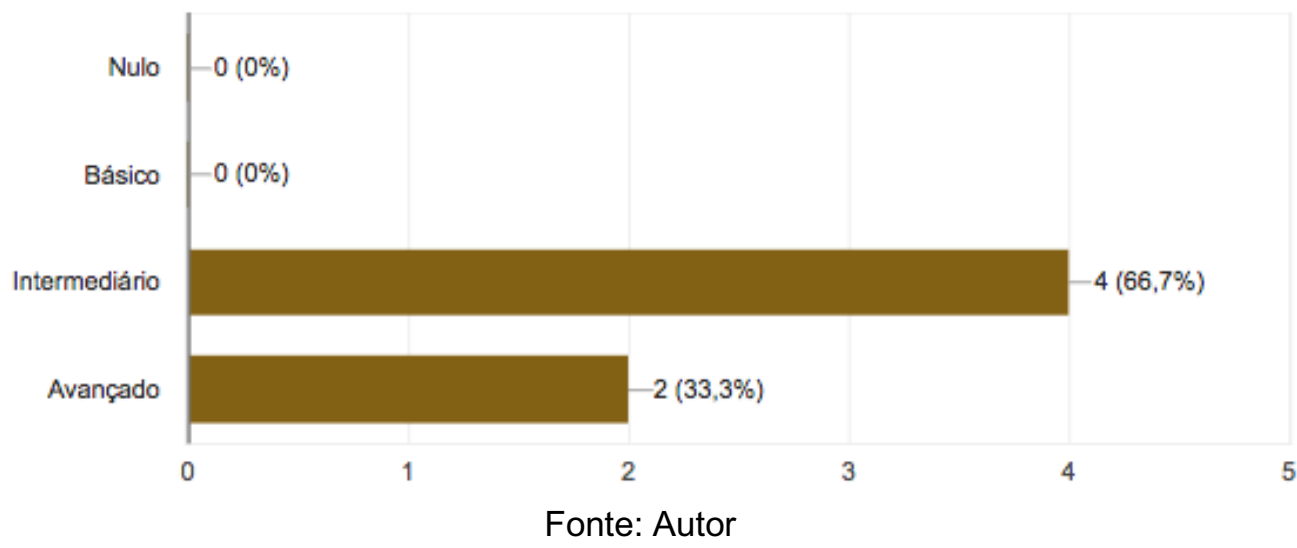

Dentre os especialistas presentes, mais de $83 \%$ se identificaram com conhecimento nulo ou básico do conteúdo da norma Britânica PAS 1192-2:2013 (Gráfico 11) que está em vigor desde abril de 2016 no Reino Unido e é utilizada como base para o desenvolvimento de documentos orientativos por diversos países ao redor do mundo como Cingapura e Chile por exemplo. Apenas 1 dos participantes mencionou ter conhecimento avançado na norma inglesa. 
Gráfico 11: Nível de conhecimento na norma britânica PAS1192-2:2013

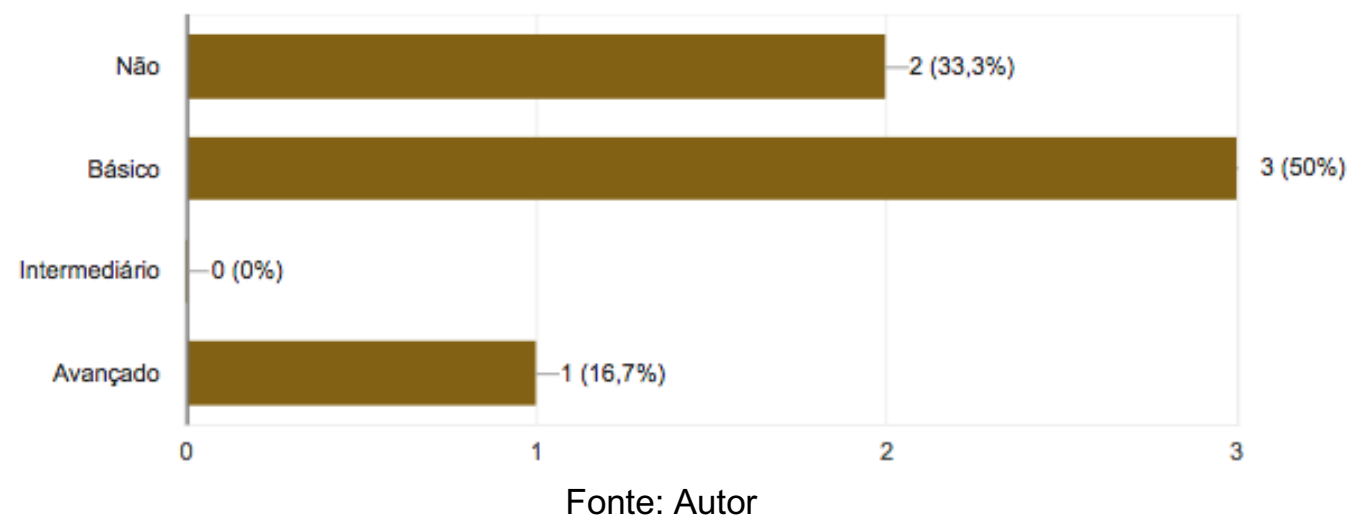

Em contrapartida, mais de $83 \%$ dos participantes de identificaram com conhecimento básico da ISO 19650 (Gráfico 12) e 16,7\%, 1 pessoa, se declarou com conhecimento nulo. Isso se dá principalmente por dois fatores: 1) a ISO ter como base a norma Britânica PAS 1192-2:2013; e 2) por, até o momento da atividade, não ter sido publicada em sua forma final.

Gráfico 12: Nível de conhecimento na norma ISO19650

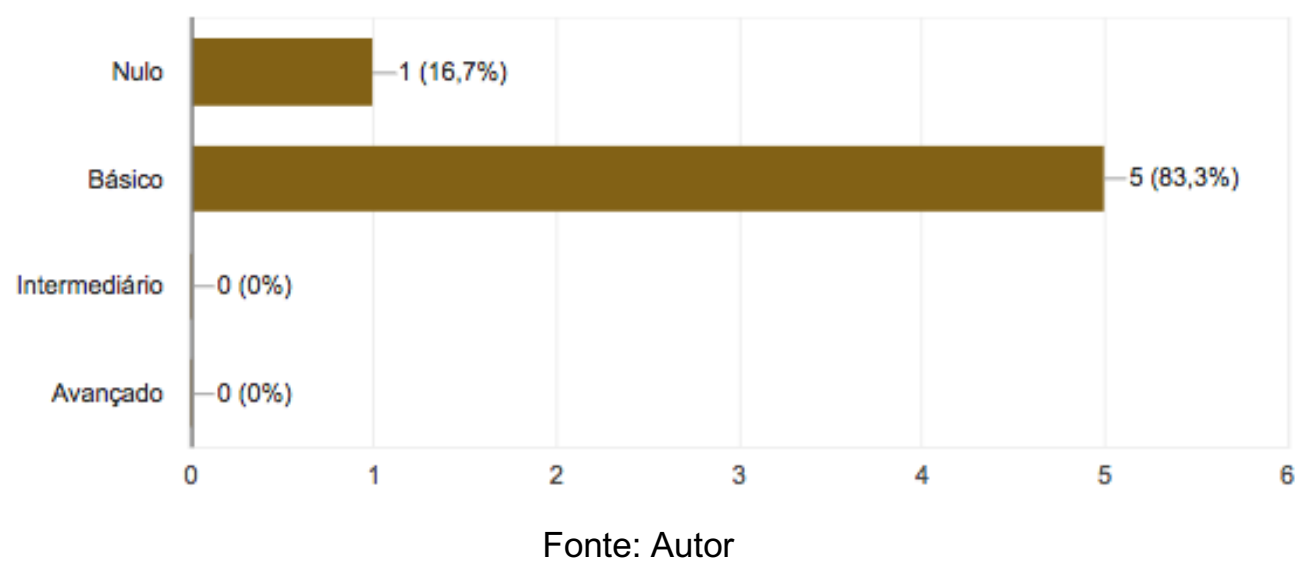

Referente ao nível de conhecimento sobre modelos federados (Gráfico 13), $50 \%$ dos especialistas se descreveram como conhecedores intermediários e os demais como conhecedores avançados no tema. Esse entendimento se mostra importante para este estudo principalmente por se tratar de um requisito no processo de trabalho com modelos utilizando o Ambiente Comum de Dados (CDE) especificado pela ISO 19650. 
Gráfico 13: Conhecimento com Modelos Federados

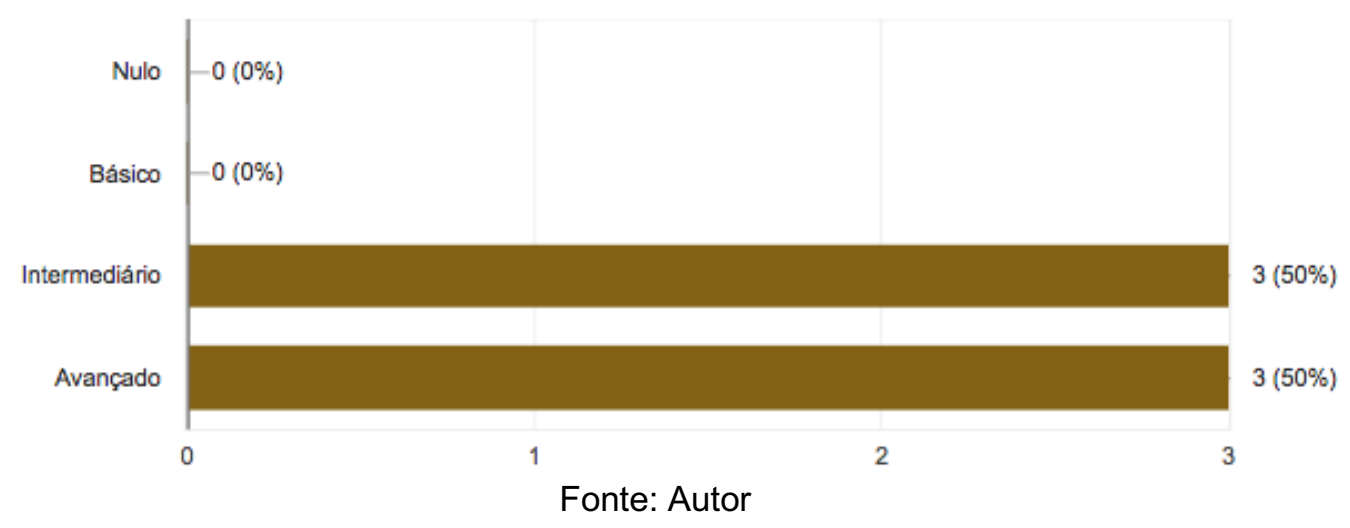

Conforme apresentado no Gráfico 14, 33\% dos participantes declara muito alta a importância de disponibilização de material BIM pelo contratante. Importante notar que a totalidade declara ser alta/muito alta a importância de disponibilização de material pelo contratante.

Gráfico 14: Importância de disponibilização de material BIM pelo contratante

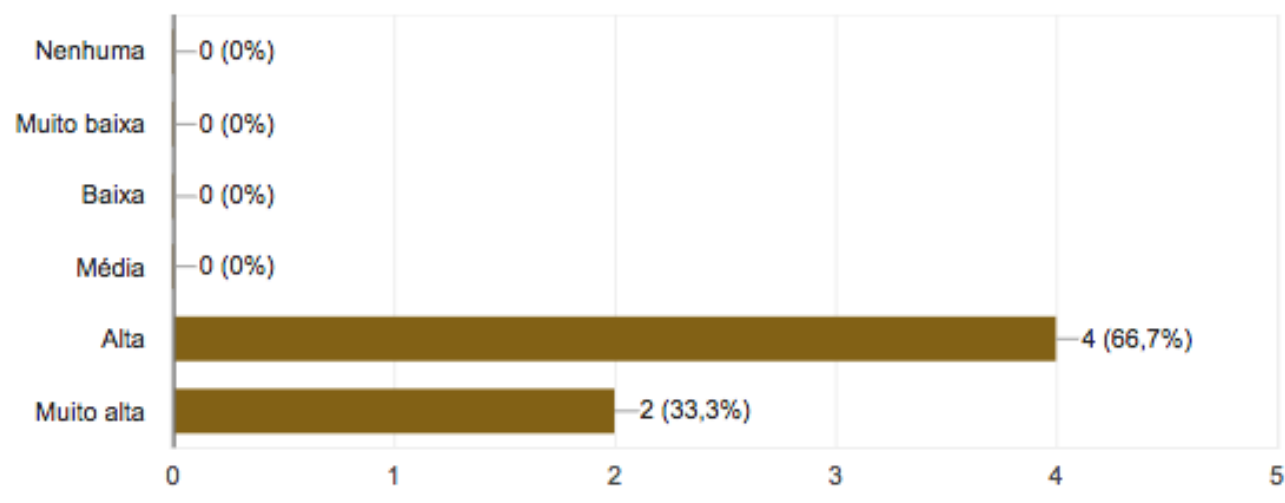

Fonte: Autor

Item considerado como uma das bases para o gerenciamento das informações e dados BIM pela ISO 19650, o conhecimento referente ao documento Plano de Execução BIM foi apontado como intermediário por mais de $66 \%$ dos especialistas (Gráfico 15). Somente 2 dos especialistas presentes $(33,3 \%)$ disseram ter conhecimento avançado sobre o conteúdo do documento. 
Gráfico 15: Conhecimento no Plano de Execução BIM

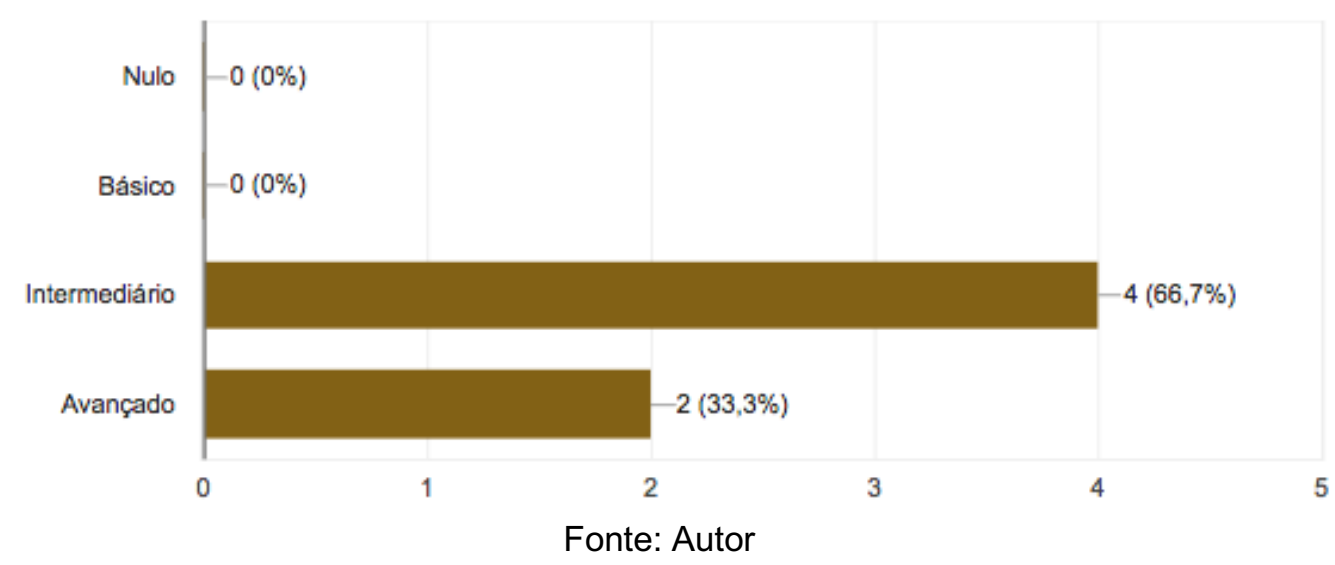

O conhecimento referente ao Plano de Mobilização (Gráfico 16), outro documento importante apresentado pela ISO 19650 no processo de gerenciamento de informações e dados BIM foi informado por 33,3\% como intermediário, entre os especialistas presentes. Entretanto, a maioria dos especialistas $(66,6 \%)$ se declararam com conhecimento nulo ou básico no conteúdo do documento.

Gráfico 16: Entendimento sob o Plano de Mobilização

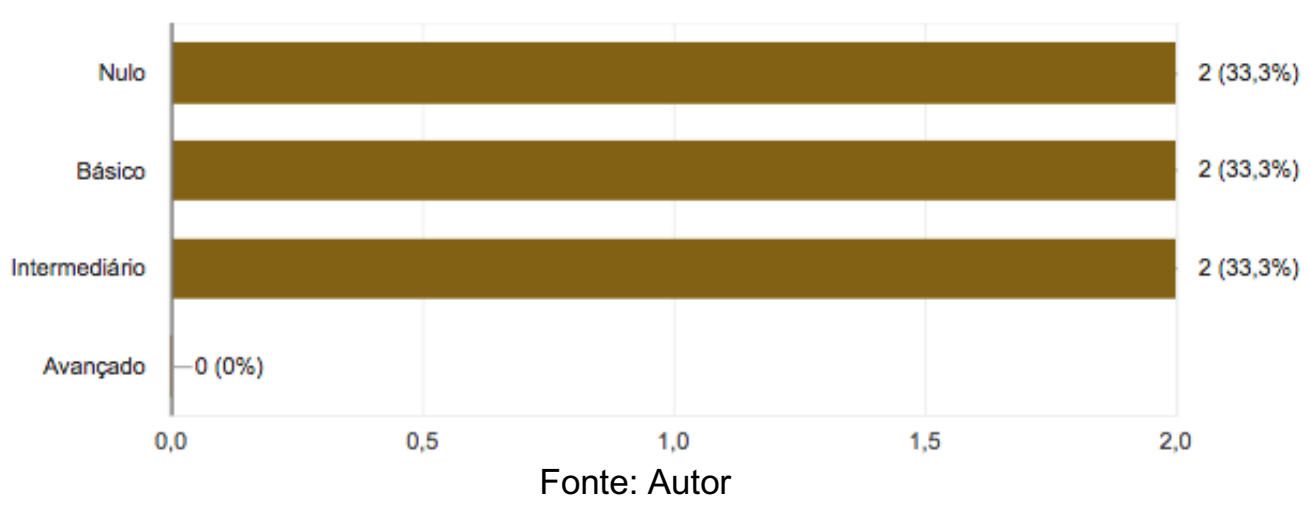

Referente ao entendimento sobre o funcionamento de sistemas de gerenciamento de informações (GED), 100\% dos especialistas presentes se declararam com conhecimento intermediário ou avançado no sistema (Gráfico 17). Isso se deve pelo GED ser o sistema mais solicitado pelos contratantes da cadeia da construção brasileira para o desenvolvimento da gestão das atividades de projeto (design) e de obra. 
Gráfico 17: Entendimento sobre funcionamento de sistemas de gerenciamento de informações

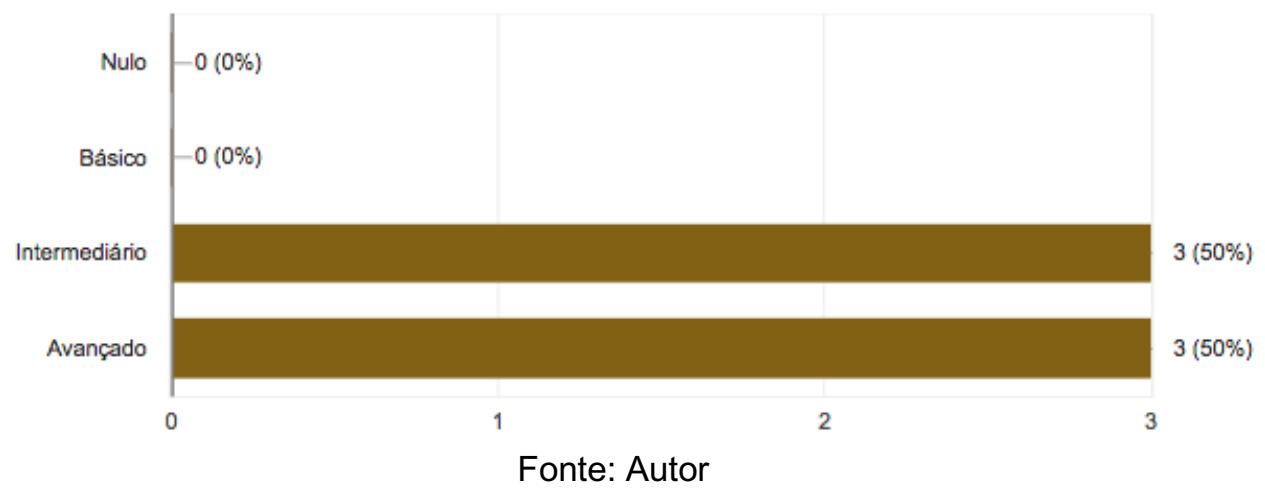

Referente ao LOD (Level of Development), requisito este presente na ISO 19650 referente ao processo de desenvolvimento dos modelos BIM durante a etapa de projeto (design), 33,3\% dos presentes indicaram ter nível avançado no tema. Os que se indicaram com nível intermediário sobre o LOD representam 66,7\% (Gráfico 18).

Gráfico 18: Entendimento referente a LoD

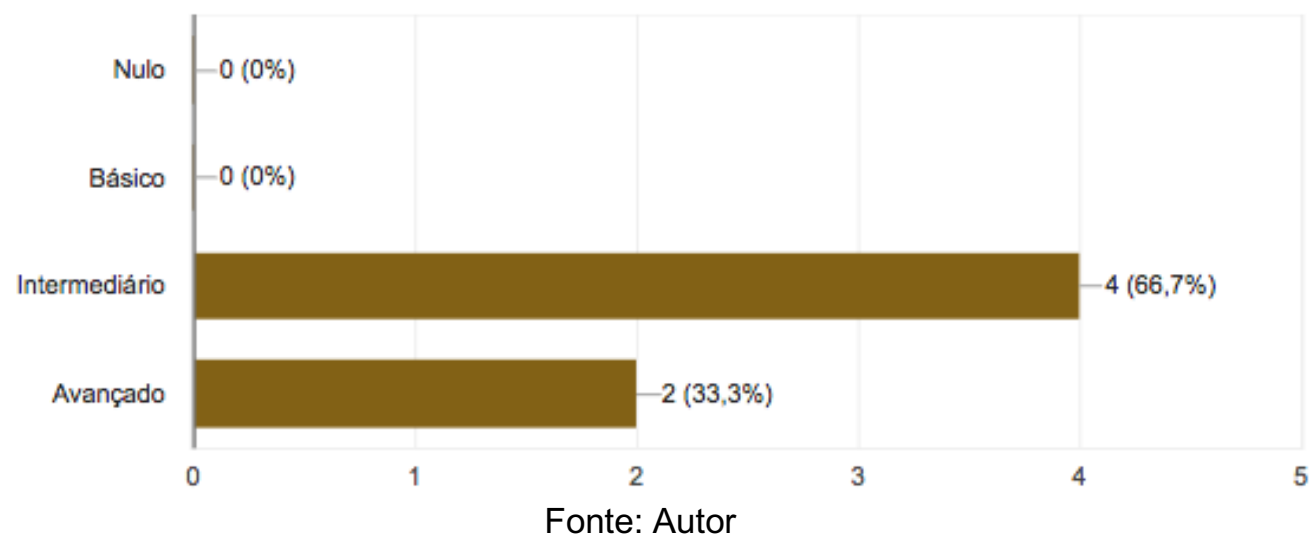

No conhecimento referente ao LOI (Level of Information), requisito este presente na ISO 19650 referente ao processo de desenvolvimento dos modelos BIM durante a etapa de projeto (design) e da obra, apenas $1(16,7 \%)$ especialista indicou seu conhecimento como básico no assunto. Os demais $83,3 \%$ dos presentes indicaram ter nível intermediário ou avançado no tema (Gráfico 19). 
Gráfico 19: Entendimento referente a LOI

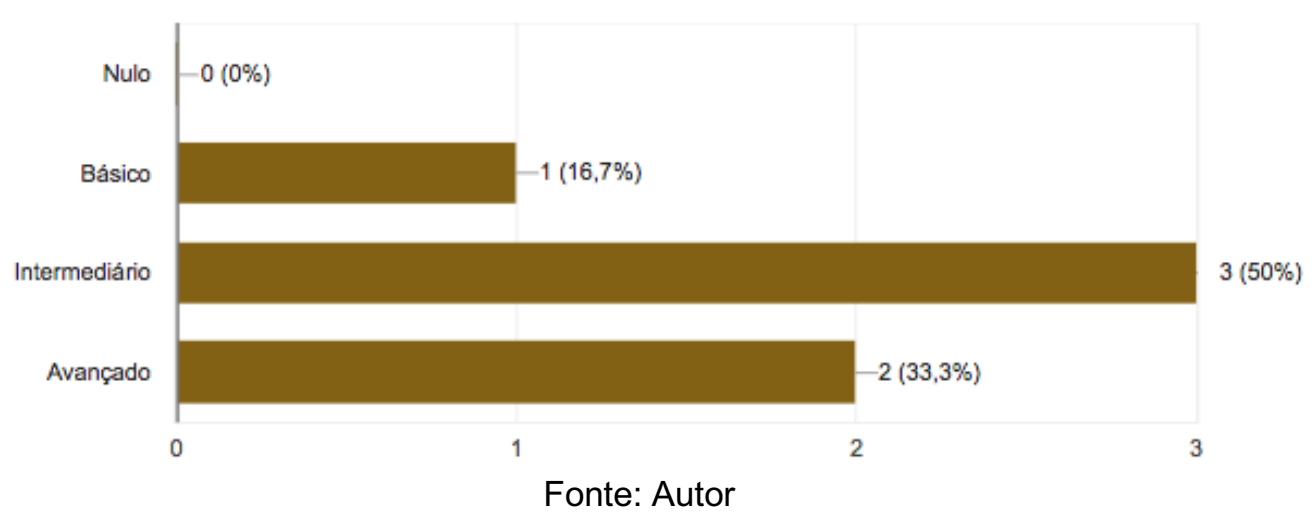

Quando questionados sobre o entendimento referente ao COBie (Gráfico 20), requisito este presente na norma ISO 19650 como formato para organização das informações e dados durante as etapas de projeto (design) e obra e forma de entrega dos mesmos na etapa final do contrato, $66,7 \%$ dos presentes se denominaram com conhecimento básico sobre o tema. Apenas 33,3\% dos especialistas se mostraram com entendimento intermediário com o COBie.

Gráfico 20: Entendimento referente ao COBie

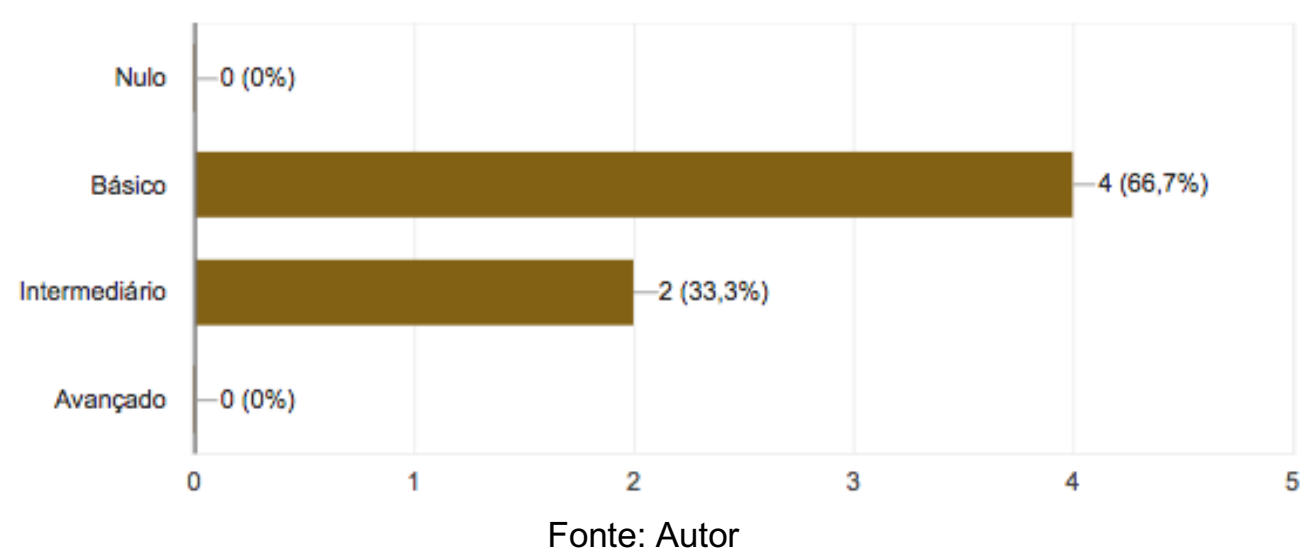

Como tipo de produtos que são entregues pelos especialistas presentes aos seus contratantes, 33,3\% informaram que entregam modelos BIM. Importante salientar que um dos tipos de entregáveis considerados como requisitos na ISO 19650 não é considerado pelos especialistas presentes: dados a serem utilizados na fase de O\&M (Gráfico 21). 
Gráfico 21: Tipos de entregáveis

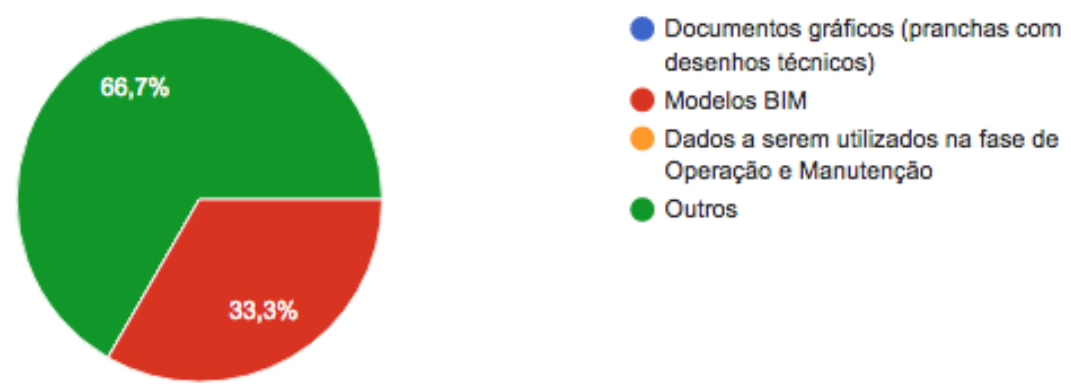

Fonte: Autor

Nos itens apresentados no Gráfico 22, o que mais apresentou importância para os especialistas presentes para impulsionar o BIM no Brasil foi a cobrança de sua utilização pelos contratantes (83,3\%). Em segundo lugar, com $50 \%$ das menções dos participantes, foi identificada a disponibilização de Regulamentação e Normas como fator que pode impulsionar o BIM no Brasil. Em terceiro lugar, com 33,3\%, foi mencionada a educação BIM como fator importante no processo de disseminação do BIM no Brasil. Empatados com $16,7 \%$ cada, a disponibilidade de bibliotecas e certificações BIM ficaram logo em seguida. A disponibilidade de incentivos fiscais e a criação de associações BIM não tiveram menção pelos especialistas presentes.

Gráfico 22: Fatores que podem impulsionar o BIM no Brasil

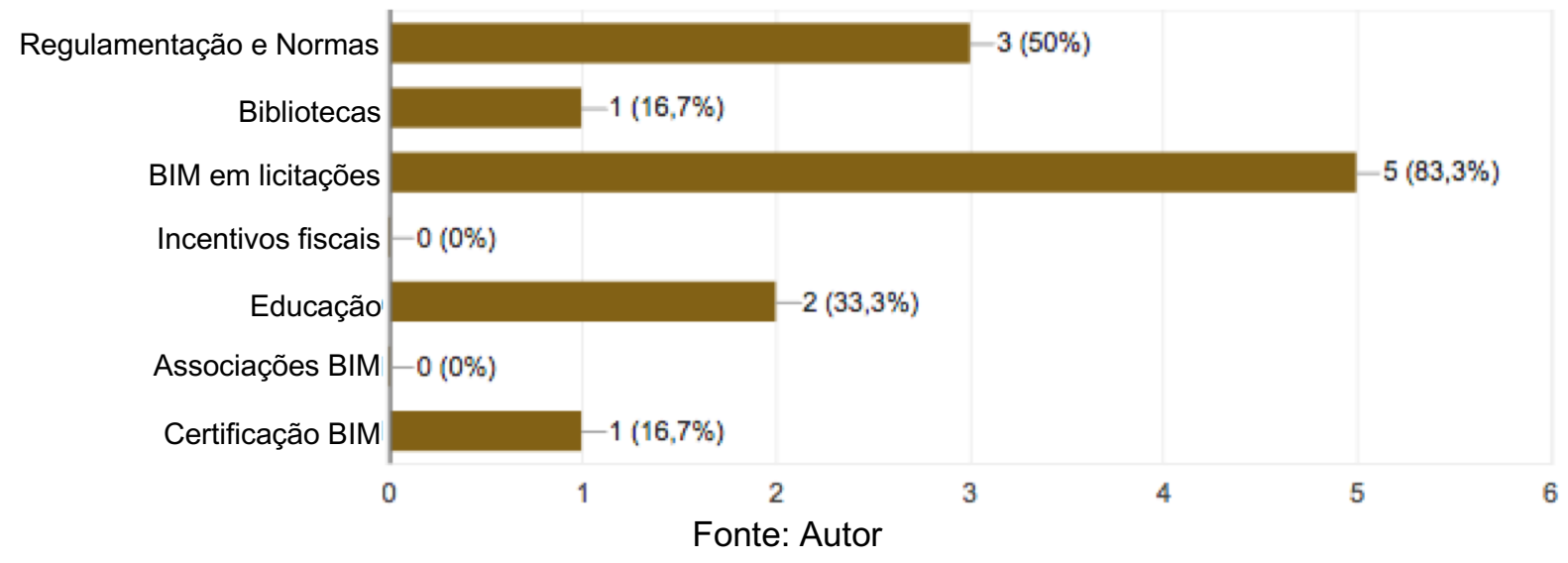

Conforme a consolidação das informações levantadas através do questionário geral, é possível notar similaridades entre os participantes da atividade do Grupo Focal. Estas similaridades são: 1) o conhecimento entre a diferença entre LOD e LOI; 2) entendimento, mesmo que básico, do conceito COBie; 3) conhecimento do Plano de Execução BIM; 4) baixo conhecimento na Norma ISO19560; e 5) a experiência BIM. 


\subsubsection{Respostas levantadas}

Como base para o desenvolvimento da atividade do grupo focal com os especialistas presentes, foram desenvolvidas perguntas específicas sobre os requisitos principais constantes nos dois volumes da norma ISO 19650 nas fases de contratação, produção colaborativa considerando as etapas de projeto (design) e de obra e entrega no encerramento do processo.

Conforme apurado pelas respostas dadas pelos especialistas presentes na atividade, foram apontados como os principais materiais a serem disponibilizados pelo contratante na fase de licitação: 1) uso do BIM; 2) especificações técnicas; 3) definição do uso do projeto, diretrizes e normas e padronização; 4) programa de necessidades; e 5) bibliotecas, modalidade contratual, modelos BIM e a EAP (Gráfico 23).

Gráfico 23: Materiais a serem disponibilizados pelo contratante na fase de licitação

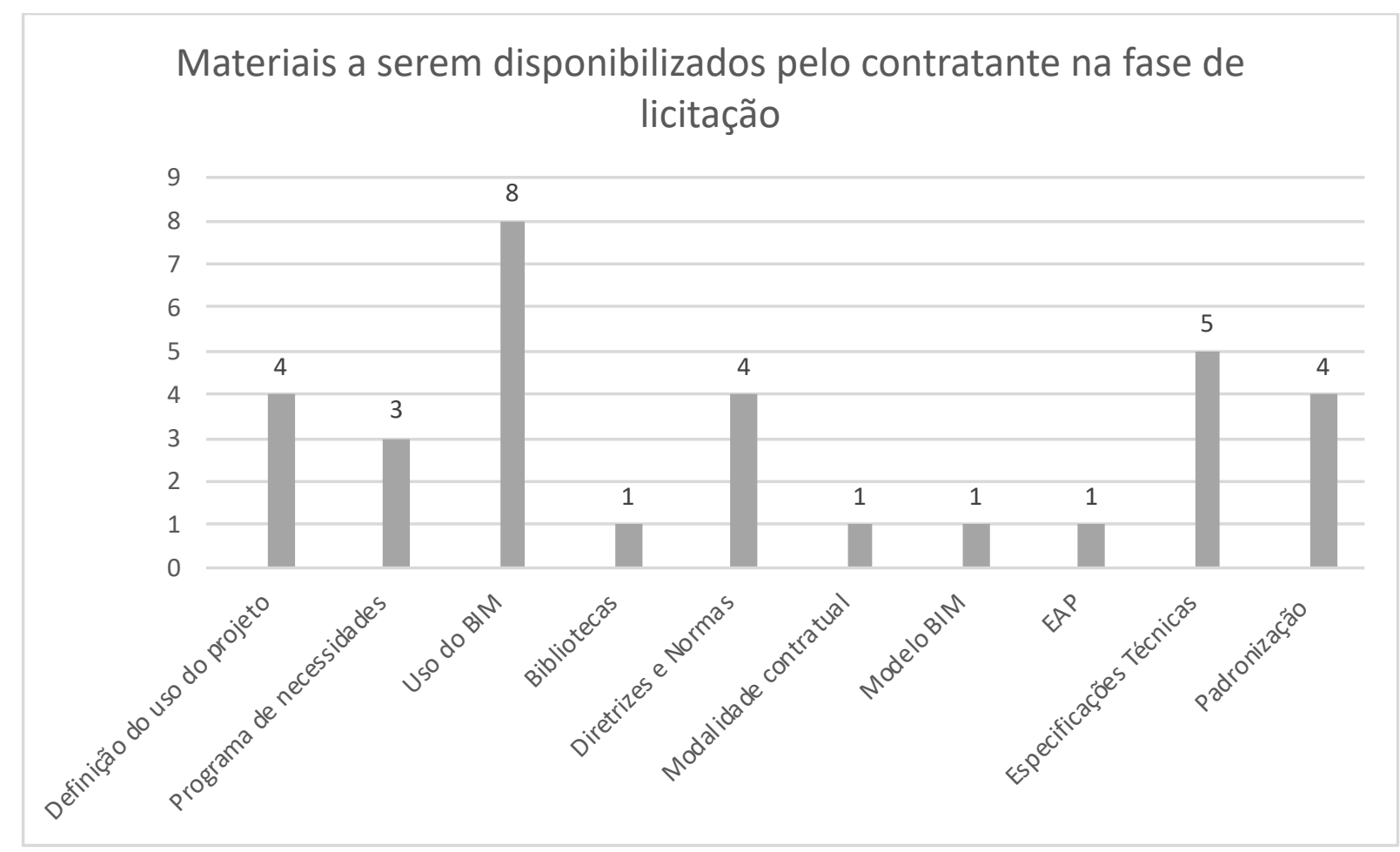

Fonte: Autor 
Entre as principais funcionalidades necessárias que devem existir em um sistema de gerenciamento de informações, Gráfico 24, foi possível notar que a disponibilização e a transparência das informações gerais do projeto são os itens mais citados entre os participantes. Em seguida, o fluxo de trabalho, rastreabilidade e segurança das informações são os itens mais importantes para os especialistas.

Gráfico 24: Funcionalidades necessárias em um sistema de gerenciamento de informações

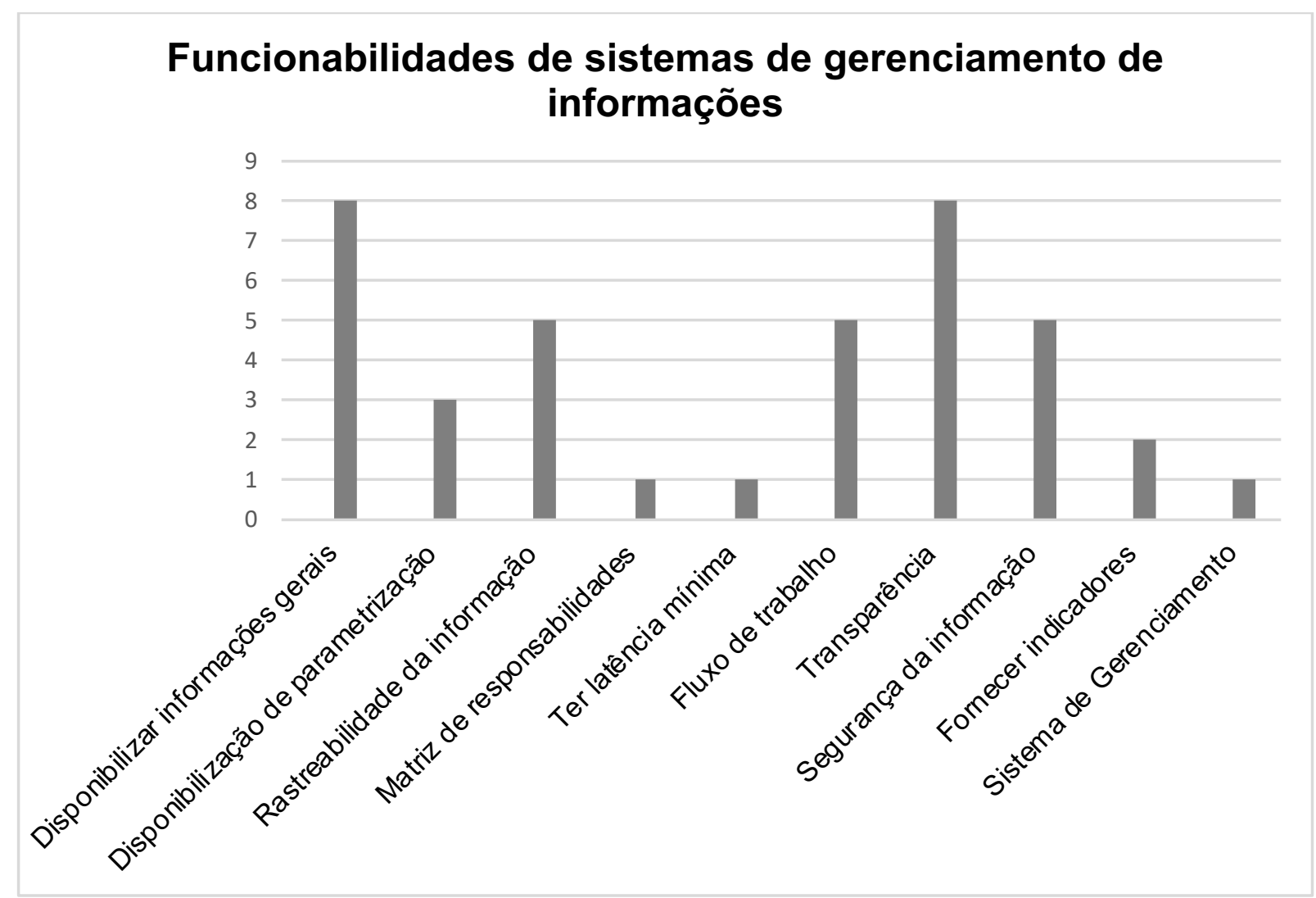

Fonte: Autor

Questionados sobre em que etapa do processo de contratação a parte contratada deve desenvolver e entregar ao contratante o documento Plano de Execução BIM, foi possível identificar que a maioria dos especialistas entende a importância da entrega deste documento junto à proposta (Gráfico 25). 
Gráfico 25: Etapa onde o Plano de Execução BIM deve ser entregue

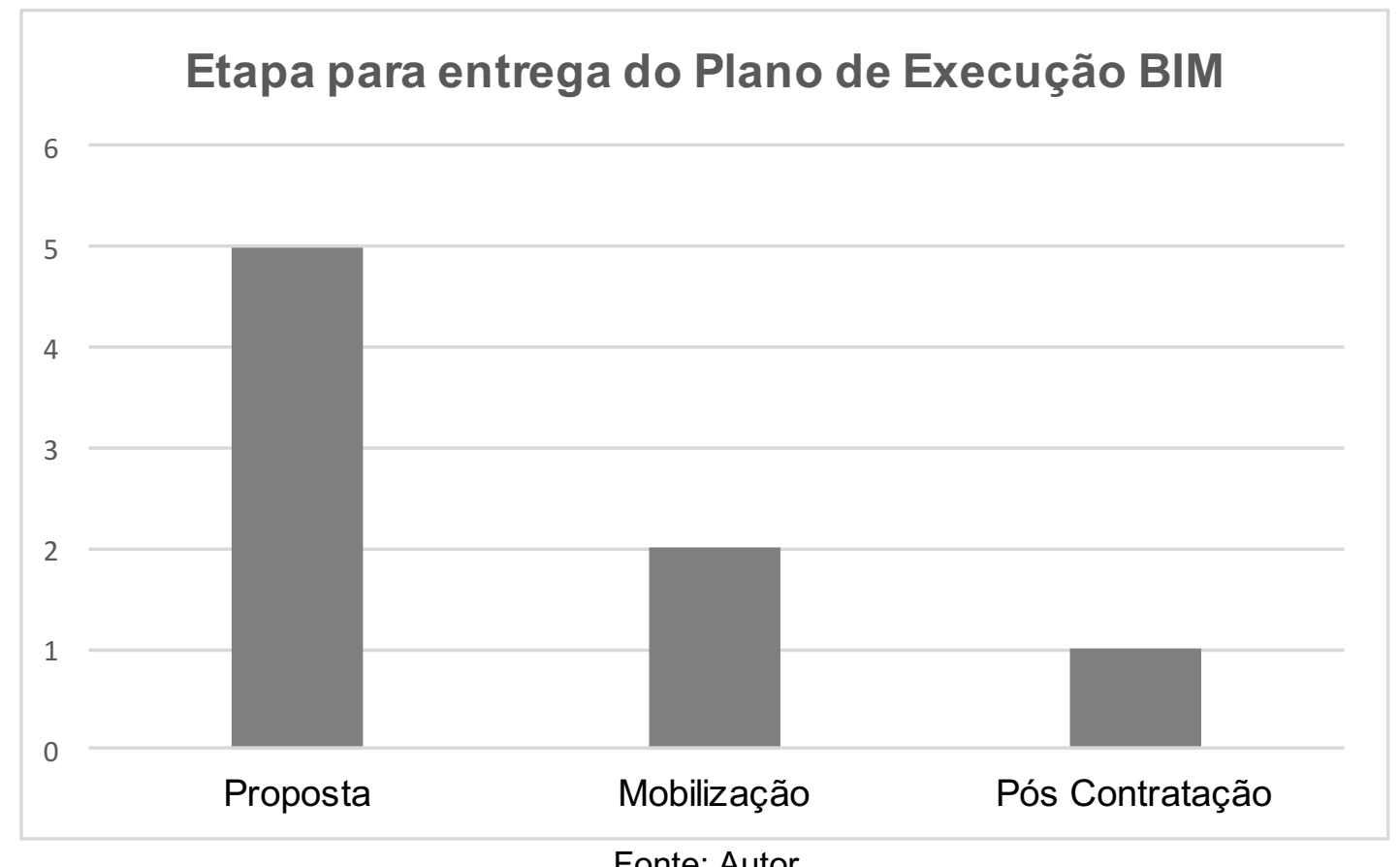

Fonte: Autor

Questionados sobre os itens fundamentais que devem constar no Plano de Execução BIM (Gráfico 26), os especialistas enfatizaram como relevância: 1) o plano de comunicação, nível de desenvolvimento, nível de representação gráfica, requisitos de projeto, definição das equipes; 2) interoperabilidade, fluxo de desenvolvimento, revisão e aprovação; 3) Georeferenciamento, objetivo do projeto, plano de sistema de gerenciamento do projeto e suporte técnico; e 4) matriz de responsabilidade e o uso do PMBOK.

Gráfico 26: Itens fundamentais que devem constar no Plano de Execução BIM

Itens fundamentais no Plano de Execução BIM

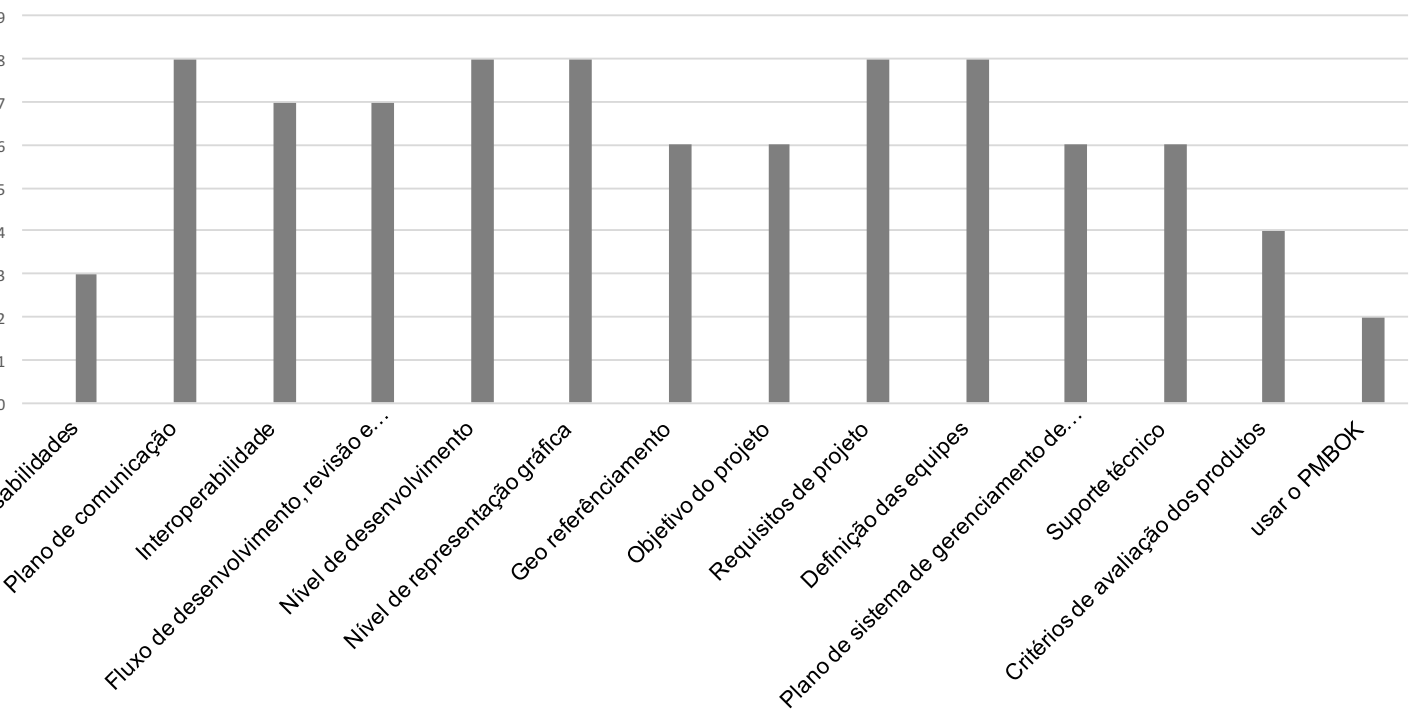

Fonte: Autor 
Referente a avaliação da capacidade técnica dos profissionais e das empresas, os especialistas enfatizaram o CAT (Certidão de Acervo Técnico) emitido pelos conselhos de classe (CAU e CREA) como principais instrumentos. Importante salientar que todos os especialistas presentes relataram a importância da verificação e validação, por especialistas, do material produzido em BIM para ser inserido no CAT emitidos pelos conselhos de classe dos engenheiros (CREA) e dos arquitetos e urbanistas (CAU).

Outros instrumentos foram citados pelos presentes como possíveis tipos de avaliação de capacidade técnica: 1) certificação BIM; 2) qualificação ISO; 3) certificação emitida pelos contratantes; 4) evidências de trabalhos similares; e 5) concursos públicos para desenvolvimento do projeto básico em BIM onde o contratante poderia avaliar tanto o atendimento do programa de necessidades quanto o nível de experiência BIM no modelo desenvolvido pelas partes interessadas.

Gráfico 27: Avaliação de Capacidade Técnica

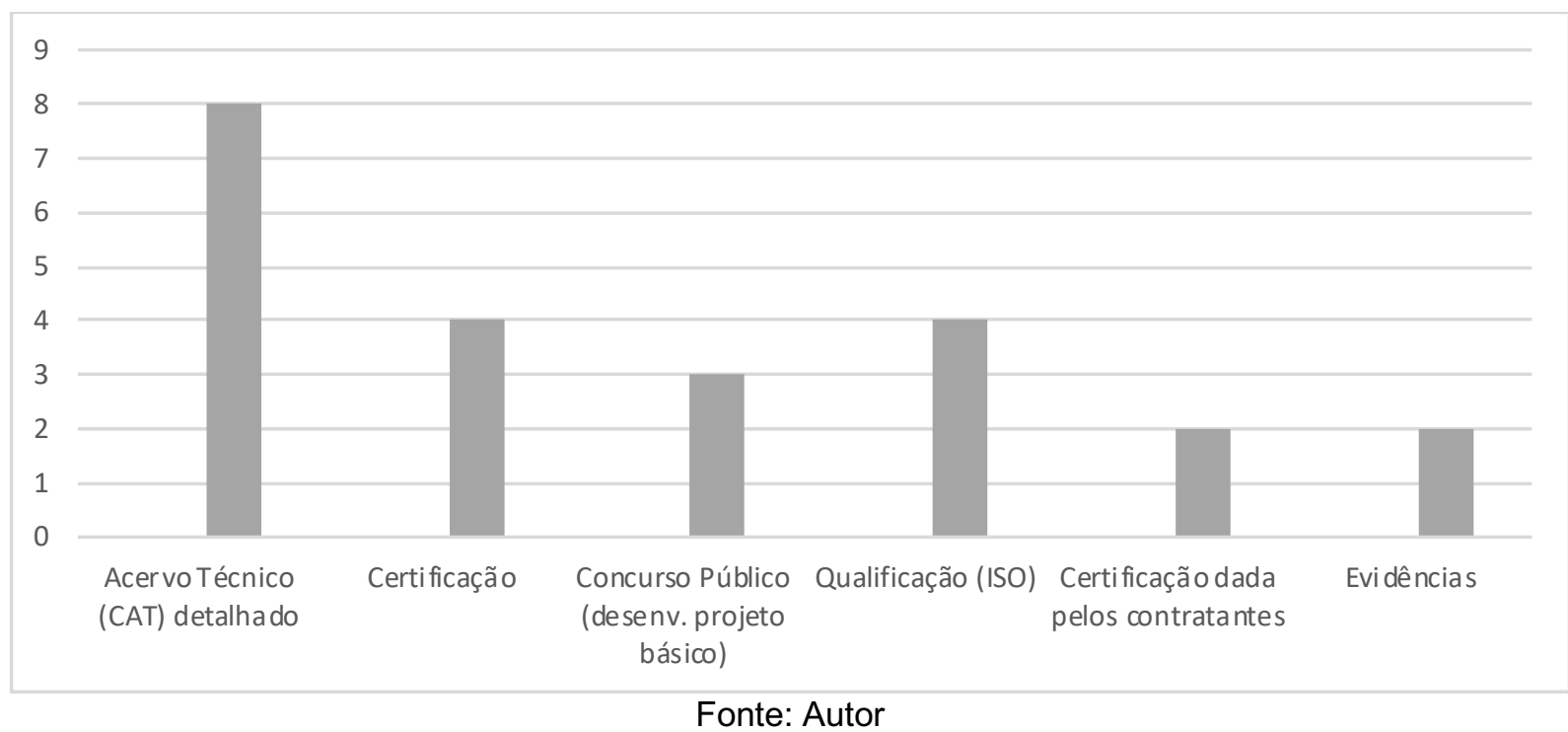

Fonte: Autor

As principais funções na gestão de informações BIM (Gráfico 28) levantadas pelos especialistas foram: 1) BIM manager; 2) gerente de $\mathrm{TI}$; 3) gerentes de planejamento, de risco e comunicação; 4) gerente de interfaces; e 5) gerentes de processos e controle. 
Gráfico 28: Principais funções na gestão de informações BIM

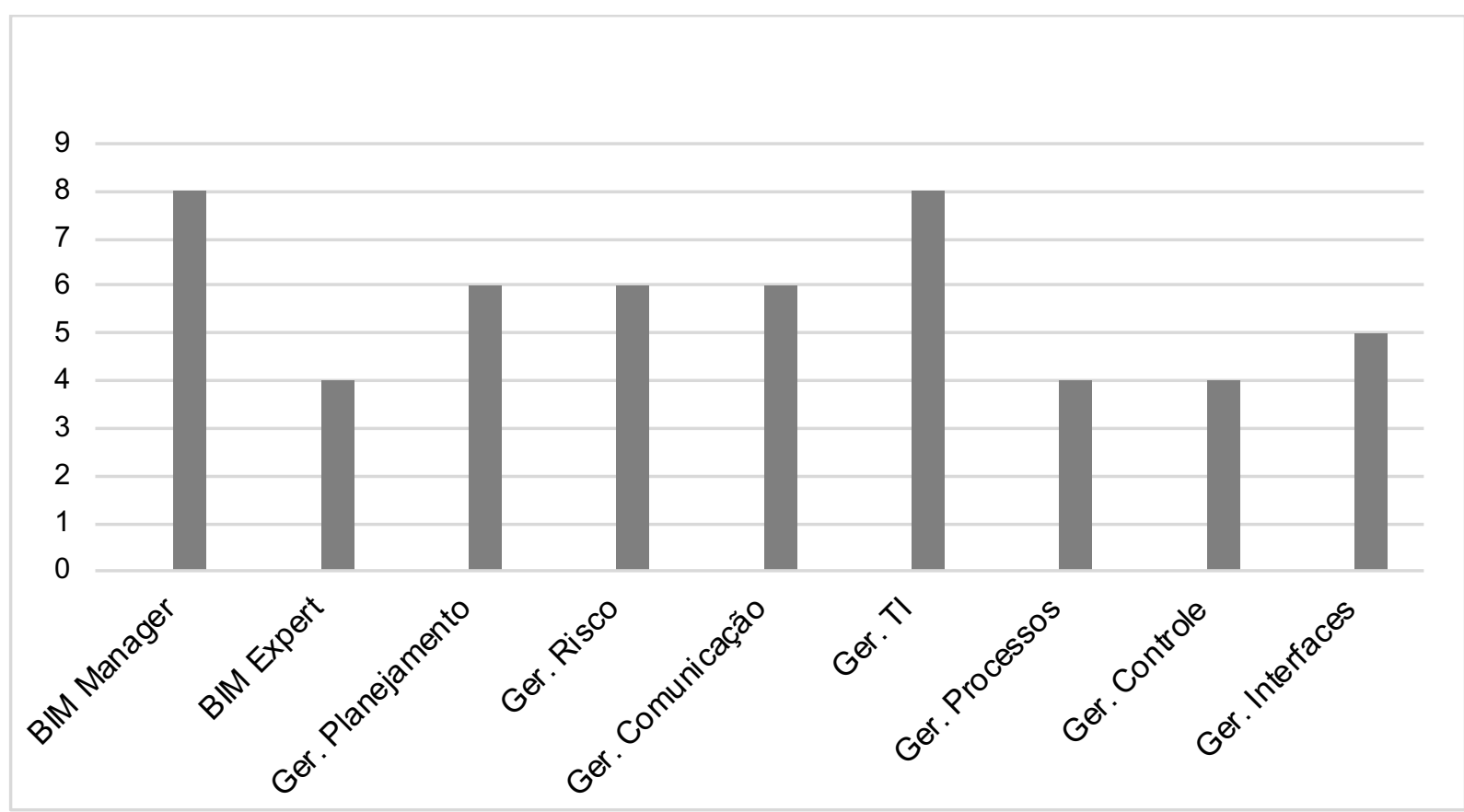

Fonte: Autor

Gráfico 29: Principais atividades na fase de Mobilização

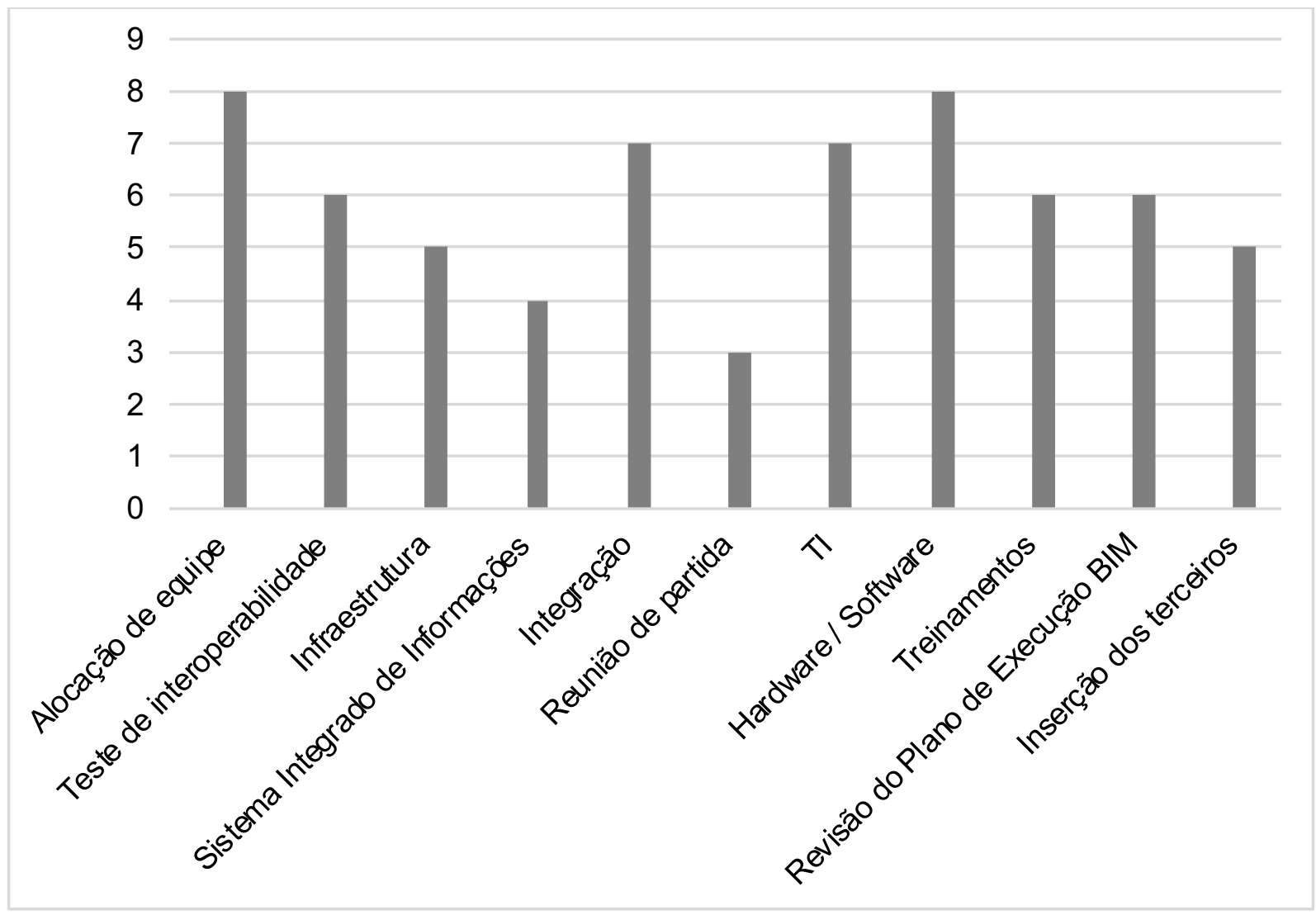

Fonte: Autor

As principais atividades levantadas pelos especialistas na fase de mobilização (Gráfico 29) foram: 1) alocação de equipe e de hardware/software; 2) integração entre 
todos os envolvidos no processo e a área de $\mathrm{TI}$; 3) treinamentos, a revisão do Plano de Execução BIM e o teste de interoperabilidade; 4) inserção de terceiros; e 5) o sistema de integrado de informações.

Quando questionados sobre o fluxo mais adequado que deve existir em um sistema de gerenciamento de informações, os especialistas apresentaram informações que deram base para o desenvolvimento do Fluxograma 1 apresentado abaixo.

Fluxograma 1: Fases apropriadas que devem estar presentes em um sistema de gerenciamento de informações

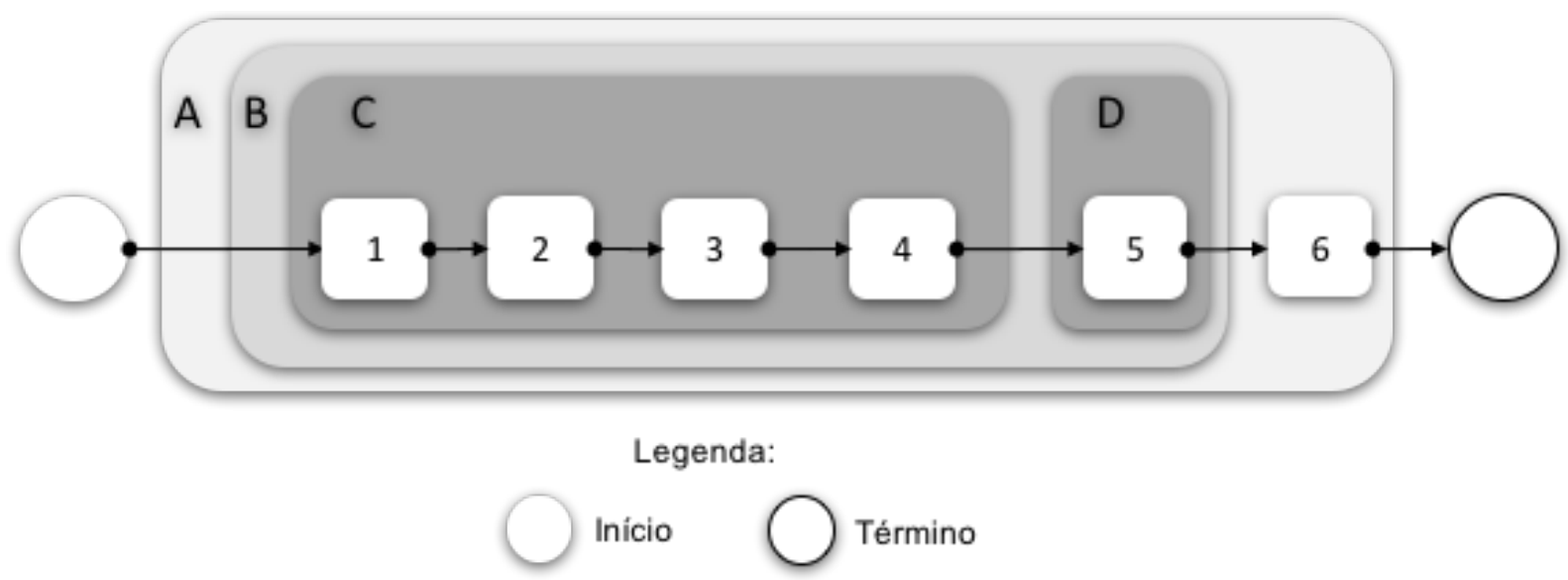
A. Sistema Integrado de Informaçöes;
B. Ambiente de gestäo;
C. Ambiente de trabalho interno de cada disciplina; $e$
D. Ambiente de publicaçäo de informaçäo.

1. Produção;

2. Verificação;

3. Revisão;

4. Aprovação;

5. Publicaçăo;e

6. Uso da Informação.

Fonte: Autor

Importante salientar que todos os especialistas indicaram a importância do ambiente de publicação dos produtos aprovados para que se evite a utilização, pelos integrantes das diversas equipes do projeto, de informações que ainda estão na fase de desenvolvimento, revisão ou em fase de aprovação.

Desta forma, através da coleta dos dados obtidos nas discussões e comentários feitos pelos especialistas presentes na atividade desenvolvida, foi possível consolidar os dados e utiliza-los como base para validação e complemento dos itens pertencentes no PNBIM como pode ser visto na Tabela . 
Tabela 12: Comparativo entre tópicos entre o Piloto PNBIM e após comentários levantados pelo Grupo Focal

\begin{tabular}{|c|l|}
\hline Proposta Inicial & $\begin{array}{c}\text { Comentários levantados no Grupo } \\
\text { Focal e inseridos no PNBIM }\end{array}$ \\
\hline Não havia & $\begin{array}{l}\text { Termo de Referênca: lançamento de } \\
\text { concursos públicos em parceria com o } \\
\text { Conselho de Arquitetura e Urbanismo (CAU) } \\
\text { para desenvolvimento de projetos (design) }\end{array}$ \\
\hline Não havia & Plano de Execução BIM: Worksets de trabalho \\
\hline Navia & Plano de Execução BIM: Exportação de layers \\
\hline $\begin{array}{l}\text { Disponibilização do Ambiente Comum de } \\
\text { Dados (CDE): a aquisição e instalação deve } \\
\text { ocorrer pelo Contratante no início da } \\
\text { contratação }\end{array}$ & $\begin{array}{l}\text { Disponibilização do Ambiente Comum de } \\
\text { Dados (CDE): a aquisição e instalação deve } \\
\text { ocorrer na fase de Mobilização }\end{array}$ \\
\hline
\end{tabular}

Fonte: Autor 


\section{CONCLUSÕES E TRABALHOS FUTUROS}

Como resultante, este trabalho, baseado na norma internacional ISO 19650 e nas práticas nacionais atuais desenvolvidas pelos agentes da cadeia da construção, disponibiliza ao mercado um protocolo de gerenciamento BIM nas fases de contratação, projeto (design) e obra em empreendimentos civis. Através do estudo é possível verificar que atividades pertencentes à cadeia da construção civil nacional tais como desenvolvimento do termo de referência, da licitação e da proposta - devem ser melhor estruturadas a fim de clarificar o processo de contratação, produção, gerenciamento e entrega das informações e dados BIM.

Na medida que a utilização do BIM altera as práticas tradicionais da construção no que se refere aos processos, forma de trabalho, comunicação e principalmente no modelo de negócio entre contratantes e contratados, é necessário que mudanças sejam implantadas em todo o ciclo de atividades para que, através do trabalho colaborativo no desenvolvimento de modelos BIM integrados utilizando ambientes virtuais, se possa obter a máxima vantagem na extração de informações e dados necessários para a construção e operação de empreendimentos civis.

A ISO 19650 estabelece as diretrizes de como as atividades de gerenciamento BIM devem ser desenvolvidas durante a etapa do CAPEX e traz instrumentos fundamentais para que se possa obter o sucesso nas contratações que demandem BIM como base de suas atividades. O Plano de Execução BIM, o Ambiente Comum de Dados (CDE) e a utilização do COBie são alguns itens base na norma que demonstram como a correta estruturação dos parâmetros permitem que o fluxo de informações, iniciado em etapas de projeto (design), possa ser utilizado na etapa de O\&M do empreendimento.

Atualmente, no Brasil, como mostrado neste trabalho, já há numerosas solicitações que demandam o BIM no desenvolvimento de atividades presentes na cadeia da construção civil para cumprimento do escopo contratado. Normas, guias e protocolos estão disponíveis no mercado nacional onde o foco principal dos documentos está no desenvolvimento de modelos para possibilidade de extração da documentação gráfica dos produtos de projeto (design) para serem utilizados na etapa de obra. Entretanto, o mercado da construção nacional é carente de orientativos específicos referentes às atividades de desenvolvimento, de gerenciamento e da entrega das informações e dos dados integrantes do BIM. 
Para se obter todos os benefícios possíveis a partir da utilização do BIM, é necessário que padronizações de desenvolvimento, gerenciamento e de uso das informações e dados sejam claramente definidas ainda da fase de contratação. Desta forma, fatores como implantação e gestão das informações e dados são partes integrantes do documento denominado Protocolo Nacional BIM (PNBIM) que é uma ferramenta que deve ser utilizada por todos os envolvidos no gerenciamento das atividades constantes na cadeia da construção quando a contratação demandar a utilização do BIM para o atendimento do escopo contratado.

Através da realização da atividade do Grupo Focal com a presença de especialistas que atuam no mercado, foi possível coletar os dados que serviram de validação ao conteúdo no PNBIM relevantes à gestão das informações e dados BIM durante as fases de contratação, produção e entrega de serviços BIM pertencentes a cadeia da construção civil.

Como constatado neste trabalho, o BIM apresenta uma grande oportunidade de melhora no desenvolvimento, organização e controle das informações e dados gerados durante a fases de contratação, projeto e da obra em empreendimentos civis.

Durante a fase de levantamento dos dados e desenvolvimento do conteúdo deste documento, foram levantadas oportunidades para futuras pesquisas sobre pontos que ainda necessitam de desenvolvimento. Abaixo estão listadas sugestões para possíveis pesquisas no setor da construção civil com base nos trabalhos BIM:

- Testar o Protocolo Nacional BIM (PNBIM) em um projeto real para validação de seu conteúdo;

- Desenvolvimento de documento com os requisitos a serem utilizados para a implantação, desenvolvimento e gerenciamento das informações e dados no Ambiente Comum de Dados (CDE) na fase do CAPEX;

- Desenvolvimento de metodologia para avaliação das soluções disponíveis no mercado a serem utilizadas em cada etapa na fase do CAPEX (design, planejamento, controle) que se integrem ao $\mathrm{CDE}$;

- Levantamento e análise das ferramentas e soluções disponíveis a serem utilizadas em cada etapa na cadeia da construção civil (design, planejamento, gerenciamento, controle) que se integrem ao $\mathrm{CDE}$;

- Estudo de viabilidade para abertura de concursos públicos para desenvolvimento de projetos básicos de arquitetura em BIM através de convênios entre os contratantes e conselhos profissionais, tais como o CAU (Conselho de Arquitetos e Urbanistas); e 
- Análise do COBie e proposição de diretrizes nacionais com requisitos mínimos necessários por tipo de empreendimento para dar suporte à utilização das informações geradas pelo BIM na fase de O\&M. 


\section{REFERÊNCIAS}

AMCA. BIM-MEP AUS: Practices \& Specifications e Workflows, 2012. Disponível em: <http://www.bimmepaus.com.au/>. Acesso em: 15 ago. 2015.

AURICCHIO, C. E. P. Antecipando o futuro. $11^{\circ}$ Congresso Brasileiro da Construção - ConstruBusines. São Paulo: FIESP, 09, mar. 2015.

BARBOUR, R.; GRUPOS FOCAIS - Tradução Marcelo Figueiredo Duarte. Bookman $-2009$.

BRITISH STANDARDS INSTITUTION. PAS 1192-2: 2013 Specification for information management for the capital/delivery phase of construction projects using building information modelling. The British Standards Institution, 2013. Disponível em: <http://shop.bsigroup.com/Navigate-by/PAS/PAS-1192-22013/>. Acesso em: 15 dez. 2015.

BOLPAGNI, M. B. Faces of “LOD”. BIM Think Space. 19 Jul 2016, Disponível em: < http://www.bimthinkspace.com/2016/07/the-many-faces-of-lod.html>. Acesso em: 12 fev. 2018.

BRODT, W; EAST, E. W; KIRBY, J. G. Prepared for the Government-Industry Forum: Engineering, Construction, and Facilities Asset Management: A Cultural Revolution, The National Academies, Washington, DC, 31 Outubro de 2006.

CAREZZATO, G. G.; BARROS, M. S. B.; SANTOS, E. T. BIM em gerenciadoras de empreendimentos de infraestrutura, 2016. XVI Encontro Nacional de Tecnologia do Ambiente Construído. Anais..., São Paulo:ANTAC, Novembro de 2016.

CATELANI, W. S.; SANTOS, E. T. Normas Brasileiras sobre BIM. Revista CONCRETO \& Construções, n.84, p.54-59, 2016.

CHAVES, F. J; TZORTZOPOULOS, P; FORMOSO, C. T.; SOMMER, L. Implementação de BIM: comparação entre as diretrizes existentes na literatura e um caso real. In: Encontro Nacional de Tecnologia do Ambiente Construído, 2014, Maceió. Anais..., Maceió: ANTAC p. 1468-1477. Disponível em: <http://www.infohab.org.br/entac2014/anais.html) >. Acesso em: 15 dez. 2015.

CIC. BUILDING INFORMATION MODEL (BIM) PROTOCOL: Standard Protocol for use in project using Building Information Models, 2013. BIM Standards. Disponível em: <http://www.bimtaskgroup.org/bim-protocol/>. Acesso em: 15 dez. 2015.

CIC. CIC Building Information Modelling Standards Draft 6.1. Construction Industry Council, BIM Standards. 2014.

CPTM - COMPANHIA PAULISTA DE TRENS METROPOLITANOS. O USO DO BIM EM PROJETOS DE ESTAÇOES FERROVIARIAS - Experiência na prática - CPTM. 23a SEMANA DE TECNOLOGIA METROFERROVIARIA. $4^{\circ}$ PREMIO TECNOLOGIA E DESENVOLVIMENTO METROFERROVIARIOS - CATEGORIA 3, 2017, São Paulo. Disponível em: <http://www.aeamesp.org.br/blog/2017/09/27/t64-o-uso-bim-em- 
projetos-de-estacoes-ferroviarias-experiencia-na-pratica-cptm-nas-acoes-de-gestaoda-manutencao/>. Acesso em: 13 fev. 2018.

DELATORRE, J. P. M., SANTOS, E. T. Introdução de novas tecnologias: o caso do BIM em empresas de construção civil. In: XV Encontro Nacional da Tecnologia do Ambiente Construído, 2014, Maceió. Anais... Maceió: UFAL, 2014. p. 2842-2851.

EAST, W. E. Construction Operations Building Information Exchange (COBIE): Requirements Definition and Pilot Implementation Standard, 2007. Disponível em: <handle.dtic.mil/100.2/ADA491932>. Acesso em: 15 ago. 2015.

EASTMAN, C.; TEICHOLZ, P.; SACKS, R.; LISTON, K. BIM Handbook: A Guide to Building Information Modeling for Owners, Managers, Designers, Engineers and Contractors, 2nd Edition. John Wiley \& Sons, Inc., 2011.

FDE - FUNDAÇÃO PARA O DESENVOLVIMENTO DA EDUCAÇÃO. Relatório do Grupo de Trabalho Relativo a tecnologia BIM. GT-BIM - Grupo de Trabalho relativo à Tecnologia BIM. Março 2017. Disponível em: < http://www.fde.sp.gov.br/PagePublic/InternaNoticias.aspx?codNoticia=774\&codigoMe nu=49\&AspxAutoDetectCookieSupport=1>. Acesso em: 13 fev. 2018.

FIOCRUZ I - Ministério da Saúde. Fundação Oswaldo Cruz. Contratação para elaboração de estudo preliminar, anteprojeto e projeto executivo de arquitetura e engenharia da nova sede do centro de pesquisa René Rachou no polo tecnológico de Belo Horizonte - FIOCRUZ MINAS. RDC Presencial No 9/2014. Disponível em: < http://www.comprasnet.gov.br/ConsultaLicitacoes/download/ download_editais_detalhe.asp?coduasg=254462\&modprp=99\&numprp=92014>.

Acesso em: $12 \mathrm{fev} .2018$.

FIOCRUZ II - Ministério da Saúde. Fundação Oswaldo Cruz. Contratação de gerenciamento de empreendimento (fiscalização dos projetos de arquitetura e engenharias, apoio à licitação, planejamento e fiscalização das obras e acompanhamento da operação assistida) para a implantação da nova sede do centro de pesquisa René Rachou no polo tecnológico de Belo Horizonte FIOCRUZ MINAS. RDC Presencial No 9/2014. Disponível em: < http://www.comprasnet.gov.br/ConsultaLicitacoes/download/download_editais_detalh e. asp? coduasg $=254462 \&$ modprp $=99 \&$ numprp $=92014>$. Acesso em: $1 \overline{2}$ fev. $2 \overline{0} 18$.

GU, N e LONDON, K. Understanding and facilitating BIM adoption in the AEC industry. Automation in Construction. v.19, [S.n], pag. 988-999, dec. 2010.

GSC. CADERNO DE APRESENTAÇÃO DE PROJETOS BIM. Governo de Santa Catarina. Secretaria de Estado do Planejamento. Diretoria de Planejamento. Comitê de Obras Públicas. 2014. Disponível em: < http://www.spg.sc.gov.br/visualizarbiblioteca/acoes/comite-de-obras-publicas/427-caderno-de-projetos-bim/file>. Acesso em 16 fev. 2018.

HAMIL, S. An Introduction to the NBS BIM Toolkit; Technical Support NBS BIM Toolkit; last updated 8 agosto 2016. Disponível em: < https://toolkit.thenbs.com/articles/an-introduction-to-the-toolkit/>. Acesso em: $15 \mathrm{dez}$. 2016. 
ISO/DIS 19650-1.2:2017 - Organization of information about construction works / Information management using building information modelling. Disponível em: $<$ https://www.iso.org/standard/68078.html>. Acesso em 30 jul. 2018.

JETCO. Joint Statement Brazil - United Kingdom; British Secretary of State for International Trade and his Brazilian counter partner emphasized the importance of current bilateral cooperation. Disponível em: <http:/l https://www.gov.uk/government/news/jetco-2016-joint-statement-brazil-unitedkingdom>. Acesso em 08 dez. 2016.

KASSEM, M. Building Information Modelling in the European Union: The case of the UK France and the Netherlands. FIESP - SECONCIC Seminar. 2014.

KASSEM, M.; AMORIM, S. R. L. BIM: BUILDING INFORMATION MODELING no Brasil e na União Européia. MDIC/UE. Brasília, p. 162. 2015.

KASSEM, M.; SUCCAR, B.; DAWOOD, N. A proposed approach to comparing the BIM maturity of countries. Proceedings do CIB W78 2013, 30th International Conference. Pequim, China: 9-12, out. 2013.

KASSEM, M.; SUCCAR, B.; DAWOOD, N. Building Information Modeling: Analyzing Noteworthy Publications of Eight Countries Using a Knowledge Content Taxonomy. In: ASCE Building Information Modeling: Aplications and Practices. Gainesville, FL: University of Florida, 2015. Cap. 13, p. 329-371.

LEHTIRANTA, L., JUNNONEN, J.M., KÄRNÄ, S., PEKURI, L. The Constructive Research Approach: Problem Solving for Complex Projects. Chapter 8 of (9781-4094-4880-8) by Beverly Pasian, (DATA). Disponível em: $<$ http://www.gpmfirst.com/books/designs-methods-and-practices-research-projectmanagement/constructive-research-approach>. Acesso em 09 jan. 2016.

LUKKA, K. The Constructive Research Approach. Metodix, 2014. Disponível em: $<w w w . m e t o d i x . c o m / e n / s i s a l l y s / 01$ menetelmat/02_metodiartikkelit/lukka_const_rese arch_app/kooste>. Acesso em: $14 \mathrm{dez} .2015$.

MAINARDI NETO, A. I. B. O BIM chegou à primeira estação: Ponte Grande. 21 Semana de Tecnologia Metroferroviária - $2^{\circ}$ Prêmio Tecnologia e Desenvolvimento Metroferroviários. Categoria 3 - Tecnologias de implantação, operação e manutenção de sistemas de transportes, Junho de 2015. Disponível em: < http://www.aeamesp.org.br/biblioteca/stm/21sml10rl.pdf>. Acesso em: 10 dez. 2016.

MAINARDI NETO, A. I. B.; SANTOS, E. T. Verificação de regras em modelos BIM: um estudo de caso sobre projeto de arquitetura de estações metroviárias. VII Encontro de Tecnologia de Informação e Comunicação na Construção, Anais..., Recife, Novembro de 2015.

MAY, I;TAYLOR, M; IRWIN, D. Crossrail: A Case Study in BIM, Conferência Internacional BIM - BIC. São Paulo, Brasil: 29-30, set. 2016. Disponível em: <https://drive.google.com/drive/folders/0B1hdnRcRR5YHQ2d1NmFuMVhYSmM>. Acesso em: 10 dez. 2016. 
MATTHEWS, A. UK BIM Level 2, Sixth Society of Construction Law International Biennial Conference. São Paulo, Brasil: 13-15, set. 2016

MCGRAW-HILL. Detailed Findings Non-Users of BIM, jul. 2009. Disponível em: $<$ http://www.bim.construction.com/research/pdfs/2009_BIM_Non-Users_of_BIM.pdf>. Acesso em: 15 ago. 2015.

MCGRAW-HILL. The business value of BIM for Construction in Global Markets. McGraw-Hill Construction. Bedford, MA, E.U.A. 2014.

MASCENA, E. Licitação conceito e finalidade. Dez 2017. Disponível em: < https://dremanuelmascena.jusbrasil.com.br/artigos/437367557/licitacao-conceito-efinalidade>- Acesso em: jan. 2018

MDIC - Ministério da Indústria, Comércio Exterior e Serviços. Decreto cria comitê estratégico para a disseminação do BIM no Brasil. Disponível em:< http://www.mdic.gov.br/index.php/noticias/2543-decreto-cria-comite-estrategico-paraa-disseminacao-do-bim-no-brasil>. Acesso em 16 jan 2018.

MORAIS, M. de. Método para Implantação de BIM e custeio-meta em Habitação de Interesse Social. Tese de Doutorado apresentada a Faculdade de Engenharia Civil, Arquitetura e Urbanismo da Unicamp para obtenção de títudo de Doutor em Engenharia Civil na área de Arquitetura e Construção. 27 de julho de 2016.

NBS. The IFC/COBie Report 2012 Disponivel em: < https://www.thenbs.com/knowledge/ifc-cobie-report-2012>. Acesso em: 10 dez. 2016.

NBS. What is the Common Data Environment (CDE). Disponivel em: $<$ https://www.thenbs.com/knowledge/what-is-the-common-data-environment-cde>. Acesso em: 10 dez. 2016.

NBS. BIM Toolkit - Introducing the BIM Toolkit from NBS. Disponível em: < https://www.thenbs.com/services/our-tools/nbs-bim-toolkit>. Acesso em: $10 \mathrm{dez}$. 2016.

NASCIMENTO, L. A.; SANTOS, E. T. A indústria da construção na era da inovação. Ambiente Construído, Porto Alegre, v. 3, n. n. 1, jan./mar. 2003. p. 69-81.

NEXAAS. 3 dicas para a elaboração de um contrato de prestação de serviços. Disponível em: < http://nexaas.com/blog/3-dicas-para-a-elaboracao-de-um-contratode-prestacao-de-servicos/>. Acesso em: jan. 2018.

OLIVEIRA, A. R.; LEITE FILHO, C. A. P.; RODRIGUES, C. M. C. - O Processo de Construção dos Grupos Focais na Pesquisa Qualitativa e suas Exigências Metodológicas - Anais..., XXXI Encontro ANPAD - Rio de Janeiro de 22 a 26 de setembro de 2007. 
OYEGOKE, A. The constructive research approach in project management research. International Journal of Managing Projects in Business, Vol. 4 No. 4, 2011. p. 573595.

PRATES, R.O.; BARBOSA, S.D.J. (2003) Avaliação de Interfaces de Usuário Conceitos e Métodos Anais do XXIII Congresso Nacional da Sociedade Brasileira de Computação. XXII Jornadas de Atualização em Informática (JAI). Anais..., SBC 2003. Agosto de 2003.

RICS. Building Information Modelling for Project Managers. Publicado pelo Royal Institute of Chartered Surveyors. Maio 2017. Disponível em: < http://www.rics.org/us/knowledge/research/insights/bim-for-project-management/>. Acesso em: 13 fev. 2018.

SILVA, F. A. C. Construtoras, entidades setoriais e fornecedores se mobilizam e aumentam uso do processo de Modelagem da Informação da Construção no País. Construção Mercado, n. 162, jan. 2015. Disponível em: $<$ http://construcaomercado.pini.com.br/negocios-incorporacaoconstrucao/162/construtoras-entidades-setoriais-e-fornecedores-se-mobilizam-eaumentam-uso-335413-1.aspx>. Acesso em: 16 ago. 2015.

SEIL; GOVERNO DO ESTADO DO ARANÁ. Histórico. Portal BIM Paraná. Disponível em: $\quad<$ http://www.bim.pr.gov.br/modules/conteudo/conteudo.php? conteudo=1>. Acesso em: 10 jan. 2017.

SMITH, P. BIM implementation - global strategies. Procedia Engineering, v.85, p. 482-492, 2014.

SUCCAR, B. Building information modeling framework: A research delivery foundation for industry stakeholders. Automation in Construction, 18, 2009. 357-375.

SOUZA, L. L. A.; AMORIM, S. R. L.; LYRIO, A. M. Impactos do uso do BIM em escritórios de Arquitetura: Oportunidades no mercado imobiliário. Gestão \& Tecnologia de Projetos, vol. 4, n. $n^{\circ} 2$, nov. 2009. p. 26-53.

VAN AKEN, J. E. Management Research Based on the Paradigm of the Design Sciences: The Quest for Field-Tested and Grounded Thechnological Rules. Journal of management studies, v.41, n. 2, march 2004, p. 219-246, 2004.

TAYLOR, M. Crossrail: A Case Study in BIM, Conferência Internacional BIM - BIC. São Paulo, Brasil: 29-30, set. 2016. Disponível em:

<https://drive.google.com/drive/folders/OB1hdnRcRR5YHQ2d1NmFuMVhYSmM>. Acesso em: 10 dez. 2016.

TCEMG - Tribunal de Contas do Estado de Minas Gerias. Como Elaborar Termo de Referência ou Projeto Básico - O impacto do Termo de Referência (TR) ou Projeto Básico (PB) na eficácia das licitações e contratos administrativos. Minas Gerias, Brasil. Disponível em: <http://www.tce.mg.gov.br/img/2017/Cartilha-Como-ElaborarTermo-de-Referencia-ou-Projeto-Basico2.pdf. Acesso em jan. 2018. 
WILSON, W.S. e HENG, L. Building information modeling and changing construction practices. Automation in Construction. v. 20, [S.n], pag. 99-100, mar. 2011. 


\section{APÊNDICE A - Protocolo Nacional BIM (PNBIM)}

\section{Introdução}

Atualmente no Brasil diversas são as solicitações dos contratantes públicos e privados que demandam o BIM para o desenvolvimento de atividades nas etapas de projeto (design) e obra. O principal foco de tais contratações está no desenvolvimento de modelos BIM para possibilidade de extração da documentação gráfica dos produtos de projeto (design) para serem utilizados na etapa de obra. Neste sentido, o mercado da construção nacional é carente de orientativos específicos referentes às atividades de desenvolvimento, de gerenciamento e da entrega das informações e dos dados integrantes do BIM.

Com base no estudo da norma ISO19650:2017 e o comparativo com o mercado nacional, é possível identificar que as utilizações das mesmas no setor da construção civil brasileira podem ser aplicadas. Entretanto, ações devem ser iniciadas e procedimentos devem ter seu desenho atualizado para que as orientações da ISO possam ser seguidas no mercado nacional.

A norma internacional ISO19650:2017 orienta todos os envolvidos de um projeto em como os trabalhos em BIM devem ser contratados, desenvolvidos de forma colaborativa e entregues aos contratantes e ocupantes do empreendimento.

Este protocolo foca a entrega das informações em três macro fases no fluxo do desenvolvimento do empreendimento que vai desde a etapa de início do CAPEX, passando pela contratação, desenvolvimento colaborativo e arquivamento das informações e dados. Dentro destas fases são apresentadas micro fases que descrevem atividades e desenvolvimento de documentações que em sua maior parte já são presentes no mercado nacional, mas algumas, como demonstra este documento, devem ser criadas para maximizar o gerenciamento de todo o processo pertencente ao ciclo de empreendimentos tanto dos setores público e privados.

O público-alvo deste documento inclui organizações e responsáveis pela contratação, concepção, construção, comissionamento, operação e manutenção de edifícios e de ativos de empreendimentos civis. Todas os pontos descritos neste documento possuem o objetivo de garantir de maneira macro os requisitos e processos a serem utilizados em contratos públicos e privados. É necessário que ajustes finos sejam acrescidos a este documento dependendo da necessidade de cada empreendimento. 


\section{Objetivo}

Este Protocolo Nacional BIM (PNBIM) tem como objetivo principal disponibilizar ao mercado da construção brasileira um documento técnico, com base no estudo dos dois volumes da norma ISO19650:2017, com orientações objetivas para todos os envolvidos no processo de contratação, desenvolvimento dos projetos (design) e a construção de empreendimentos civis que possuem em seu escopo o BIM como metodologia de trabalho.

\section{Atividades macro para produção de informações e dados}

Para haver um melhor entendimento do conteúdo deste Protocolo, o mesmo está dividido em 3 macro fases principais: 1) Contratação; 2) Produção Colaborativa; e 3) Entrega. Cada fase representa a uma etapa pertencente à cadeia produtiva da construção civil nacional para desenvolvimento de empreendimentos tanto na área pública quanto na privada. (Fluxograma 2)

Fluxograma 2: Relacionamento das atividades macro para produção de informações.

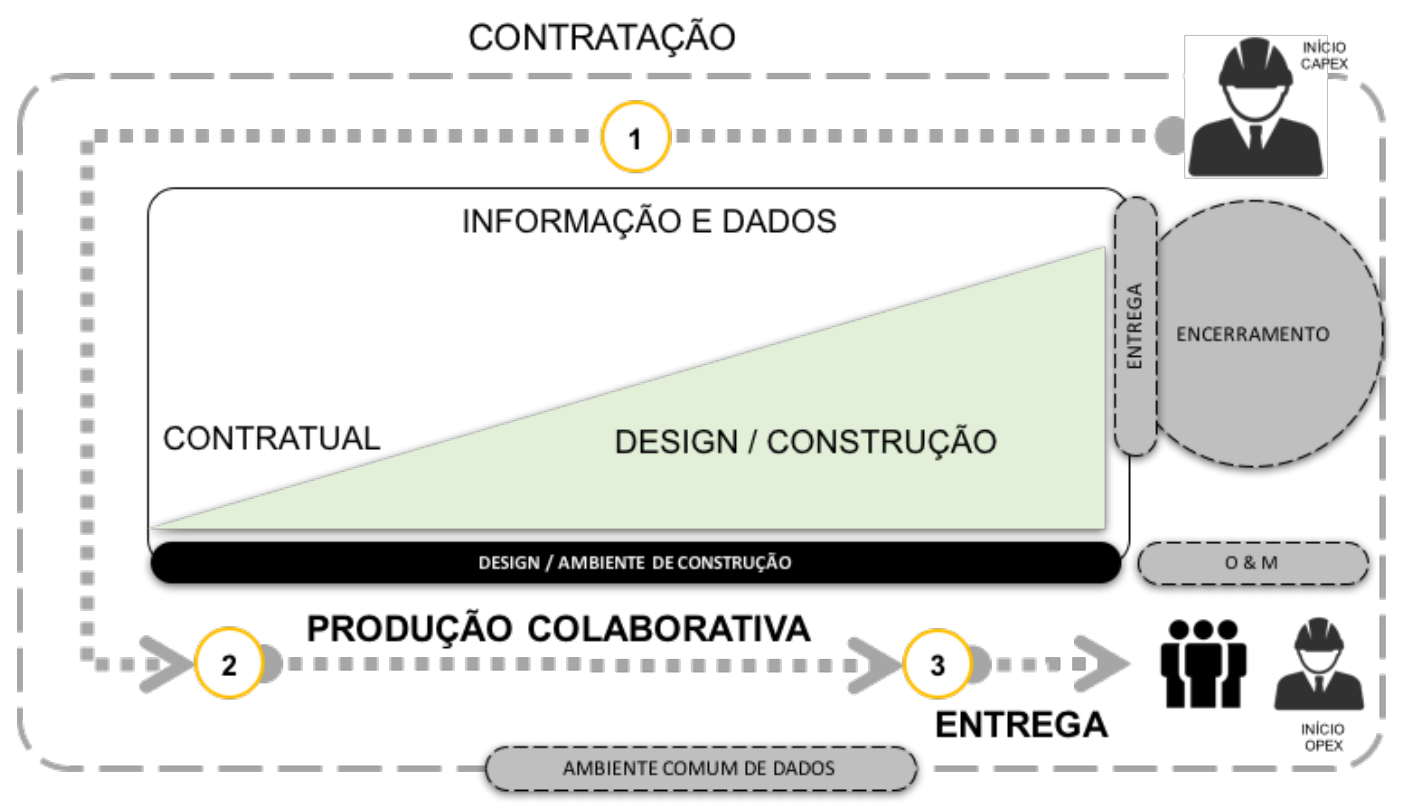

Fonte: Autor

- Contratação: tem como objetivo contratar as empresas e consultores com a melhor competência no mercado para gerenciar e desenvolver as informações e dados exigidos pelo contratante. 
- Produção Colaborativa: tem como objetivo gerenciar o desenvolvimento e organização das informações e dados BIM que aumentam de complexidade ao longo das fases de projeto (design) e de obra, tudo isso dentro de um sistema padronizado que deva possibilitar o trabalho colaborativo entre todos os envolvidos no processo ao longo da cadeia produtiva do empreendimento.

- Entrega: tem como objetivo entregar todas as informações e dados, documentos e modelos digitais de forma organizada que possam ser utilizadas pelos contratantes ou seus contratados para o gerenciamento de ativos e operação dos empreendimentos.

\section{Micro atividades e responsabilidades relacionadas na produção e gerenciamento das informações e dados}

Para melhor exemplificar o fluxo das atividades e documentos macro que devem ser gerados e disponibilizados durante o ciclo de desenvolvimento de informações e dados BIM em um empreendimento, as macro etapas apresentadas neste protocolo foram divididas como pode ser observado no Fluxograma 3.

Desta forma, espera-se que o leitor obtenha o entendimento sob a importância e complexidade existentes em cada etapa do processo quando é necessária a utilização do BIM dentro do processo de desenvolvimento de informações e dados em um empreendimento.

Antes de serem cobertos os conteúdos de cada documento existente nas micro fases pertencentes ao processo, é necessário entender as responsabilidades individuais de cada setor envolvido. 
Fluxograma 3: Subfases relacionadas ao fluxo do desenvolvimento de informações e dados BIM do empreendimento.

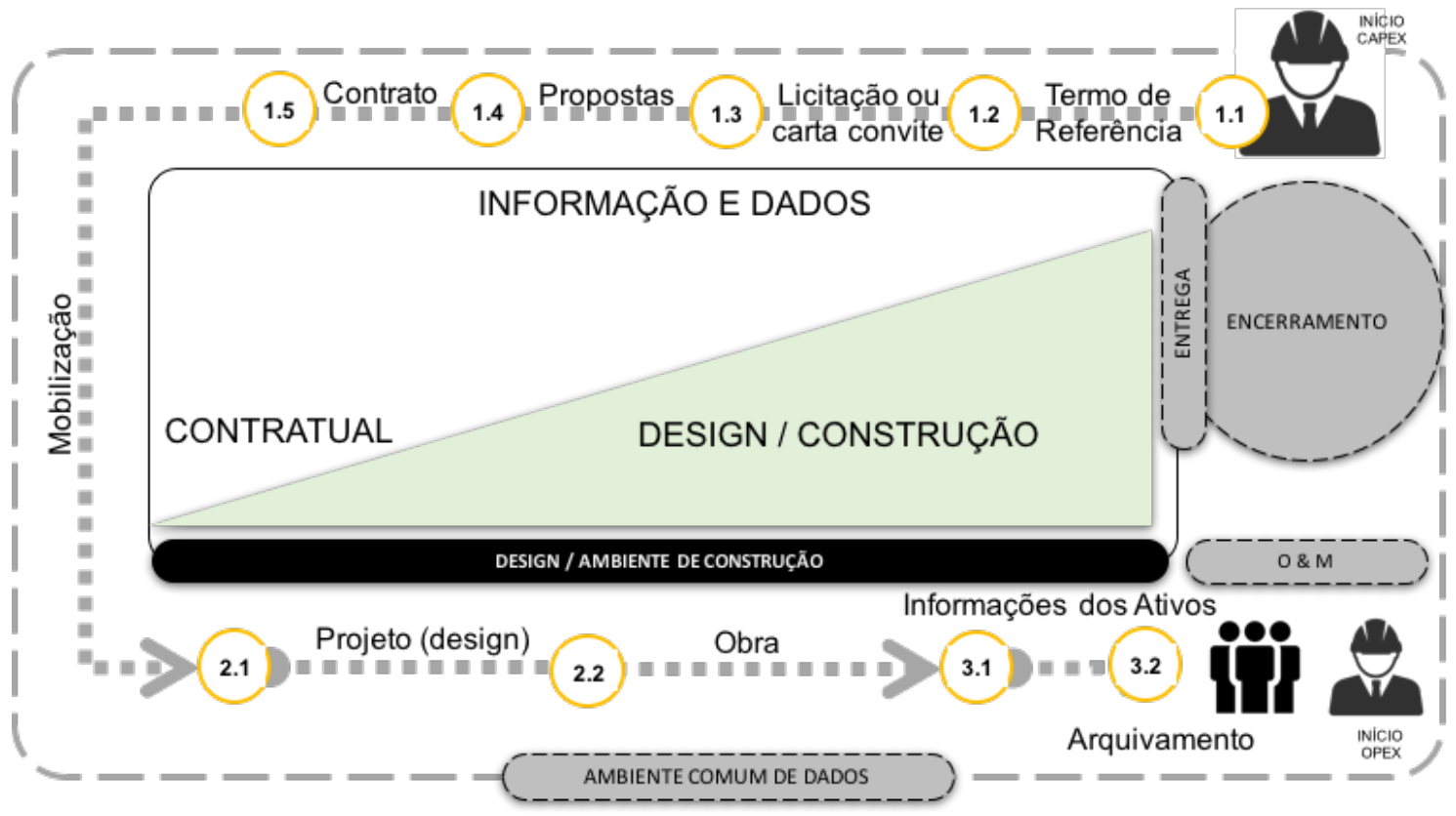

Fonte: Autor

Conforme apresentado abaixo, diversos são os profissionais necessários para que o desenvolvimento, controle e gerenciamento das atividades exigidas com o BIM sejam executadas da maneira esperada. Estes profissionais estão divididos em 3 grupos: 1) equipe de projeto; 2) equipe de entrega; e 3) equipe de desenvolvimento (Figura 17).

Figura 17: Relacionamento de interação entre as partes interessadas

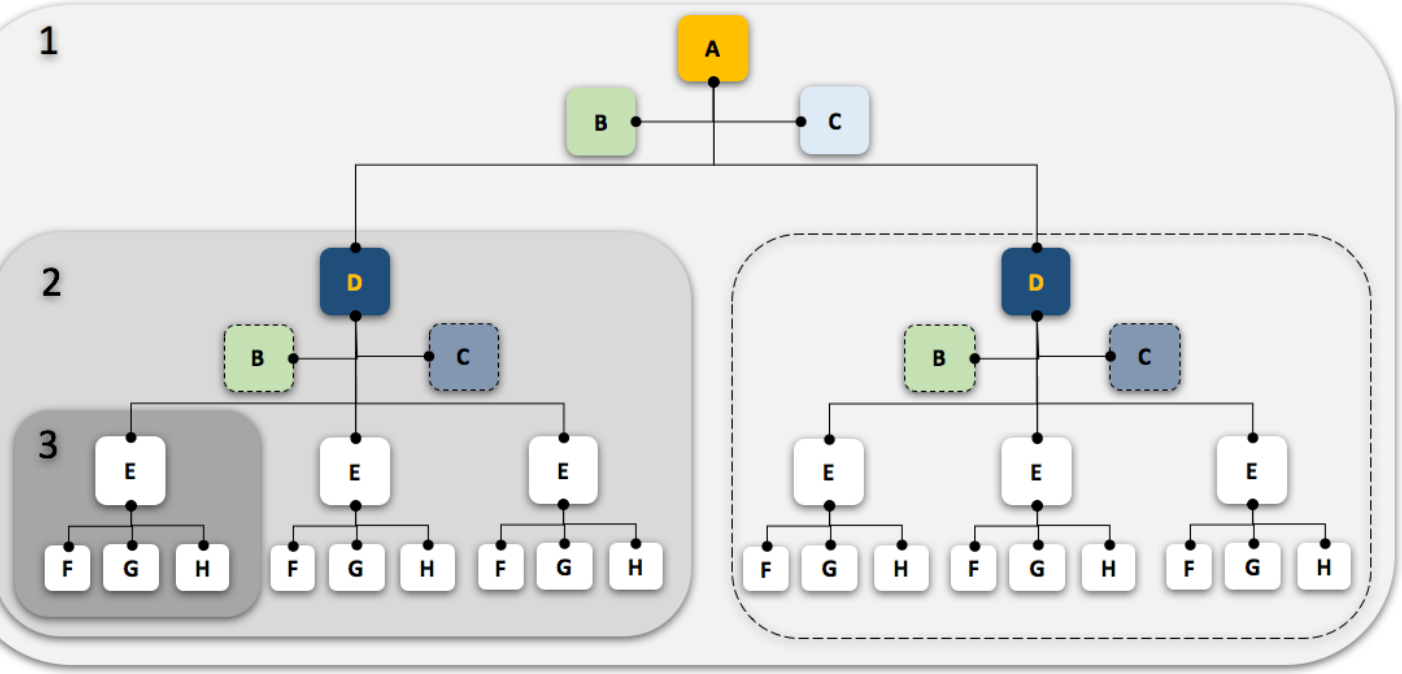

Fonte: Adaptado da ISO19650 
Os agentes de cada grupo têm como responsabilidade:

A. Patrocinador do projeto: é o responsável geral por todas as atividades contratadas.

B. Gerente de informações do projeto: tem como responsabilidade definir requisitos do projeto, estabelecer confiabilidade na troca de informações através do sistema de dados e as ferramentas de gerenciamento de dados, garantir a interação e a coordenação das informações com os modelos BIM, configurar as informações para a produção do projeto e determinar os formatos para a troca das informações e dados entre os modelos BIM.

C. Gerente de entrega das informações e dados do projeto: dirige a produção das informações e dados em concordância com os padrões, métodos e procedimentos de acordo com os sistemas acordados.

D. Líder de entrega das equipes envolvidas: tem como responsabilidade definir processos internos do contratante, produzir material de apoio tais como, guias normas e padrões com base nas especificações do contratante.

E. Gerente de produção de cada disciplina: é responsável pelo cumprimento de todas as atividades conforme o acordado em contrato.

F. Gerente de produção das informações e dados: é responsável pelo desenvolvimento de todas as informações e dados conforme contratado.

G. Gerente de interfaces: é responsável pela coordenação dos protocolos de comunicação, treinamentos e mapeamento de competências BIM entre todos os envolvidos.

H. Autor das informações: desenvolve modelos com informações e dados consistentes em conformidade as atividades especificadas. 


\section{Documentações por fases}

\section{Termo de Referência}

O Termo de Referência (TR) é um instrumento obrigatório para toda contratação pública sendo desenvolvido a partir de estudos técnicos devendo conter todas as informações necessárias para caracterizar o objeto bem como as condições da licitação e da contratação (TCEMG; 2017). Mesmo com a característica apresentada acima, é indicado que o TR seja também desenvolvido e utilizado em contratações privadas.

Para o desenvolvimento das atividades necessárias com o foco de atingir o escopo proposto, com a utilização do BIM recursos, ações e informações devem ser incorporadas para subsidiar todos aqueles que possam se interessar pela concorrência. Pontos, como os citados abaixo, são fundamentais para garantir o bom entendimento a todos os envolvidos no processo.

- Informações técnicas e jurídicas: Tais informações devem ser padronizadas e devem conter no mínimo informações base tais como: 1) escopo do projeto; 2) atribuições gerais; 3) marcos; 4) responsáveis; e valores destinados a execução dos trabalhos referentes ao escopo apresentado.

- Informações padronizadas BIM do cliente: tem como objetivo levantar, ou em sua falta desenvolver, informações claras e objetivas referentes a: 1) padrões de informações contendo plano de trabalho, cronograma macro com as principais datas de entrega, procedimento de troca de informação, sistema de classificação, definição do método do nível de desenvolvimento esperado em cada fase do empreendimento objetivando seu uso durante a fase de operação e manutenção do empreendimento; e 2) método e procedimentos para produção de informação contendo informações sobre ativos existentes, caso houver, o fluxo de desenvolvimento, segurança e entrega das informações; 3) informações de referência e recursos compartilhados disponibilizando, ou em sua falta desenvolvendo, templates do Plano de Execução BIM, dos modelos 3D, estilos gráficos dos projetos 2D e a biblioteca de objetos; 4) Ambiente Comum de Dados (CDE) contendo o padrão de codificação, atributos, fluxo de aprovação, histórico de atividades e permissionamento; e 5) protocolo de informações especificando as obrigações e responsabilidades entre os envolvidos, direitos de propriedade, o uso das informações dos ativos existentes, caso 
existam, uso dos recursos compartilhados, uso das informações do projetos e a reutilização das informações.

- Equipe de análise técnica qualificada: A equipe técnica interna do contratante deve ter sua capacitação comprovada para levantar e desenvolver todo material necessário para subsidiar a elaboração do termo de referência. Esta equipe é também responsável pelo acompanhamento, verificação e aprovação dos trabalhos que serão desenvolvidos pela empresa contratada. Caso não existam profissionais internos habilitados para tal função o contratante deve eleger nesta fase uma empresa que será responsável por todo o processo representando o contratante.

Uma boa alternativa para os órgãos públicos que pretendem contratar empresas para o desenvolvimento de projetos (design) utilizando o BIM e ainda não possuem o projeto básico do empreendimento definido seria, em conjunto com o CAU (Conselho de Arquitetura e Urbanismo), lançar concursos públicos entre os associados da instituição. Desta forma, seria possível escolher o projeto que mais se adeque ao escopo, tanto referente aos requisitos exigidos no programa de necessidades quanto na qualidade de informações e dos modelos BIM.

\section{Licitação ou Carta Convite}

A licitação pública ou carta convite é um procedimento administrativo anterior às contratações. No setor público a licitação é um instrumento obrigatório e no setor privado pode ser feita por carta convite a um grupo específico de concorrentes.

Os objetivos da licitação, por exemplo são: 1) escolher a proposta mais vantajosa; 2) garantir igualdade de tratamento a todos os licitantes; 3) e promover desenvolvimento nacional sustentável. (MASCENA; 2017)

Os instrumentos têm como finalidade orientar todos os interessados no processo licitatório em como os trabalhos devem ser executados para garantir que $o$ escopo a ser contratado seja alcançado.

Entre todas as informações necessárias que devem ser disponibilizadas aos licitantes, existem, como podem ser verificadas abaixo, informações fundamentais quando a contratação exige a utilização do BIM.

- Requisitos de troca de informações: apresenta diretrizes referentes a: 1) requisitos de troca de informações definindo parâmetros de cada 
informação como da organização, das informações dos ativos existentes, caso hajam e informação do projeto; 2) métodos de produção e o uso das informações de referência ou recursos compartilhados; 3) estabelecer cronograma com as datas marco de entrega contendo tempo de revisão e aprovação;

- Informações de referência: tem como objetivo fornecer material de apoio necessário aos interessados tais como: 1) informações gerais sobre os recursos compartilhados, das informações desenvolvidas nas fases anteriores a contratação e guias/materiais de apoio; 2) informações sobre os ativos existentes; 3) normas internas e/ou padrões nacionais ou da indústria a serem utilizados; 4) exemplos de entregáveis; 5) os níveis de desenvolvimento (LOD / LOI) em cada fase;

- Critérios de avaliação e atendimento a esclarecimentos: estabelece o critério de pontuação através de procedimentos de avaliação tais como: 1) do conteúdo do Plano de Execução BIM (PEB); 2) da experiência individual dos integrantes da equipe técnica; 3) experiência da empresa em projetos similares 4) plano de mobilização e 5) plano de risco.

- Compilação das informações da licitação: esclarece de forma clara e objetiva pontos relevantes aos interessados tais como: 1) requisitos de troca de informação; relevância aos recursos compartilhados utilizando o Ambiente Comum de Dados (CDE); 3) atendimento aos critérios de avaliação; 4) marcos de entrega; 5) padrão de informações do projeto; 6) métodos e procedimento do desenvolvimento das informações; e 6 protocolos.

\section{Proposta}

A proposta tem como objetivo apresentar ao contratante às diretrizes gerais sugeridas pela parte interessada referentes ao desenvolvimento das atividades necessárias para o cumprimento do escopo a ser contratado. $O$ documento deve conter informações de: 1) serviços, envolvendo os recursos humanos; 2) suas interfaces; 3) as práticas de gestão e controle das atividades; 4) a definição e escopo dos procedimentos; 5) Plano de Execução BIM; e 6) valor global e por etapa. A proposta deve ser elaborada obedecendo às diretrizes da Norma ISO 9001/2000 ou Norma BIM Brasileira que esteja em vigor. 
Abaixo estão listados e descritos os tópicos mínimos sugeridos que devem fazer parte da proposta, entretanto outros tópicos devem ser inseridos no documento conforme a necessidade específica de cada projeto.

- Informações Gerais: são apresentadas resumo das informações geria referentes ao atendimento do escopo a ser contratado apresentado as partes interessadas, prazo com suas respectivas datas marcos e nome do empreendimento.

- Características do Empreendimento: deve ser apresentado resumo das características do projeto que está sendo contratado utilizando as orientações fornecidas pelo contratante.

- Objetivos do Empreendimento: devem ser apresentados os objetivos fins do empreendimento.

- Escopo dos Serviços Contratados: o escopo contratado deve ser descrito de forma clara e fluxos devem ser apresentados para dar suporte e clareza a descrição.

- Recursos Humanos: devem ser apresentados em forma de organograma todos os profissionais envolvidos nas fases do contrato para desenvolvimento das atividades necessárias para cumprimento do escopo contratado. Devem ser informadas as atribuições individuais de cada profissional.

- Plano de Mobilização: um Plano de Mobilização deve conter em seu conteúdo a estratégia referente a: 1) contratação e/ou mobilização de equipe técnica qualificada apresentada no tópico de recursos humanos; 2) aquisição e disponibilização de equipamentos e licenças necessários para o bom desenvolvimento das atividades; 3) aquisição, testes e disponibilização do Ambiente Comum de Dados (CDE); e 4) estratégia de treinamentos para nivelamento de conhecimento entre todas as equipes envolvidas no processo.

- Comunicação: um Plano de Comunicação deve ser desenvolvido e inserido a proposta com o objetivo de formalizar entre as partes interessadas: 1) matriz de todos os envolvidos contendo nome, função, competência e informações para contato (telefones e e-mail); 2) matriz de 
responsabilidades entre todos os envolvidos; 3) informações gerais para realização das reuniões tais como frequência, local, equipamentos diversos necessários, as atas; e 4) relatórios.

- Ambiente Comum de Dados: o sistema, suas funcionalidades e permissionamento devem ser descritos afim de dar todas as informações de uso necessárias aos que irão utilizar o sistema. Uma descrição completa com o fluxo deve fazer parte deste tópico apresentando como será o processo de elaboração, aprovação e publicação de todas as informações e dados do Ambiente Comum de Dados (CDE).

- Planejamento - Integração: deve ser apresentado cronograma com as atividades do projeto onde devem constar os documentos que serão desenvolvidos e que devem estar presentes na Lista de Documentos (LD). No cronograma deve ter como base os documentos: 1) definição do escopo das atividades; 2) estrutura analítica do empreendimento (EAE); 3) lista de documentos (LD); modelos BIM; 4) planilha de quantitativos; 5) orçamento de referência (CAPEX) quando este existir; e 6) cronograma com todas as fases do projeto.

- Custos: devem ser inseridas informações referentes a: 1) forma de medição; 2) prazo de avaliações; e 3) sequência de aprovações.

- Riscos: deve ser apresentado Plano de Riscos com estratégia e metodologia para assegurar uma efetiva e eficiente gestão dos possíveis riscos durante a duração das atividades contratuais.

- Execução dos Trabalhos: devem ser descriminadas as atividades necessárias para o bom desenvolvimento dos produtos contratados, que não façam parte integrante ou que possam complementar do Plano de Execução BIM (PEB).

- Qualidade: devem ser inseridas as informações e os processos referentes as atividades para o gerenciamento e o controle de qualidade das informações que forem geradas por todos os envolvidos no projeto.

- Suprimentos: deve ser apresentado o processo da atividade de suprimentos com suas atividades a fim de auxiliar a licitação da obra. 
- Encerramento do Projeto: destinasse a fase de entrega dos produtos gerados nas fases de projeto (design) e obra sendo 1) documentação; 2) informações e dados estruturados; e 3) modelos gráficos.

Para que o trabalho possa ser realizado de maneira adequada e de forma colaborativa, o Ambiente Comum de Dados (CDE) deve ter como funcionalidade: 1) verificação do progresso de trabalho; 2) verificação / revisão / aprovação dos responsáveis; 3) compartilhamento de toda informação e dados aos respectivos responsáveis; 4) fluxo de revisão / aprovação; 5) publicação dos produtos gerados; e 6) arquivamento das informações e dados de forma organizada e para serem utilizadas na fase de Operação e Manutenção do empreendimento a ser construído (Fluxograma 4).

Fluxograma 4: Fluxograma das atividades utilizando o Ambiente Comum de Dados (CDE)

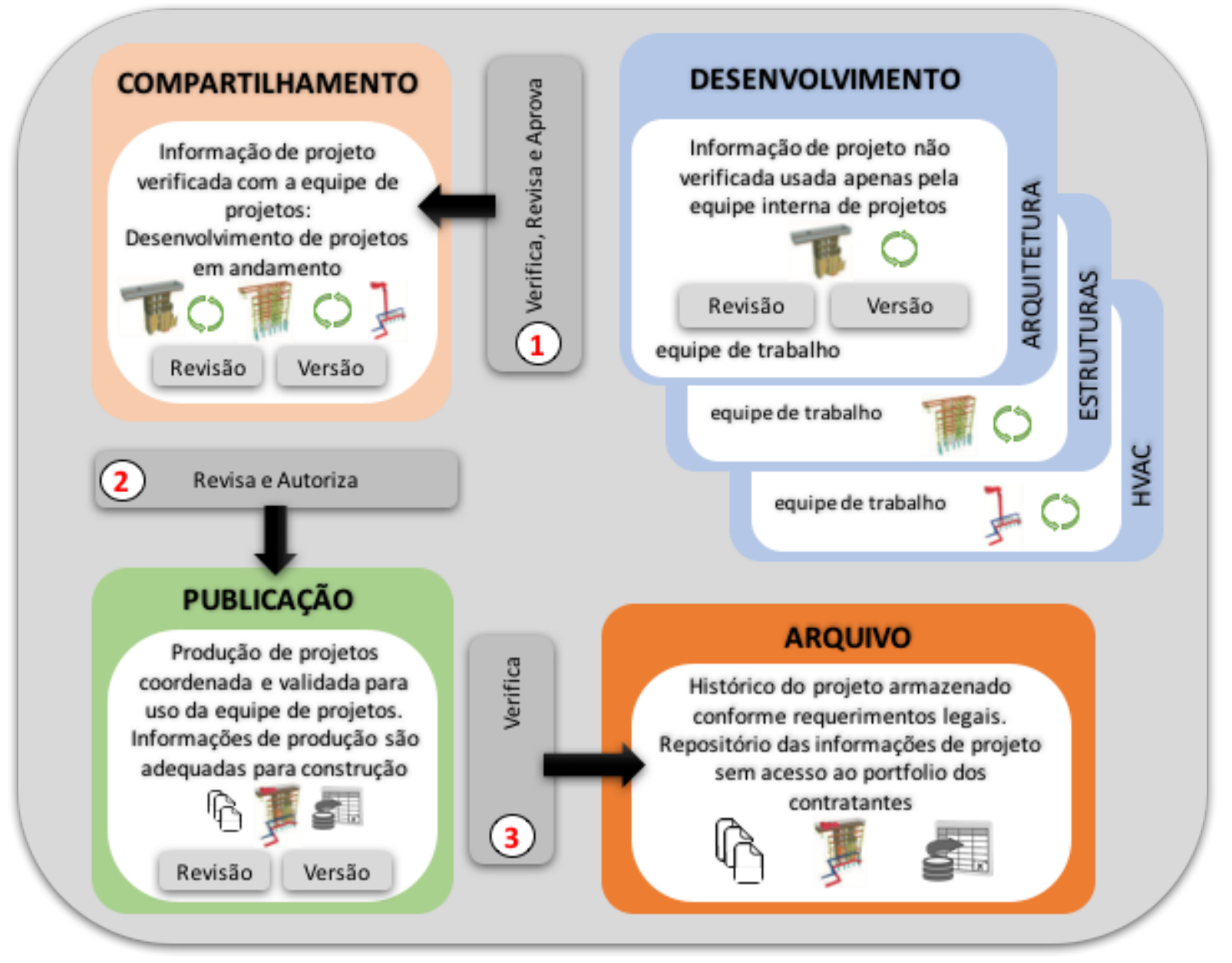

Fonte: Adaptado da PAS1192-2:2013 e ISO19650 
O Plano Execução BIM (PEB) é um documento de referência que deve ser utilizado por todos os envolvidos nas atividades BIM no contrato. O PEB deve ser desenvolvido em duas etapas. A primeira na fase de qualificação das empresas participantes sendo esta parte integrante da proposta técnica-comercial. A segunda etapa deve ser entregue após a assinatura do contrato.

O responsável por seu desenvolvimento, as atualizações, divulgação e monitoramento deve ser um profissional da área de arquitetura ou engenharia com atuação BIM comprovada. Este profissional no Brasil vem sendo denominado como coordenador BIM. Em seu conteúdo são descritas as informações pertinentes para se poder desenvolver todas as atividades BIM necessárias para a entrega dos produtos contratados.

A primeira versão do PEB deve ser elaborada ainda na fase de licitação e deve ser anexada a proposta técnica-comercial para análise pela equipe técnica qualificada do contratante. Em sua falta, o contratante deve contratar, antes da submissão das propostas elaboradas pelas partes interessadas, consultoria técnica adequada. A partir da escolha da empresa que apresente a melhor proposta de atendimento ao escopo, o PEB deve ter seu conteúdo completado.

Abaixo estão listados e descritos os tópicos mínimos sugeridos que devem fazer parte ao PEB, entretanto outros tópicos devem ser inseridos no documento conforme a necessidade específica de cada projeto. Importante informar que para cada projeto deve ser desenvolvido, verificado e aprovado um novo PEB de referência respeitando o escopo individual de cada contrato.

- Equipes de projeto: detalham-se os envolvidos no projeto, seus papéis e responsabilidades, além de seu contato, permitindo acesso fácil para todos os envolvidos no projeto.

- Matriz de responsabilidades: A matriz de responsabilidades é desenvolvida para dar as diretrizes referentes as atividades e limites de atuação entre os responsáveis.

- Softwares utilizados: neste item são especificados quais softwares serão utilizados, bem como a versão de utilização. Isso garante que todos tenham ciência de quais softwares precisam e de como as informações serão trocadas entre eles. 
- Nomenclatura e organização de arquivos em BIM: esta padronização é de extrema relevância, visto que, além do aspecto organizacional, as diferentes projetistas envolvidas referenciam arquivos umas das outras. Sendo assim, uma vez criadas as referências, é importante que as nomenclaturas permaneçam inalteradas para evitar retrabalho. Também é importante a padronização da nomenclatura das bibliotecas utilizadas no modelo, bem como dos seus parâmetros, para garantir a extração adequada de informações desse.

- Processo de troca de arquivos: neste item é estabelecida a forma com que os arquivos serão trocados, levando-se em conta a plataforma utilizada, a periodicidade da atualização dos arquivos e as permissões de acesso das empresas envolvidas.

- Informações do projeto: Neste item são dadas as informações do projeto que serão utilizadas como parâmetros do modelo como localização do empreendimento e ponto de referência do modelo a ser compartilhada e utilizada por todos os envolvidos no projeto e futuramente na fase de obra.

- Localização: deve ser descrito a localização geográfica do empreendimento contendo informações de latitude e longitude, endereço completo e qualquer outra informação relevante para o desenvolvimento das atividades.

- Processo de compartilhamento de coordenadas: é de suma importância a definição do sistema de compartilhamento de coordenadas entre os modelos, antes do início da modelagem, para garantir que a coordenação poderá ser realizada adequadamente em etapas futuras. Todas as partes envolvidas devem ter o conhecimento de qual é o sistema adotado e de como garantir que seus softwares de autoria BIM trabalhem neste sistema corretamente.

- Level of Development (LOD): os níveis de desenvolvimento são chave para balizar o desenvolvimento dos modelos BIM dentro de cada fase de design. Sua definição é responsável para garantir que a representação geométrica dos objetos pertencentes ao modelo BIM será adequada as utilizações no modelo dentro das atividades BIM pertencentes no processo de desenvolvimento de projetos (design) e da obra. 
- Level of Information (LOI): Sua definição é responsável para garantir que as informações corretas serão inseridas nos objetos ao logo do desenvolvimento do projeto (design) e da obra. Indefinições ou falhas em fazer cumprir estas diretrizes tem repercussões negativas no decorrer do projeto.

- Navegador do projeto: este item refere-se à organização interna do arquivo do modelo, especificamente nas vistas que ele contém. Visa-se padronizar a sua organização para facilitar a leitura dos diversos arquivos de modelo, em especial para a gerenciadora e para o cliente, que não trabalharam no desenvolvimento do arquivo.

- Worksets de trabalho: Os worksets são grupos que englobam coleções de elementos do modelo e podem ser criados arbitrariamente pelos usuários. A padronização da divisão dos worksets garante fluidez e coerência na troca de informações entre os diversos agentes envolvidos no projeto.

- Compatibilização BIM: descreve os procedimentos que devem ser seguidos para a realização da compatibilização dos modelos BIM que estão sendo desenvolvidos por todas as disciplinas envolvidas.

- Diretrizes para 4D/5D: caso seja demandado pelo cliente a criação das análises de sequenciamento construtivo (4D) e a orçamentação (5D), é imprescindível a definição de diretrizes claras para balizar a criação do modelo BIM pelas projetistas. Estas atividades alteram a forma com que o modelo deve ser concebido, bem como a forma e as informações que devem ser consideradas na criação das bibliotecas.

- Fluxo de trabalho: Determina o fluxo de trabalho entre as partes envolvidas sendo consideradas todas as etapas de desenvolvimento dos modelos BIM e as demais atividades ligadas à gestão e entrega dos produtos contratados.

- Diretrizes gerais de desenvolvimento de design: Descreve como os projetos em BIM devem ser desenvolvidos para atingir o escopo contratado.

- Cronograma de desenvolvimento de projetos em BIM: Informa a sequência e datas marco de todas as atividades relacionadas ao trabalho em BIM incluindo datas de entregas de produtos, relatórios de análises e 
reuniões multidisciplinares análise de detecção de interferências por exemplo.

- Exportação de layers: este item é relevante caso seja demandada pelo cliente final a entrega de arquivos CAD 2D. A definição prévia do esquema de exportação do arquivo de modelo BIM poupa tempo e retrabalho nas etapas de entrega.

- COBie: Informa ações para desenvolvimento e preparo das informações e dados a serem entregues no final do projeto.

\section{Contrato}

Trata-se de um acordo firmado entre duas, sendo uma delas nomeada como contratante e a outra como contratada. A primeira tem como responsabilidade desenvolver um serviço do interessa da parte contratante mediante a retribuição financeira. Neste tipo de acordo, as duas partes possuem direitos e deveres no momento da assinatura. (NEXAAS; 2017)

A partir da análise das propostas recebidas o contratante, com base nos resultados adquiridos, elege a empresa, ou em algumas ocasiões o consórcio vencedor. Conforme o fluxo de atividades temos como base: 1) nomeação da empresa selecionada; 2) elaboração do contrato de prestação de serviços; e 3) assinatura do contrato.

- Nomeação da (s) empresa (s) selecionada (s): fase em que é nomeada a empresa ou consórcio vencedor que atingiu a maior pontuação técnica e preço total mais próximo ao que consta na licitação ou carta convite.

- Elaboração do contrato de prestação de serviços: elabora-se o contrato padrão do contratante constando como anexo todas as informações essenciais fornecidas pela parte a ser contratada com base nos critérios constantes na licitação ou carta convite. Deve constar deste anexo documentos tais como: 1) Plano de Execução BIM em versão atualizada; 2) matriz de responsabilidades; 3) master plan de entrega das informações e dados. 
- Assinatura do contrato: após todos os critérios e fases anteriores serem aprovados é feita a assinatura foram do contrato de prestação de serviços entre todas as partes interessadas.

\section{Mobilização}

- Mobilização das equipes qualificadas: fase de disponibilização de recursos para o desenvolvimento de todas as atividades envolvidas no contrato para o bom desenvolvimento das atividades previstas.

- Disponibilização dos equipamentos, licenças e infraestrutura: aquisição, testes e início das operações de toda a infraestrutura física necessária.

- Disponibilização do Ambiente Comum de Dados (CDE): aquisição, instalação e parametrização de dados e todos os fluxos envolvidos no processo de produção, controle, gerenciamento e entrega das informações e dados. Importante salientar que o CDE deve ser testado e aprovado nesta fase.

- Treinamentos das equipes internas e terceirizadas para nivelamento de conhecimento referente as atividades necessárias e para atendimento do escopo contratado: fase em que se deve aplicar treinamentos teóricos e práticos para todos os envolvidos no processo de desenvolvimento, controle, gerenciamento e entrega das informações e dados.

- Teste de desenvolvimento de informações: fase em que devem ser desenvolvidos os testes de produção, verificação e publicação das informações e dados baseado nas diretrizes contidas no Plano de Execução BIM.

- Revisão das informações do Modelo (LOD / LOI): fase de verificação e testes de produção das informações dos modelos BIM referentes ao desenvolvimento geométrico e de inserção das informações e dados pertencentes em cada etapa do processo baseado no conteúdo do Plano de Execução BIM. 
- Pacote de revisão: tem como objetivo testar o processo e o fluxo de revisão, aprovação e publicação dos produtos desenvolvidos em todas as fases contratadas devendo ser pertencentes ao Ambiente Comum de Dados (CDE).

- Processo de entrega: certificar que todos os pacotes de entrega são extraídos dos modelos BIM pertencentes ao Ambiente Comum de Dados (CDE).

\section{Produção Colaborativa}

Conforme estabelecido, os responsáveis pela fase de desenvolvimento dos projetos (design) devem desenvolver todas as atividades utilizando o Ambiente Comum de Dados (CDE) e devem: 1) submeter as informações e dados dos modelos; 2) fazer as devidas autorizações de utilização entre os envolvidos; 3) revisar todas as informações e dados necessários; 4) aprovar; e 5) disponibilizar o material final para as próximas fases do processo.

$\mathrm{Na}$ fase de obra todo o gerenciamento e controle das atividades referentes a construção e montagem de equipamentos devem também ser desenvolvidas pelo Ambiente Comum de Dados. Além disso, o conteúdo das informações e dados contidos nos modelos devem ser atualizados conforme especificado no COBie, tendo sua publicação feita após as devidas verificações e aprovações.

\section{Conteúdo desenvolvido por fase}

Conforme já descrito neste protocolo, todas as informações e dados gerados no processo BIM para o desenvolvimento de um empreendimento devem ser amadurecidas conforme as etapas e fases estipuladas no planejamento apresentado e aprovado pelas partes envolvidas. Conforme apresentado no Fluxograma 5, o LOD (Level Of Development) ou Nível de Desenvolvimento possui uma codificação para caracterizar cada grau de definição.

- 100: Elemento do modelo 3D representado graficamente de forma genérica atribuindo somente sua localização no espaço. 
- 200: Elemento do modelo 3D representado graficamente de forma genérica atribuindo sua localização no espaço, quantidades aproximadas, orientação e forma.

- 300: Elemento do modelo 3D apresentando todas as características encontradas no LOD 200 com informações não gráficas anexadas as suas propriedades e possuindo tamanho e formas específicas.

- 350: Elemento do modelo 3D apresentando todas as características encontradas no LOD 300 apresentado as interfaces com outros sistemas de construção.

- 400: Elemento do modelo 3D apresentando todas as características encontradas no LOD 350, entretanto contendo informações de forma, tamanho e detalhes de montagem específicos.

- 500: O elemento é a representação fiel da montagem ou instalação na obra contendo informações necessárias a serem utilizadas na fase de operação e manutenção do empreendimento.

Fluxograma 6: Fluxo completo do desenvolvimento de informações e dados do empreendimento.

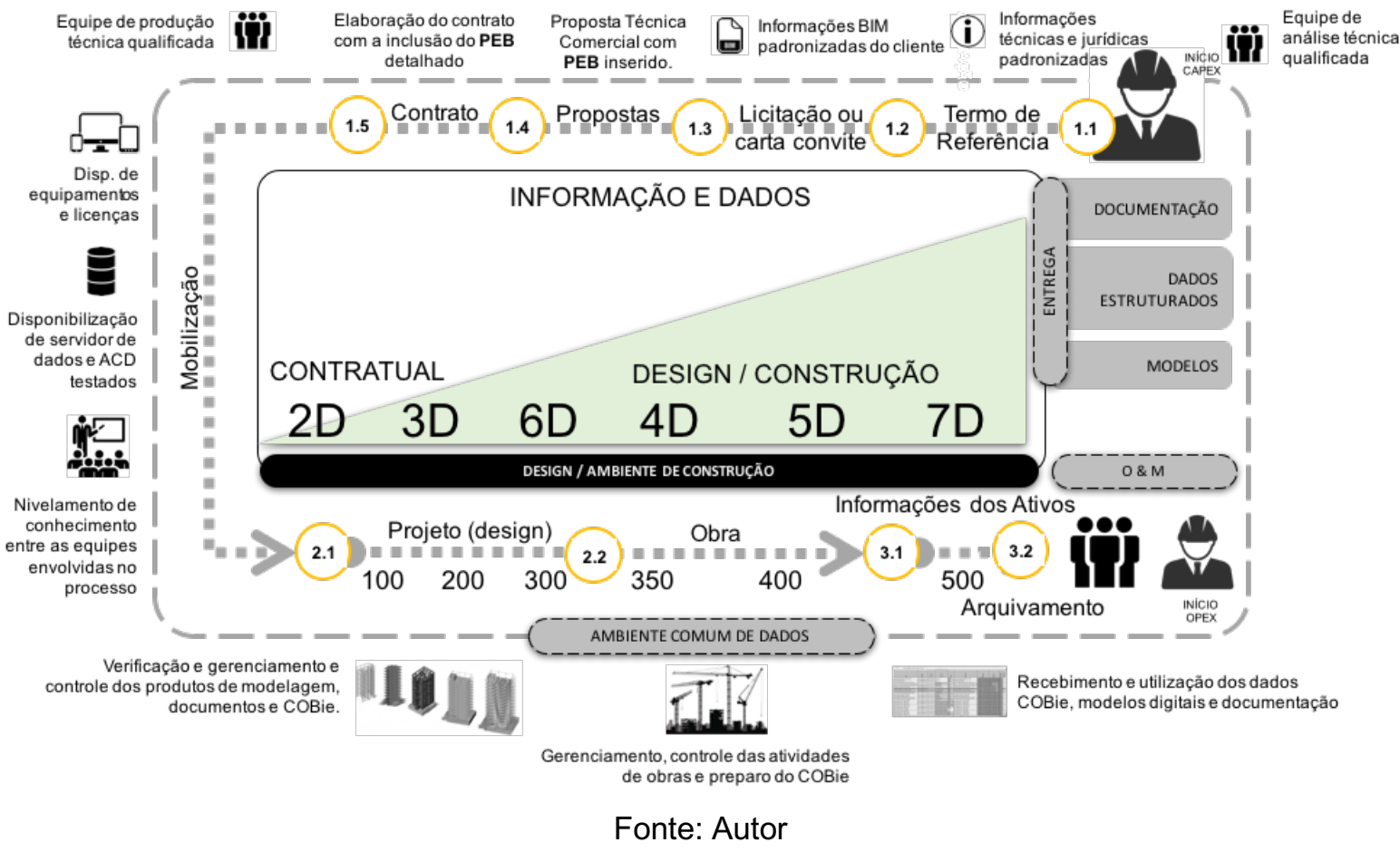


Uma codificação semelhante também é necessária para caracterizar cada grau de definição da informação e dados inseridos em cada objeto pertencente ao modelo BIM, neste caso o LOI (Level of Information).

- 100: Informações básicas inseridas nos elementos do modelo 3D.

- 200: Informações genéricas inseridas nos elementos do modelo 3D com definição de materiais.

- 300: Informações e dados apresentando inseridas nos elementos do modelo 3D todas as características encontradas no LOI $200 \mathrm{com}$ informações não gráficas anexadas as suas propriedades e possuindo definição de materiais e codificação dos elementos como determinado no PEB.

- 350: Informações e dados inseridos nos elementos do modelo 3D apresentando todas as características encontradas no LOI 300 apresentado as interfaces com outros sistemas de construção.

- 400: Informações e dados apresentando todas as características encontradas no LOI 350, entretanto contendo informações do fornecedor e ou fabricante.

- 500: Esta atividade destina-se a fase de execução de obra. As Informações e dados inseridos nos elementos do modelo 3D apresentando todas as características encontradas no LOI 400 , entretanto contendo informações que são levantadas e/ou obtidas na fase de obra, tais como: 1) Informações de nota fiscal; 2) garantias quando aplicável; 3) localização geográfica de instalação do equipamento; 4) informações necessárias para a operação e manutenção do objeto construído; e 5) demais informações apontadas no PEB.

\section{Informações dos Ativos}

Os ativos construídos na fase de obra devem ter suas informações e dados estruturados em 3 tipos como observado na Figura 18. Os tipos de entregáveis são: 1) documentação; 2) dados estruturados; e 3) modelos gráficos. 
- Documentação: são todos os documentos produzidos ao longo do processo do desenvolvimento do empreendimento tais como: 1) contratos; 2) relatórios; 3) procedimentos; 4) medições; e 5) todos os demais documentos existentes.

- Dados estruturados: são todos os dados inseridos em cada elemento existente nos modelos gráficos. Estes devem ser entregues em formato de planilha conforme o formato COBie.

- Modelos gráficos: são todos os modelos finalizados no período de obra contendo exata localização e informações dos ativos construídos.

Figura 18: Assuntos a serem arquivadas por tipo com utilização do Ambiente Comum de Dados (CDE)

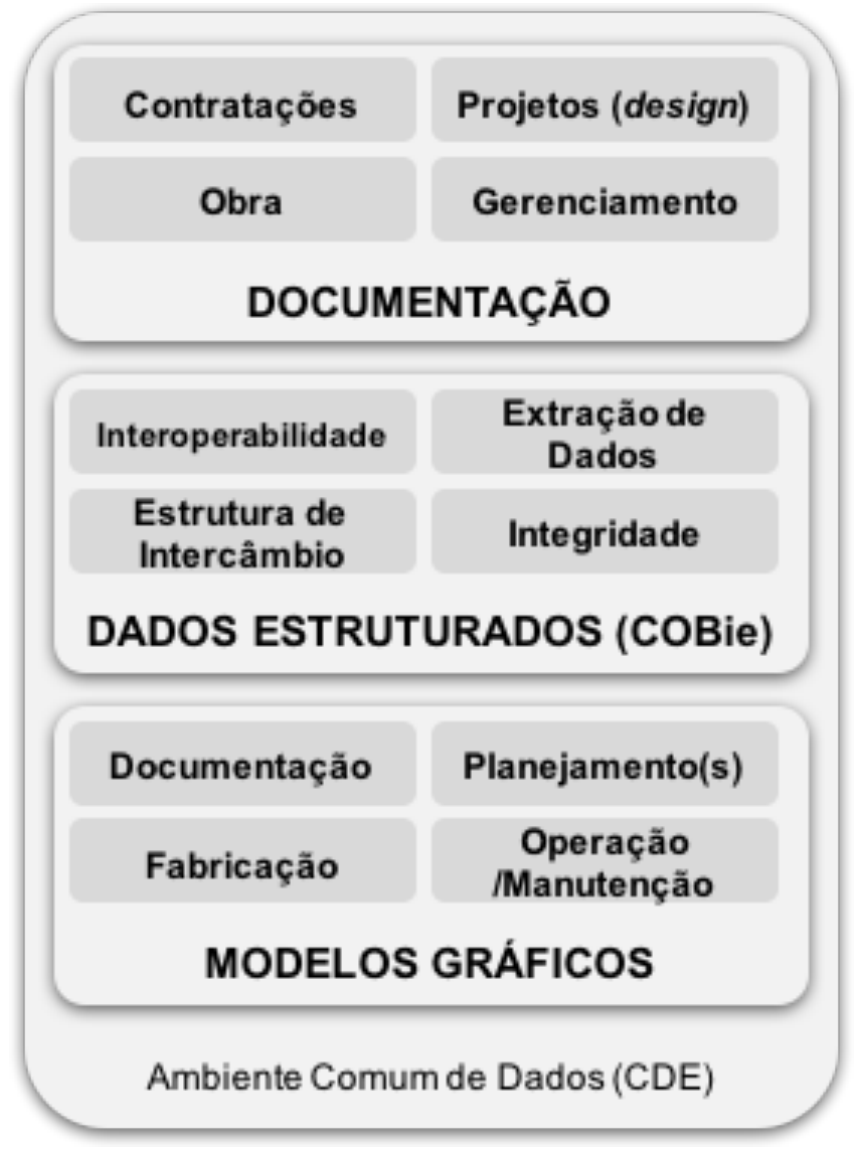

Fonte: Adaptado de PAS1192-2:2013 


\section{Arquivamento}

A fase de arquivamento é destinada a entrega do Ambiente Comum de informações (CDE) contendo todo o histórico do processo de contratação, desenvolvimento e construção dos ativos presentes no empreendimento. As lições aprendidas durante todas as fases também devem ser inseridas no CDE para finalização das atividades. 


\subsection{APÊNDICE B - Licitações Públicas}

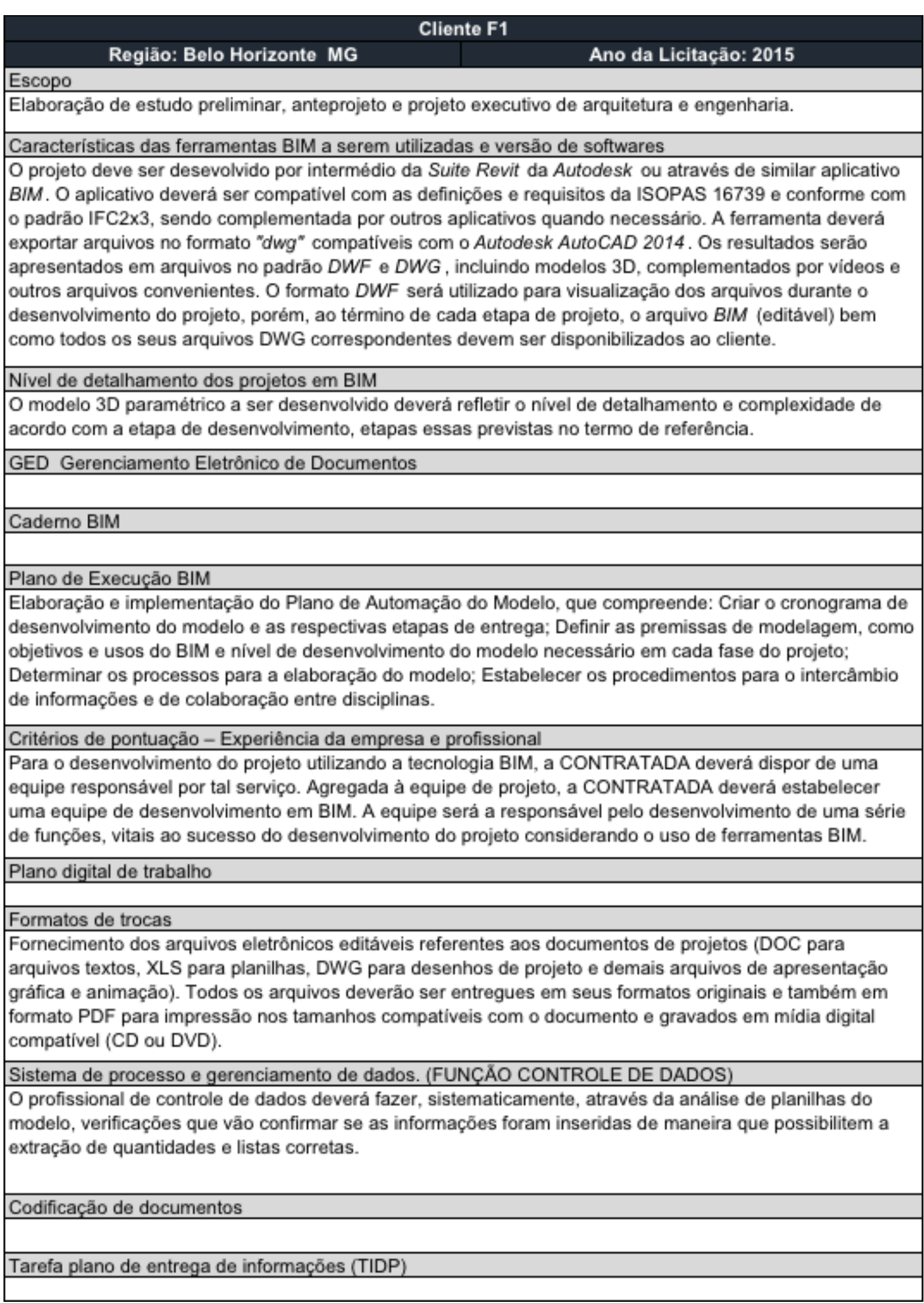




\section{Cliente F2}

Região: Belo Horizonte MG

Ano da Licitação: 2015

Escopo

Gerenciamento de empreendimento (Fiscalização dos projetos de arquitetura e engenharias, apoio à licitaçāo, planejamento e fiscalização das obras e acompanhamento da operação assistida).

Características das ferramentas BIM a serem utilizadas e versão de softwares

Os serviços em BIM devem ser desenvolvidos por intermédio da Suite Revit da Autodesk (de acordo com a respectiva disciplina) ou através de similar aplicativo BIM. O aplicativo deverá ser compativel com as definições e requisitos da ISO/PAS 16739 e conforme com o padrão IFC $2 \times 3$, sendo complementada por outros aplicativos quando eventualmente necessários.

Nivel de detalhamento dos projetos em BIM

GED Gerenciamento Eletrônico de Documentos

Serão cadastrados e arquivados as documentaçōes relativas às etapas de Projeto e Obra. Deverá dispor de controle automático de revisōes, workflow, mecanismos para revisão, listas mestras, acompanhamento de atividades, controle de cópias e visualizadores de arquivos de modo a proporcionar integração entre os profissionais envolvidos.

Caderno BIM

O CADERNO BIM contém os procedimentos para desenvolvimento de projetos com a Modelagem da Informação da Construção.

\section{Plano de Execução BIM}

Estabelecer e acordar um plano de execução BIM, garantindo o seu cumprimento e melhoria contínua e, também, praticar todas e quaisquer responsabilidades ou funções, conforme exigidas pelo próprio Plano de Execução BIM.

Critérios de pontuação - Experiência da empresa e profissional

A equipe Bim deve ser composta minimamente por dois profissionais de nivel superior e um profissional de nivel técnico, sendo estabelecido um coordenador.

Plano digital de trabalho

Formatos de trocas

Conjunto completo com todos os documentos dos projetos impressos (uma cópia) colocados em pastas tipo jeca e arquivos digitais, incluindo, entre outros: Arquivos digitais com extenção .dwg (AUTOCAD) e em PDF em escala (plantas dobradas formatos ABNT); Arquivos digitais com extensāo .rvt (REVIT) e IFC (2x3) dos projetos desenvolvidos em BIM; Todos os arquivos gravados em midia digital CD (Compact Disc)

Sistema de processo e gerenciamento de dados. (FUNÇÃO CONTROLE DE DADOS)

Executar funçōes vitais ao desenvolvimento e à atualização dos modelos BIM. Tais funçōes correspondem à modelagem propriamente dita, à compatibilizaçāo (realizaçāo da detecçāo de conflitos - clash detection), à customização, à configuração de parâmetros, ao desenvolvimento de bibliotecas e ao controle de dados.

Codificação de documentos

Tarefa plano de entrega de informaçōes (TIDP) 
Escopo

Contratação de gerenciamento de empreendimento (Validação dos projetos de arquitetura e engenharias, elaboração de projeto de pavimentação e drenagem, apoio à licitação, planejamento e fiscalização das obras e acompanhamento da operação assistida)

Características das ferramentas BIM a serem utilizadas e versão de softwares

Os serviços em BIM devem ser desenvolvidos por intermédio da Suite Revit da Autodesk (de acordo com a respectiva disciplina) ou através de similar aplicativo BIM. O aplicativo deverá ser compativel com as definições e requisitos da ISO/PAS 16739 e conforme com o padrão IFC $2 \times 3$, sendo complementada por outros aplicativos quando eventualmente necessários. A ferramenta BIM deverá exportar arquivos no formato .dwg compativeis com o Autodesk AutoCAD 2014 sem perda de informaçōes e com o padrão de layers da CONTRATANTE; tal padrão será fornecido à GERENCIADORA pelo "Cademo de Procedimentos para Desenvolvimento de Projetos em Sistemas CAD". Caso ocorram disciplinas não contempladas no padrão de layers da CONTRATANTE, a GERENCIADORA deverá utilizar o material produzido pela ASBEA, Diretrizes Gerais para Intercambialidade de Projetos em CAD.

Nivel de detalhamento dos projetos em BIM

GED Gerenciamento Eletrônico de Documentos

Serão cadastrados e arquivados as documentaçães relativas às etapas de Projeto e Obra. Deverá dispor de controle automático de revisōes, workflow, mecanismos para revisão, listas mestras, acompanhamento de atividades, controle de cópias e visualizadores de arquivos de modo a proporcionar integração entre os profissionais envolvidos.

Caderno BIM

Será fornecido pela CONTRATANTE, o Caderno BIM caderno de procedimentos para desenvolvimento de projetos em BIM.

\section{Plano de Execução BIM}

Estabelecer e acordar um plano de execução BIM, garantindo o seu cumprimento e melhoria contínua $e$, também, praticar todas e quaisquer responsabilidades ou funçōes, conforme exigidas pelo próprio Plano de Execução BIM.

Critérios de pontuação - Experiência da empresa e profissional

A equipe Bim deve ser composta minimamente por dois profissionais de nivel superior e um profissional de nivel técnico, sendo estabelecido um coordenador.

\section{Plano digital de trabalho}

Formatos de trocas

Conjunto completo com todos os documentos dos projetos impressos (uma cópia) colocados em pastas tipo jeca e arquivos digitais, incluindo, entre outros: Arquivos digitais com extenção .dwg (AUTOCAD) e em PDF em escala (plantas dobradas formatos ABNT); Arquivos digitais com extensāo .rvt (REVIT) e IFC (2x3) dos projetos desenvolvidos em BIM; Todos os arquivos gravados em midia digital CD (Compact Disc).

\section{Sistema de processo e gerenciamento de dados. (FUNÇÅO CONTROLE DE DADOS)}

Executar funçōes vitais ao desenvolvimento $e$ à atualização dos modelos BIM. Tais funções correspondem à modelagem propriamente dita, à compatibilização (realização da detecção de conflitos - clash detection), à customização, à configuração de parâmetros, ao desenvolvimento de bibliotecas e ao controle de dados.

Codificação de documentos 
Escopo

Contratação de gerenciamento de empreendimentos (Fiscalização dos projetos de arquitetura $e$ engenharias, apoio à licitação, planejamento e fiscalizaçāo das obras e acompanhamento da Operação Assistida).

Características das ferramentas BIM a serem utilizadas e versão de softwares

Os serviços em BIM devem ser desenvolvidos por intermédio da Suite Revit da Autodesk (de acordo com a respectiva disciplina) ou através de similar aplicativo BIM. O aplicativo deverá ser compativel com as definiçōes e requisitos da ISO/PAS 16739 e conforme com o padrão IFC 2x3, sendo complementada por outros aplicativos quando eventualmente necessários. A ferramenta BIM deverá exportar arquivos no formato .dwg compativeis com o Autodesk AutoCAD 2014 sem perda de informaçōes e com o padrão de layers da CONTRATANTE; tal padrão será fornecido à GERENCIADORA pelo "Cademo de Procedimentos para Desenvolvimento de Projetos em Sistemas CAD". Caso ocorram disciplinas não contempladas no padrão de layers da CONTRATANTE, a GERENCIADORA deverá utilizar o material produzido pela ASBEA, Diretrizes Gerais para Intercambialidade de Projetos em CAD.

Nivel de detalhamento dos projetos em BIM

\section{GED Gerenciamento Eletrônico de Documentos}

Serão cadastrados e arquivados as documentaçōes relativas às etapas de Projeto e Obra. Deverá dispor de controle automático de revisōes, workflow, mecanismos para revisão, listas mestras, acompanhamento de atividades, controle de cópias e visualizadores de arquivos de modo a proporcionar integração entre os profissionais envolvidos.

Cademo BIM

O CADERNO BIM contém os procedimentos para desenvolvimento de projetos com a Modelagem da Informação da Construção. Nesse documento, consta de forma sistêmica as definiçōes e parâmetros para a padronização e apresentação dos elementos parametrizados, os elementos de projeto com informação construtiva e a forma de apresentação da documentação referente ao projeto, os quais contribuirão com a construção da biblioteca digital com objetos BIM. Há a definiçāo, padronização e apresentação de elementos minimos que compōem as várias disciplinas de um projeto de arquitetura e projetos complementares, com suas respectivas fases permitindo a construção de Modelos Digitais da Construção em 3D, 4D, 5D ou " $n$ " D. Este documento também abrange outras informaçōes alinhadas com a ISO 16739:2013.

Plano de Execução BIM

Estabelecer e acordar um plano de execução BIM, garantindo o seu cumprimento e melhoria contínua $e$, também, praticar todas e quaisquer responsabilidades ou funçōes, conforme exigidas pelo próprio Plano de Execução BIM.

Critérios de pontuação - Experiência da empresa e profissional

A equipe Bim deve ser composta minimamente por dois profissionais de nivel superior e um profissional de nivel técnico, sendo estabelecido um coordenador.

Plano digital de trabalho

Formatos de trocas

Conjunto completo com todos os documentos dos projetos impressos (uma cópia) colocados em pastas tipo jeca e arquivos digitais, incluindo, entre outros: Arquivos digitais com extenção .dwg (AUTOCAD) e em PDF em escala (plantas dobradas formatos ABNT); Arquivos digitais com extensāo .rvt (REVIT) e IFC (2x3) dos projetos desenvolvidos em BIM; Todos os arquivos gravados em midia digital CD (Compact Disc).

Sistema de processo e gerenciamento de dados. (FUNÇÅO CONTROLE DE DADOS)

Executar funçōes vitais ao desenvolvimento e à atualização dos modelos BIM. Tais funções correspondem à modelagem propriamente dita, à compatibilização (realização da detecção de conflitos - clash detection), à customização, à configuração de parâmetros, ao desenvolvimento de bibliotecas e ao controle de dados.

Codificação de documentos

Tarefa plano de entrega de informações (TIDP) 
Escopo

Prestação de serviços de engenharia consultiva para apoio gerencial, compreendendo as macroatividades de gerenciamento, supervisão, elaboração e atualização de projetos e supervisão das obras e serviçōes de unidades prisionais.

Características das ferramentas BIM a serem utilizadas e versão de softwares

Os serviços em BIM devem ser desenvolvidos por intermédio da Suite Revit da Autodesk (de acordo com a respectiva disciplina) ou através de similar aplicativo BIM. O aplicativo deverá ser compativel com as definiçōes e requisitos da ISO/PAS16739 e conforme com o padrão IFC $2 \times 3$, sendo complementada por outros aplicativos quando eventualmente necessários. A ferramenta deverá exportar arquivos no formato. dwg compativeis com o Autodesk AutoCAD 2014, utilizado pela CONTRATANTE, sem perda de informaçōes e com o padrão de layers da CONTRATANTE. A Detecção de Conflitos deverá ser feita através de software especifico como Navisworks ou similar, e deverá ser utilizado pela GERENCIADORA para garantir maior qualidade de compatibilização dos projetos presentados pelas PROJETISTAS.

Nivel de detalhamento dos projetos em BIM

GED Gerenciamento Eletrônico de Documentos

Caderno BIM

Plano de Execução BIM

Critérios de pontuação - Experiência da empresa e profissional

Comprovação da experiência da empresa e sua capacidade operacional, com relação aos serviços a serem executados, apresentando atestado de serviços executados, devidamente registrados no CREA/CAU comprovando sua experiência em serviços do objeto da LICITAÇÃo.

A experiência e aptidão dos componentes da Equipe Chave deverão ser comprovadas através de Atestados emitidos por Entidades Públicas ou Privadas, devidamente registrados no CREA ou CAU (quando for o caso) e acompanhados das respectivas Certidōes de Acervo Técnico.

Plano digital de trabalho

Formatos de trocas

Sistema de processo e gerenciamento de dados. (FUNÇÃO CONTROLE DE DADOS)

Codificação de documentos

Tarefa plano de entrega de informações (TIDP) 


\section{Cliente M}

Regiāo: Sāo Paulo SP

Ano da Licitação: 2012

Escopo do Projeto

Elaboração dos projetos executivos de Engenharia Civil, acabamento, comunicação visual e paisagismo das estaçōes e do pátio água espraiada e acompanhamento técnico da obra.

Características das ferramentas BIM a serem utilizadas e versão de softwares

Nivel de detalhamento dos projetos em BIM

GED Gerenciamento Eletrônico de Documentos

Caderno BIM

Plano de Execução BIM

Critérios de pontuação - Experiência da empresa e profissional

Atestado(s) de capacidade técnica emitido(s) por pessoa jurídica de direito público ou privado, em nome da PROPONENTE individual, ou de membros do Consórcio, que comprove(m) ter ela executado ou estar executando serviço pertinente e compativel em características com o objeto da presente licitação. A PROPONENTE deverá apresentar relação explicita e declaração formal da disponibilidade dos profissionais com curso superior responsáveis pela prestação dos serviços licitado.

Plano digital de trabalho

Formatos de trocas

Sistema de processo e gerenciamento de dados. (FUNÇÅO CONTROLE DE DADOS)

Codificação de documentos

Tarefa plano de entrega de informaçōes (TIDP) 


\section{Regiẫo: Rio de Janeiro RJ}

Ano da Licitação: 2014

Escopo do Projeto

Serviços de transposição do Anteprojeto de Arquitetura do Edificio Anexo do padrão CAD, para a plataforma BIM, conforme as especificaçōes deste Edital e de seus Anexos.

Características das ferramentas BIM a serem utilizadas e versão de softwares

O modelo deve ser desenvolvido pela Contratada atendendo às diretivas do padrão IFC, conforme norma ISO 16739:2013, e segundo as orientaçōes do 'Termo de Referência para desenvolvimento de projetos com o uso da Modelagem de Informação da Construção (BIM)*. O modelo deve ser entregue ao cliente pela Contratada no formato .rvt. Todas as pranchas de documentação do modelo BIM 3D consolidado devem ser também exportadas para arquivos em padrão .dwg compativel com o software Autodesk AutoCAD® versāo 2014.

Nivel de detalhamento dos projetos em BIM

Detalhar o modelo e renderizar até 10 vistas selecionadas pelo cliente, segundo o Concept Design Pack que integra o Anteprojeto de Arquitetura para o Edificio Anexo. O Nivel de Desenvolvimento das zonas do Edificio Anexo a serem representadas nas vistas renderizadas deve ser capaz de abarcar todas as informaçōes disponiveis no Concept Design Pack. Ou seja, nas regiōes a serem representadas nas vistas renderizadas, o nivel de desenvolvimento do modelo deverá ser detalhado até o ND 300 . O modelo do Anteprojeto para o Edificio Anexo a ser desenvolvido pela Contratada deve corresponder ao Nivel de Desenvolvimento - ND - 200 .

GED Gerenciamento Eletrônico de Documentos

Caderno BIM

Plano de Execução BIM

Critérios de pontuação - Experiência da empresa e profissional

Declaração fornecida pela Licitante, afirmando que será indicado como responsável técnico Arquiteto e Urbanista ou Engenheiro Civil, com registro regular no respectivo Conselho, que comprove, por meio de Certidāo de Acervo Técnico, experiência prévia na modelagem, usando a tecnologia BIM, de edificios com área construida igual ou superior a $10.000 \mathrm{~m} 2$; e II. atestado de capacidade técnica, expedido por pessoa jurídica de direito público ou privado, que comprove que o Licitante já prestou serviços de modelagem, usando a tecnologia BIM, de edifícios com área construida igual ou superior a $10.000 \mathrm{~m} 2$.

Plano digital de trabalho

Formatos de trocas

Idem item Características das ferramentas BIM a serem utilizadas e versāo de softwares

Sistema de processo e gerenciamento de dados. (FUNÇÃO CONTROLE DE DADOS)

A Contratada deve garantir a total integridade da transposição das informaçōes do modelo desenvolvido em software proprietário para o padrāo IFC, de forma a permitir o intercâmbio de informaçōes e o trabalho conjunto de diferentes profissionais, que, eventualmente, poderāo utilizar diferentes plataformas de software BIM.

Codificação de documentos

Tarefa plano de entrega de informaçōes (TIDP) 
Escopo do Projeto

Elaboração de Estudos de Viabilidade Técnica, Estudos Preliminares, Anteprojetos, Análise de

Projetos Executivos, realizaçāo de Ensaios Geotécnicos e de Pavimentos, Sondagens e Ensaios de

Campo, elaboração de Projeto Executivo de Fundações e de Urbanização do Sitio Aeroportuário.

Características das ferramentas BIM a serem utilizadas e versão de softwares

Todos os desenhos deverão ter como origem o ARQUIVO BIM e o Programa Padrão para a execução dos desenhos será um software que garanta a compatibilidade do modelo 3D com a plataforma Autodesk Revit, possibilitando a abertura, visualizaçāo e edição de geometria e dados (valores dos parâmetros) em softwares desta plataforma, sem perdas ou distorçōes de informaçōes. Independentemente do programa utilizado para execução dos desenhos, deverão ser fornecidos, em todas as etapas, os Arquivos Eletrônicos nas versōes "rvt" e "dwg", além dos arquivos em "pdf". Para os documentos produzidos em "dwg" e "rvt" deverāo ser indicadas, em cada desenho, as configuraçōes adotados (espessuras de linhas, textos, familias e etc), disponibilizando os arquivos originais desenvolvidos na concepção. Todas as pranchas de desenho, originadas do modelo tridimensional, deverāo ser geradas pelas folhas correspondentes no arquivo BIM original.

Nivel de detalhamento dos projetos em BIM

GED Gerenciamento Eletrônico de Documentos

Utilizar softwares de gerenciamento de documentos

Caderno BIM

Plano de Execução BIM

A proponente deverá explicitar no seu Plano de Trabalho conhecimento sobre a metodologia no gerenciamento dos projetos, informando que recursos (formulários, instrumentos, ferramentas, etc) serão utilizados nas disciplinas de gerenciamento de escopo, gerenciamento de tempo, gerenciamento de custo e gerenciamento de risco, para o perfeito desenvolvimento do objeto.

Critérios de pontuação - Experiência da empresa e profissional

Ao total foram estabelecidos 59 (cinquenta e nove) quesitos de avaliação, todos justificados individualmente, cujos critérios de pontuação relacionamse com a valoração de empresas e profissionais que comprovem possuir conhecimentos necessários para a execução do objeto.

Plano digital de trabalho

Formatos de trocas

Idem item Características das ferramentas BIM a serem utilizadas e versāo de softwares

Sistema de processo e gerenciamento de dados. (FUNÇÅO CONTROLE DE DADOS)

Codificação de documentos

Os documentos deverāo apresentar carimbos que deverão ser idênticos em todas as pranchas dos Estudos Preliminares e Anteprojetos (arquitetura, estrutura e instalaçōes) conforme "Familia" inserida no ARQUIVO BIM e deverá identificar o AUTOR, COORDENADOR e TÉCNICO, com campos para os respectivos números de registros nos Conselhos de Engenharia ou de Arquitetura, assinaturas, nomes e cargos; A codificação de Documentos Técnicos de Engenharia deverá ser feita de acordo com o Caderno Geral de Encargos (CGE).

Tarefa plano de entrega de informações (TIDP) 


\section{Regiăo: São Paulo SP}

Ano da Licitação: 2014

Escopo do Projeto

Equipes de apoio técnico especializadas em elaboração de estudos preliminares, consultoria e projetos acessórios e complementares (executivos e de detalhamentos técnicos), desenvolvimento de desenhos em AutoCAD, para o apoio de conceito BIM, com elaboração de planilhas orçamentárias, laudos técnicos, para atender às necessidades da CONTRATANTE.

Características das ferramentas BIM a serem utilizadas e versão de softwares

Nivel de detalhamento dos projetos em BIM

GED Gerenciamento Eletrônico de Documentos

Caderno BIM

Plano de Execução BIM

Critérios de pontuação - Experiência da empresa e profissional

Deverá ser comprovada através de certidão (ōes) de desempenho anterior, lastreada em atestado(s)

emitido(s) por pessoa(s) juridica(s) de direito público ou privado, em nome da Licitante, que demonstre(m) e comprove(m) a execução das seguintes atividades (especificadas no Anexo VIII Critérios de Pontuação da Proposta Técnica, deste Edital). Cada um dos profissionais das equipes descritas deverá atender aos requisitos especificados no ANEXO VI Pré Requisitos para Preenchimento das Funçōes, parte integrante deste Edital.

Plano digital de trabalho

Formatos de trocas

Sistema de processo e gerenciamento de dados. (FUNÇÅO CONTROLE DE DADOS)

Codificação de documentos

Tarefa plano de entrega de informaçōes (TIDP) 
Escopo do Projeto

Serviços técnicos especializados para elaboração de 6 (seis) Guias Técnicos aplicáveis ao BIM EDIFICAÇŌES.

Características das ferramentas BIM a serem utilizadas e versão de softwares

Plataforma BIM onde serāo inseridas as bibliotecas BIM e guias sobre o tema.

Guia 1: Classificação e especificação de serviços e de materiais de construção, em conformidade com a Norma de Classificação da Informação da Construção (NBR15965); Guia 2: Fundamentos BIM e

Desenvolvimento de componentes para Bibliotecas BIM, incluindo parâmetros de aplicação da Norma de Desempenho (NBR 15.575) e da Norma de Coordenação Modular (NBR15873/2010); Guia 3: Quantificação de serviços e materiais de construção em sistemas BIM; Guia 4: Contratação e Elaboração de projetos de arquitetura/engenharia com emprego de sistemas BIM, incluindo, entre outros: I. definição de fases e respectivos conteúdos considerando o nivel de evoluçăo do desenvolvimento do modelo II. coordenação de disciplinas III. detecção de interferência; Guia 5: Avaliação de desempenho energético em edificaçōes com projetos BIM, incluindo aplicação da Etiquetagem de Eficiência Energética (PROCEL EDIFICA); Guia 6: Orçamentação, planejamento e gestão de obras com projetos de arquitetura/engenharia em sistemas BIM, incluindo simulação de processos construtivos.

Nivel de detalhamento dos projetos em BIM

GED Gerenciamento Eletrônico de Documentos

Caderno BIM

Plano de Execução BIM

Elaborar e apresentar para ABDI o Plano de Trabalho (PT) do projeto, contendo todas as etapas, metodologia, produtos esperados, prazos e responsáveis, conforme especificado nesse TR.

Critérios de pontuação - Experiência da empresa e profissional Comprovar experiência na realização de trabalhos de elaboração de publicação técnica similar (Relatório, Guia, Manual, Artigo Técnico ou Livro) abrangendo o setor da Construçāo Civil. Especialista em BIM (Building Information Modeling): graduado de nivel superior em arquitetura ou engenharia há pelo menos 5 (cinco) anos e conhecimento e experiência minima de 2 (dois) anos com o tema BIM, em especial envolvido com empreendimentos/projetos em BIM, desenvolvimento de bibliotecas e templates BIM, normalização aplicada BIM, bem como ao estudo dos protocolos padrōes OpenBIM1 e ainda prática de projetos de Edificaçōes nos mais diferentes softwares/processos, tais como: Autocad, Autodesk Revit Architecture, Navisworks, Revit MEP, Revit Strucuture, Vault, QTO e MSProject, entre outros.

Plano digital de trabalho

Formatos de trocas

Sistema de processo e gerenciamento de dados. (FUNÇÃO CONTROLE DE DADOS)

Codificação de documentos

Tarefa plano de entrega de informaçōes (TIDP) 


\section{Cliente T1}

Região: Distrito Federal

Ano da Licitação: 2015

Escopo do Projeto

Serviços de Assessoramento para análise e avaliação, visando recebimento, da Atualização tecnológica e normativa dos projetos de arquitetura e engenharia, com nivel de detalhamento executivo, em plataforma BIM - Building Information Modeling e de acordo com o conceito de Engenharia Simultânea, inclusive Especificaçōes Técnicas, Memórias de Cálculo e Planilha de Quantificação.

Características das ferramentas BIM a serem utilizadas e versão de softwares

A plataforma em que serão atualizados os projetos deverá ser BIM, compativel com as definiçōes e requisitos da ISO/PAS 16739 e em conformidade com o padrão IFC 4, e os softwares da Autodesk, como o REVIT para projetos e o NavisWorks para análise, verificação de interferências, quantificação e emissāo de relatórios da Clash Detection (detecção de interferências), planejamento da execução da obra, acompanhamento da obra. No modelo BIM deverão ser incluidos atributos para permitir: a) A modelagem 4D (quantitativos), 5D (custos e sequenciamento da obra), na fase de planejamento da obra para execuçăo utilizando os softwares NavisWorks, Synchro e MS Project e 6D (operação da edificação).

Nivel de detalhamento dos projetos em BIM

Nivel de Evolução e Desenvolvimento (equivalente à terminologia em inglês LOD - Level of Development) descreve em niveis, o quanto o Modelo está desenvolvido e completo. A seguinte descrição de NED identifica os requisitos de conteúdo e seus usos autorizados para cada Modelo em cinco fases de desenvolvimento progressivo. Cada NED subsequente é construido sobre o nivel anterior e inclui todas as caracteristicas dos niveis anteriores. NED 100, 200, 300 e 400.

GED Gerenciamento Eletrônico de Documentos

Caderno BIM

Plano de Execução BIM

A CONTRATADA deve analisar e avaliar, para aprovação pelo cliente, a especificação técnica apresentada pela empresa responsável pela Atualizaçāo dos projetos, contendo o Plano de Execução para Automação do Projeto a ser aplicado no desenvolvimento dos trabalhos de Atualização, com a descrição detalhada das etapas e subetapas do Cronograma físicofinanceiro.

Critérios de pontuação - Experiência da empresa e profissional

Responsável pela execução dos serviços objeto desta licitação, constando, no

minimo: 1 (um) engenheiro civil ou arquiteto com curso de formação em BIM (Building Information

Modeling), o qual será o profissional responsável pelo acompanhamento e pela orientação de todo o processo que envolverá a transposição dos projetos de arquitetura e engenharia para a plataforma com tecnologia BIM; 1 (um) engenheiro civil ou arquiteto com experiência profissional na área de engenharia ou arquitetura igual ou superior a 10 anos, o qual será o coordenador técnico de toda a equipe envolvida no desenvolvimento do objeto deste Edital.

Plano digital de trabalho

Formatos de trocas

Idem Caracteristicas das ferramentas BIM a serem utilizadas e versāo de softwares

Sistema de processo e gerenciamento de dados. (FUNÇÅO CONTROLE DE DADOS)

Codificação de documentos

Tarefa plano de entrega de informaçōes (TIDP) 
Escopo do Projeto

Serviços de arquitetura e engenharia para: a) revisão técnica, atualização tecnológica e normativa dos projetos de arquitetura e de engenharia, com integral conversão, inclusive dos projetos já executados, para a metodologia BIM; b) elaboração de Plano de Obras, com individualização das etapas de contratação e de execução, mediante comprovação de sua viabilidade técnica e econômica; c) complementação dos projetos originais com disciplinas originalmente não contratadas; d) elaboração de Relatório de Avaliação dos projetos originais.

Características das ferramentas BIM a serem utilizadas e versão de softwares

A plataforma em que serão atualizados os projetos deverá ser BIM, compativel com as definições e requisitos da ISO/PAS 16739 e em conformidade com o padrão IFC 4, e os softwares da Autodesk, como o REVIT para projetos e o NavisWorks para análise, verificação de interferências, quantificação e emissāo de relatórios da Clash Detection (detecção de interferências), planejamento da execução da obra, acompanhamento da obra. No modelo BIM deverão ser incluidos atributos para permitir: a) A modelagem 4D (quantitativos), 5D (custos e sequenciamento da obra), na fase de planejamento da obra para execução utilizando os softwares NavisWorks, Synchro e MS Project e 6D (operação da edíficação).

Nivel de detalhamento dos projetos em BIM

Nivel de Desenvolvimento (equivalente à terminologia em inglês LOD - Level of Development) descreve em niveis, o quanto o Modelo está desenvolvido e completo. A seguinte descrição de ND identifica os requisitos de conteúdo e seus usos autorizados para cada Modelo em cinco fases de desenvolvimento progressivo. Cada ND subsequente é construido sobre o nivel anterior e inclui todas as características dos niveis anteriores. ND 100, 200, 300 e 400.

GED Gerenciamento Eletrônico de Documentos

Cademo BIM

Plano de Execução BIM

A CONTRATADA deve analisar e avaliar, para aprovação pelo cliente, a especificação técnica apresentada pela empresa responsável pela Atualizaçāo dos projetos, contendo o Plano de Execução para Automação do Projeto a ser aplicado no desenvolvimento dos trabalhos de Atualização, com a descrição detalhada das etapas e subetapas do Cronograma físicofinanceiro.

Critérios de pontuação - Experiência da empresa e profissional

Responsável pela execução dos serviços objeto desta licitação, constando, no

minimo: 1 (um) engenheiro civil ou arquiteto com curso de formação em BIM (Building Information

Modeling), o qual será o profissional responsável pelo acompanhamento e pela orientação de todo o processo que envolverá a transposição dos projetos de arquitetura e engenharia para a plataforma com tecnologia BIM; 1 (um) engenheiro civil ou arquiteto com experiência profissional na área de engenharia ou arquitetura igual ou superior a 10 anos, o qual será o coordenador técnico de toda a equipe envolvida no desenvolvimento do objeto deste Edital.

Plano digital de trabalho

Formatos de trocas

Idem Caracteristicas das ferramentas BIM a serem utilizadas e versão de softwares

Sistema de processo e gerenciamento de dados. (FUNÇÅO CONTROLE DE DADOS)

Codificação de documentos

Tarefa plano de entrega de informaçōes (TIDP) 
Escopo do Projeto

Serviços de arquitetura e engenharia para: a) revisão técnica, atualização tecnológica e normativa dos projetos de arquitetura e de engenharia, com integral conversão, inclusive dos projetos já executados, para a metodologia BIM; b) elaboração de Plano de Obras, com individualização das etapas de contratação e de execução, mediante comprovação de sua viabilidade técnica e econômica; c) complementação dos projetos originais com disciplinas originalmente não contratadas; d) elaboração de Relatório de Avaliação dos projetos originais.

Características das ferramentas BIM a serem utilizadas e versão de softwares

A plataforma em que serão atualizados os projetos deverá ser BIM, compatível com as definiçōes e requisitos da ISO/PAS 16739 e em conformidade com o padrão IFC 4, e os softwares da Autodesk, como o REVIT para projetos e o NavisWorks para análise, verificação de interferências, quantificação e emissão de relatórios da Clash Detection (deteç̧ão de interferências), planejamento da execução da obra, acompanhamento da obra. No modelo BIM deverão ser incluidos atributos para permitir: a) A modelagem 4D (quantitativos), 5D (custos e sequenciamento da obra), na fase de planejamento da obra para execução utilizando os softwares NavisWorks, Synchro e MS Project e 6D (operação da edificação).

Nivel de detalhamento dos projetos em BIM

Nivel de Desenvolvimento (equivalente à terminologia em inglês LOD - Level of Development) descreve em niveis, o quanto o Modelo está desenvolvido e completo. A seguinte descrição de ND identifica os requisitos de conteúdo e seus usos autorizados para cada Modelo em cinco fases de desenvolvimento progressivo. Cada ND subsequente é construido sobre o nivel anterior e inclui todas as características dos niveis anteriores. ND 100, 200, 300 e 400 .

GED Gerenciamento Eletrônico de Documentos

Cademo BIM

Plano de Execução BIM

A CONTRATADA deve analisar e avaliar, para aprovação pelo cliente, a especificação técnica apresentada pela empresa responsável pela Atualização dos projetos, contendo o Plano de Execução para Automação do Projeto a ser aplicado no desenvolvimento dos trabalhos de Atualização, com a descrição detalhada das etapas e subetapas do Cronograma físicofinanceiro.

Critérios de pontuação - Experiência da empresa e profissional

Responsável pela execução dos serviços objeto desta licitação, constando, no

mínimo: 1 (um) engenheiro civil ou arquiteto com curso de formação em BIM (Building Information

Modeling), o qual será o profissional responsável pelo acompanhamento e pela orientação de todo o processo que envolverá a transposição dos projetos de arquitetura e engenharia para a plataforma com tecnologia BIM; 1 (um) engenheiro civil ou arquiteto com experiência profissional na área de engenharia ou arquitetura igual ou superior a 10 anos, o qual será o coordenador técnico de toda a equipe envolvida no desenvolvimento do objeto deste Edital.

Plano digital de trabalho

Formatos de trocas

Idem Caracteristicas das ferramentas BIM a serem utilizadas e versāo de softwares

Sistema de processo e gerenciamento de dados. (FUNÇÅO CONTROLE DE DADOS)

Codificação de documentos

Tarefa plano de entrega de informações (TIDP) 
Escopo do Projeto

Elaboração de projetos de arquitetura e engenharia nas etapas de estudos preliminares, projeto básico, projeto executivo e serviços complementares.

Características das ferramentas BIM a serem utilizadas e versão de softwares

Os desenhos no formato digital deverão conter todas as pranchas de preferência no formato ".rvt", compativeis com o programa Autodesk Revit 2012. Arquivos em extensão ".dwg" compativeis com o AutoCAD 2012 também serāo aceitos.

Nivel de detalhamento dos projetos em BIM

GED Gerenciamento Eletrônico de Documentos

Cademo BIM

Plano de Execução BIM

Critérios de pontuação - Experiência da empresa e profissional

Comprovação de aptidāo da empresa para a elaboração dos projetos por meio da apresentação do CAT, acompanhada do seu respectivo Atestado de capacidade TécnicoOperacional fornecido por pessoa jurídica de direito público ou privado, devidamente registrado no CREA que comprove que a empresa licitante tenha executado diretamente, como contratada principal, um projeto de edifício de múltiplos pavimentos, de caráter institucional, comercial ou de escritórios incluindo, no mínimo, projetos: Arquitetônico, Estrutural, Elétrico, Hidráulico, de Fundação, de Climatização, de Lógica e Telefonia e de Prevenção e Combate a Incêndios, com área a ser construída de pelo menos $20.000 \mathrm{~m} 2$. Capacitação e Experiência dos Profissionais da Equipe Técnica - NEQ Minimo 30, máximo 80 pontos. Por especialidade: Mínimo de 15, máximo de 80 pontos

Plano digital de trabalho

\section{Formatos de trocas}

Na gravação das midias digitais, somente os arquivos finais deverão estar presentes. Os desenhos no formato digital deverāo conter todas as pranchas de preferência no formato ".rvt", compativeis com o programa Autodesk Revit 2012. Arquivos em extensão ".dwg" compativeis com o AutoCAD 2012 também serāo aceitos. Em todas as etapas do projeto arquitetônico deverāo ser apresentados os estudos volumétricos digitais tridimensionais. Os modelos tridimensionais deverão necessariamente ser elaborados desenvolvidos em plataforma BIM e entregues em formato ".rvt", compativeis com o Autodesk Revit 2012.

Sistema de processo e gerenciamento de dados. (FUNÇÅO CONTROLE DE DADOS)

Codificação de documentos

Identificação do projeto (etapa de projeto, especialidade/área técnica, codificação).

Tarefa plano de entrega de informaçōes (TIDP) 


\section{Cliente TR}

\section{Regiẫo: Distrito Federal}

\section{Ano da Licitação: 2015}

Escopo do Projeto

Contratação de empresa especializada em conjunto de treinamento, com fornecimento de material didático, e apoio (em horas de assessoria técnica), com objetivo de implementar o sistema BIM como processo de desenvolvimento para projetos de arquitetura e engenharia realizados pela Coordenação de Arquitetura $e$ Engenharia.

Características das ferramentas BIM a serem utilizadas e versão de softwares

Nivel de detalhamento dos projetos em BIM

GED Gerenciamento Eletrônico de Documentos

Cademo BIM

Plano de Execução BIM

Critérios de pontuação - Experiência da empresa e profissional

Plano digital de trabalho

Formatos de trocas

Sistema de processo e gerenciamento de dados. (FUNÇÃO CONTROLE DE DADOS)

Codificação de documentos

Tarefa plano de entrega de informaçōes (TIDP) 